\title{
Melhorando o desempenho de agentes BDI Jason através de filtros de percepção
}

\author{
Márcio Fernando Stabile Junior \\ DISSERTAÇÃO APRESENTADA \\ $\mathrm{AO}$ \\ Instituto De Matemática e EstatísticA \\ DA \\ Universidade DE SÃo PAUlo \\ PARA \\ OBTENÇÃO DO TÍTULO \\ DE \\ Mestre EM CiênCIAS
}

Programa: Mestrado em Ciência da Computação

Orientador: Prof. Dr. Jaime Simão Sichman

Durante o desenvolvimento deste trabalho o autor recebeu auxílio financeiro do CNPq

São Paulo, outubro de 2015 


\section{Melhorando o desempenho de agentes BDI Jason através de filtros de percepção}

Esta é a versão original da dissertação elaborada pelo candidato Márcio Fernando Stabile Junior, tal como submetida à Comissão Julgadora. 


\section{Agradecimentos}

Ao professor Jaime Simão Sichman, pela orientação, confiança e por todo o tempo dedicado a este trabalho.

Ao professor Fabio Kon, pelo apoio que possibilitou toda a análise estatística presente neste trabalho.

Ao $\mathrm{CNPq}$ por ter possibilitado e financiado esta pesquisa.

A todos os professores que depositaram em mim sua confiança, acreditando que eu poderia ir mais longe.

A todos os meus familiares que me incentivaram para que eu continuasse sempre aprendendo mais.

À minha companheira Bárbara, que sempre acreditou em mim, mesmo quando eu não acreditava.

Por último e mais importante, a Deus, por ter iluminado meu caminho e tornado tudo isso possível. 


\section{Resumo}

STABILE JR., Márcio F. Melhorando o desempenho de agentes BDI Jason através de filtros de percepção. 2015. Dissertação (Mestrado) - Instituto de Matemática e Estatística, Universidade de São Paulo, São Paulo, 2015.

Um dos problemas do paradigma BDI quando se integram agentes a ambientes virtuais ou simuladores é a ausência de controle sobre as suas percepções. Não havendo alguma forma de percepção direcionada ao objetivo, o agente pode ser inundado por informações irrelevantes causando um aumento injustificado do tempo de processamento. Com o objetivo de fornecer um maior controle sobre as percepções do agente e reduzir o seu tempo de resposta, este trabalho apresenta um mecanismo de filtragem das percepções para o interpretador Jason que visa eliminar aquelas percepções que podem ser ignoradas. Para tal, foram propostos e implementados alguns tipos de filtros pré-definidos, que foram aplicados a três cenários diferentes. Através de validações estatísticas apropriadas, mostrou-se que a aplicação de filtros de percepção pode reduzir em até 80\% o tempo de processamento de um agente, sem afetar significativamente o seu desempenho medido em termos de sua função de utilidade.

Palavras-chave: Filtro de percepção, Jason, Modelo BDI. 


\section{Abstract}

STABILE JR., Márcio F. Improving the performance of BDI Jason agents through perception filters. 2015.Thesis (Masters Degree) - Instituto de Matemática e Estatística, Universidade de São Paulo, São Paulo, 2015.

When agents are supposed to be integrated to virtual environments virtual or simulators, one of the BDI paradigm's major concerns is the lack of control over the agents' perceptions. Without having any form of goal directed perceptions, the agent may be flooded by irrelevant information thus causing an unjustified increase in processing time. In order to provide greater control on the agent's perceptions and to reduce its time response, this work presents a filtering perception mechanism for the Jason interpreter, aimed at eliminating those perceptions that can be ignored. To this end, some types of pre-defined filters have been proposed, implemented, and applied to three different scenarios. Through appropriate statistical validation methods, it was shown that applying perception filters can reduce up to $80 \%$ of an agent's processing time, without significantly affecting its performance measured in terms of its utility function.

Keywords: Perception filter, Jason, BDI Model. 


\section{Sumário}

$\begin{array}{ll}\text { Lista de Abreviaturas } & \text { ix }\end{array}$

Lista de Figuras $\quad$ xi

Lista de Tabelas $\quad$ xiii

1 Introdução $\quad 1$

1.1 Motivação . . . . . . . . . . . . . . . . . . . . . . . . . . 1

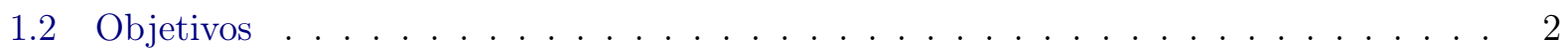

1.3 Metodologia . . . . . . . . . . . . . . . . . . . 2

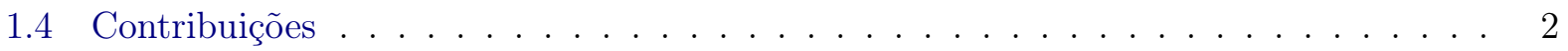

1.5 Organização do trabalho . . . . . . . . . . . . . . . . . . 3

2 Programação Orientada a Agentes $\quad 5$

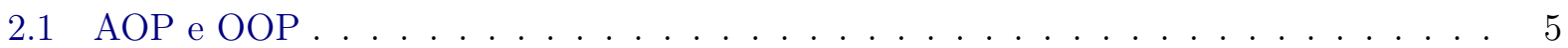

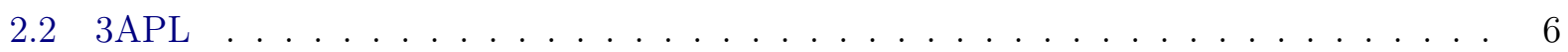

$2.3 \quad$ Jadex . . . . . . . . . . . . . . . . . . . . . . . . . . . . 6

2.4 AgentSpeak . . . . . . . . . . . . . . . . . . . . . . . 7

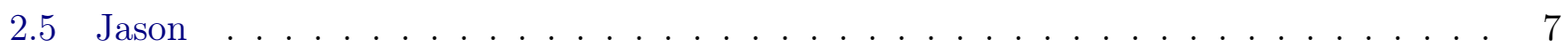

2.5.1 Ciclo de raciocínio $\ldots \ldots \ldots \ldots \ldots \ldots$

2.5.2 Exemplo de código . . . . . . . . . . . . . . . . . . . . . . . . . . . 10

2.6 Análise de desempenho de Jason . . . . . . . . . . . . . . . . . . . . . . 11

3 Filtros de Percepção em Jason $\quad 15$

3.1 Trabalhos relacionados . . . . . . . . . . . . . . . . . . . . 15

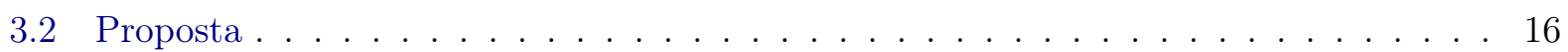

4 Estudo de Caso $\quad 19$

4.1 Simulador . . . . . . . . . . . . . . . . . . . . . . . . . . 19

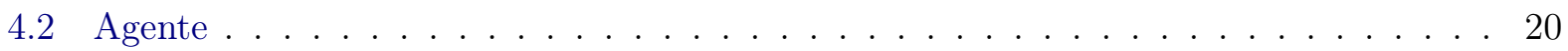

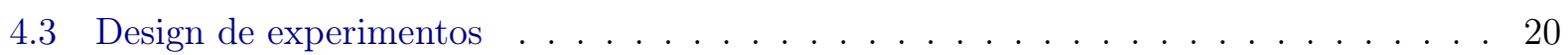

4.3.1 Design fatorial completo . . . . . . . . . . . . . . . . . . 22

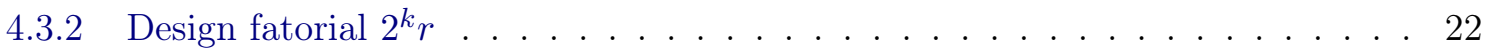

5 Experimentos e Resultados $\quad 27$

5.1 Descrição . . . . . . . . . . . . . . . . . . . . . . . 27 


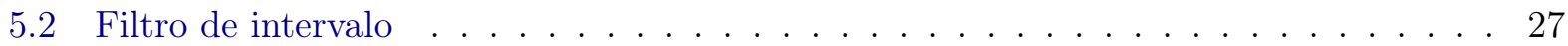

5.2 .1 Estudo reduzido sobre o tempo de processamento . . . . . . . . . 28

5.2.2 Estudo completo sobre o tempo de processamento . . . . . . . . . . . 30

5.2.3 Estudo reduzido sobre o impacto na função de utilidade . . . . . . . . . . . . 33

5.3 Filtro de propriedade . . . . . . . . . . . . . . . . . . . 34

5.3 .1 Filtro com expressões regulares . . . . . . . . . . . . . . 35

5.3.1.1 Estudo reduzido sobre o tempo de processamento . . . . . . . . 3 36

5.3.1.2 Estudo reduzido sobre o impacto na função de utilidade . . . . . . . 37

5.3.2 Filtro com comparações simples . . . . . . . . . . . . . . . . . . . 38

5.3.2.1 Estudo reduzido sobre o tempo de processamento . . . . . . . . . . 39

5.3.2.2 Estudo reduzido sobre o impacto na função de utilidade . . . . . . . 41

5.3 .3 Comparação entre os filtros de propriedade . . . . . . . . . . . . . . . 43

5.4 Múltiplos agentes . . . . . . . . . . . . . . . . . . . . . . 44

5.4 .1 Estudo reduzido sobre o tempo de processamento . . . . . . . . . . . 46

5.4.2 Estudo completo sobre o tempo de processamento . . . . . . . . . . . 47

5.4.3 Estudo reduzido sobre o impacto na função de utilidade . . . . . . . . . . . . 49

6 Conclusões $\quad 51$

6.1 Considerações finais . . . . . . . . . . . . . . . . . . . . . . 51

6.2 Trabalhos futuros . . . . . . . . . . . . . . . . . . . . 52

A Valores medidos com uso de filtros de intervalo no cenário monoagente $\quad 55$

B Valores calculados com uso de filtros de intervalo no cenário monoagente $\quad 57$

C Valores medidos com uso de filtros de intervalo no cenário multi-agentes $\quad 59$

D Valores calculados com uso de filtros de intervalo no cenário multi-agentes $\quad 63$

$\begin{array}{ll}\text { Referências Bibliográficas } & 67\end{array}$ 


\title{
Lista de Abreviaturas
}

\author{
MAPC Multi Agent Programming Contest \\ AOP Programação Orientada a Agentes (Agent Oriented Programming) \\ OOP Programação Orientada a Objetos (Object Oriented Programming) \\ BDI Crenças, Desejos e Intenções (Beliefs, Desires and Intentions) \\ MAS Sistemas Multi-Agentes (Multi-Agent Systems) \\ ADF Arquivo de Definição de Agente (Agent Definition File) \\ SST Soma Total dos Quadrados (Sum of Squares Total)
}




\section{Lista de Figuras}

2.1 Ciclo de raciocínio de um agente Jason apresentado por Bordini et al. (2007). . . . . 9

2.2 Tempo de execução dos métodos do ciclo de raciocínio do Jason no primeiro experi-

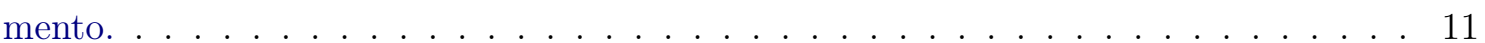

2.3 Tempo de execução dos métodos do ciclo de raciocínio do Jason no segundo experimento. . . . . . . . . . . . . . . . . . . . . . . 13

3.1 Tabela de inscrições utilizada por van Oijen e Dignum (2011) . . . . . . . . . . . . . 15

4.1 Ambiente utilizado para os testes de desempenho. . . . . . . . . . . . . . . . . 19

4.2 Gráficos quantil-quantil normal construídos por Jain (1991). . . . . . . . . . . . . . 24

4.3 Gráficos de dispersão construídos por Jain (1991) . . . . . . . . . . . . . . . . . . . 24

5.1 Filtros de intervalo: Testes visuais do estudo reduzido sobre tempos de processamento. 29

5.2 Filtros de intervalo: Testes visuais do estudo reduzido transformado sobre tempos de

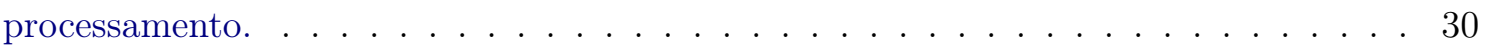

5.3 Filtros de intervalo: 95 percentil do tempo de processamento do agente. . . . . . . . 31

5.4 Filtros de intervalo: Testes visuais do estudo completo transformado sobre tempos

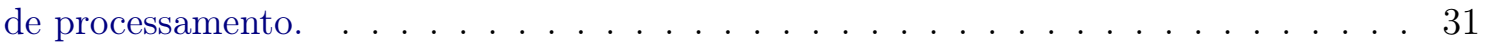

5.5 Filtros de intervalo: Porcentagem de ações executadas no tempo limite do simulador. 32

5.6 Filtros de intervalo: Testes visuais do estudo reduzido sobre valores de utilidade. . . . 33

5.7 Filtro com Expressões Regulares: Testes visuais do estudo reduzido sobre tempos de

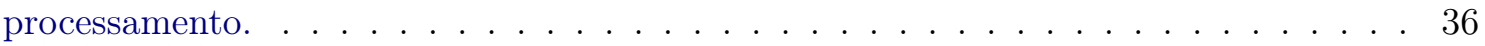

5.8 Filtro com Expressões Regulares: 95 percentil do tempo de processamento do agente. 37

5.9 Filtro com Expressões Regulares: Testes visuais do estudo reduzido transformado sobre valores de utilidade. . . . . . . . . . . . . . . . . . . . . . 39

5.10 Filtro com Comparações: Testes visuais do estudo reduzido sobre tempo de processamento. . . . . . . . . . . . . . . . . . . . . 40

5.11 Filtro com Comparações: 95 percentil dos tempos de processamento do agente. . . . 41

5.12 Filtro com Comparações: Testes visuais do estudo reduzido transformado sobre valores de utilidade. . . . . . . . . . . . . . . . . . . . . . . . . . 4 42

5.13 Comparação entre filtros de propriedade: Testes visuais do estudo reduzido sobre diferença de tempos de processamento. . . . . . . . . . . . . . . . . 44

5.14 Comparação entre filtros de propriedade: 95 percentil da diferença entre os tempos de processamento do agente. . . . . . . . . . . . . . . . . . . . . 45 
5.15 Filtro de intervalo com multi-agentes: Testes visuais do estudo reduzido transformado sobre tempos de processamento. . . . . . . . . . . . . . . . . 47

5.16 Filtro de intervalo com multi-agentes:95 percentil do tempo total de processamento

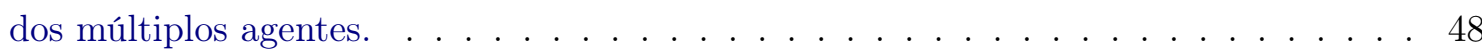

5.17 Multi-agentes: Testes visuais do estudo completo transformado sobre tempos de pro-

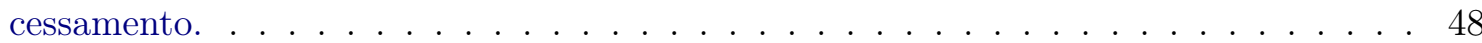

5.18 Multi-agentes: Testes visuais do estudo reduzido transformado sobre valores de utilidade. . . . . . . . . . . . . . . . . . . . . . 50 


\section{Lista de Tabelas}

2.1 Tabela comparativa entre OOP e AOP apresentada por Shoham (1993) . . . . . . 5

4.1 Número de insetos capturados após um minuto. . . . . . . . . . . . . . . . . . 22

5.1 Níveis dos fatores para o estudo reduzido sobre filtros de intervalo. . . . . . . . . . . 29

5.2 Filtros de intervalo: Tempos de processamento (ns) obtidos no estudo reduzido. . . . 29

5.3 Filtros de intervalo: Logs dos tempos de processamento do estudo reduzido. . . . . . 30

5.4 Filtros de intervalo: Variação atribuída a cada fator do estudo reduzido transformado no tempo de processamento. . . . . . . . . . . . . . . . . . . . 30

5.5 Filtros de intervalo: Variação atribuída a cada fator do estudo completo. . . . . . . . 32

5.6 Tempo mínimo necessário (seg) para que o agente consiga executar todas as ações. . 32

5.7 Filtros de intervalo: Valores de utilidade (número de insetos capturados) obtidos no estudo reduzido. . . . . . . . . . . . . . . . . . . . . 33

5.8 Filtros de intervalo: Variação atribuída a cada fator do estudo sobre o valor de utilidade. 33

5.9 Níveis dos fatores para o estudo reduzido sobre filtros de propriedade. . . . . . . . . 35

5.10 Filtro com Expressões Regulares: Tempos de processamento (ns) obtidos no estudo

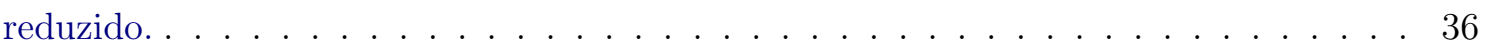

5.11 Filtro com Expressões Regulares:Logs dos tempos de processamento do estudo redu-

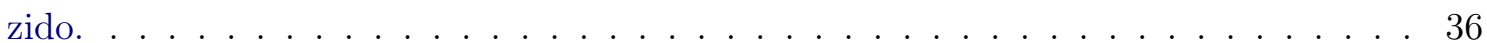

5.12 Filtro com Expressões Regulares: Variação atribuída a cada fator do estudo reduzido transformado no tempo de processamento. . . . . . . . . . . . . . . . 37

5.13 Filtro com Expressões Regulares: Valores de utilidade (número de insetos capturados) obtidos no estudo reduzido. . . . . . . . . . . . . . . . . . . 38

5.14 Filtro com Expressões Regulares: Raiz quadrada dos valores de utilidade (número de insetos capturados) obtidos no estudo reduzido. . . . . . . . . . . . . . . . 38

5.15 Filtro com Expressões Regulares: Variação de cada fator sobre a interferência na utilidade. . . . . . . . . . . . . . . . . . . . . 39

5.16 Filtro com Comparações: Tempos de processamento (ns) obtidos no estudo reduzido. 40

5.17 Filtro com Comparações: Logs dos tempos de processamento do estudo reduzido. . . 40

5.18 Filtro com Comparações: Variação atribuída a cada fator do estudo reduzido. . . . . 41

5.19 Filtro com Comparações: Valores de utilidade (número de insetos capturados) obtidos no estudo reduzido. . . . . . . . . . . . . . . . . . . . . . . . . . . 4 42

5.20 Filtro com Comparações: Logs dos valores calculados para o estudo sobre a interferência na utilidade. . . . . . . . . . . . . . . . . . . . . . . . . . 42 
5.21 Filtro com Comparações: Variação de cada fator no estudo sobre a interferência na

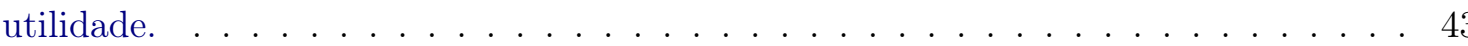

5.22 Comparação entre filtros de propriedade: Tempos de processamento (ns) obtidos nos estudos reduzidos. . . . . . . . . . . . . . . . . . . . . . . . . . . . 43

5.23 Comparação entre filtros de propriedade: Variação atribuída a cada fator do estudo reduzido transformado na diferença entre tempo de processamento. . . . . . . . . . . 44

5.24 Filtro de intervalo com multi-agentes: Tempos de processamento (ns) obtidos no estudo reduzido. . . . . . . . . . . . . . . . . . . . . . . . . . . . . . . 46

5.25 Filtro de intervalo com multi-agentes: Logs dos tempos de processamento do estudo reduzido. . . . . . . . . . . . . . . . . . . . . . . . . . . 46

5.26 Filtro de intervalo com multi-agentes: Variação atribuída a cada fator do estudo reduzido. . . . . . . . . . . . . . . . . . . . . . . . . . . . . . . . . 47

5.27 Multi-agentes: Variação atribuída a cada fator do estudo reduzido. . . . . . . . . . . 49

5.28 Filtro de intervalo com multi-agentes: Valores obtidos no estudo reduzido sobre a interferência no valor de utilidade. . . . . . . . . . . . . . . . . . . . . . . . . . . . . 49

5.29 Filtro de intervalo com multi-agentes: Valores de utilidade (número de insetos capturados) obtidos no estudo reduzido transformado. . . . . . . . . . . . . . . . . . . . 49

5.30 Multi-agentes: Variação de cada fator do estudo sobre a interferência na função de utilidade. . . . . . . . . . . . . . . . . . . . . . . . 50

A.1 Filtros de intervalo: Resultados do estudo completo sobre o tempo de processamento. 55

B.1 Filtros de intervalo: Resultados do estudo completo sobre o tempo de processamento. 57

C.1 Multi-agentes: Resultados do estudo completo sobre o tempo de processamento. . . . 59

D.1 Multi-agentes: Resultados transformados do estudo completo sobre o tempo de processamento. . . . . . . . . . . . . . . . . . . . . . 6 63 


\section{Capítulo 1}

\section{Introdução}

\subsection{Motivação}

Os sistemas de simulação se tornam cada vez mais importantes pela sua capacidade de imitar a realidade. Por permitir a avaliação de diferentes cenários, esses sistemas são uma ferramenta poderosa para avaliar os resultados de ações sobre um ambiente, já que eles permitem aos usuários compreender as características de um ambiente ou uma situação complexa sem a necessidade de reproduzi-la no mundo real, podendo identificar potenciais áreas problemáticas, e assim mitigar ações que possam ter efeitos negativos ou não desejáveis.

Além disto, certos sistemas de simulação usados em competições como o da RoboCup ${ }^{1}$ que foi analisado por Pereira et al. (2012) e do MAPC ${ }^{2}$, descrito por Ahlbrecht et al. (2013) se tornam mais complexos a cada ano, fazendo com que seja necessária uma maior capacidade de tomada de decisão para efetuar ações no ambiente.

Modelar o comportamento humano para esse tipo de situação é extremamente difícil, pois além de modelar o raciocínio individual, é necessário também modelar a tomada de decisão em grupo. Uma das maneiras utilizadas é a criação de agentes inteligentes que imitam as características gerais dos seres humanos. O paradigma de modelagem baseada em agentes tem origem no conceito de componentes que interagem de forma autônoma, que mantém controle sobre seu estado e podem realizar tarefas. Como os agentes podem incorporar mecanismos de raciocínio e aprendizagem, tornam-se agentes inteligentes. Integrar tecnologias baseadas em agentes em mundos criados por sistemas de simulação permite então aumentar o grau de realismo na representação dos comportamentos.

Jason $^{3}$ é um interpretador para uma versão estendida da linguagem de programação de agentes AgentSpeak desenvolvida por Rao (1996) que pode ser utilizado para o desenvolvimento de agentes inteligentes. Jason implementa a semântica operacional dessa linguagem e proporciona uma plataforma para o desenvolvimento de sistemas multi-agentes. Jason tem seu código aberto e é implementado na linguagem Java.

Dado que o ciclo de raciocínio do Jason é independente do simulador, realizar a integração de agentes BDI desenvolvidos em Jason com um simulador externo é uma tarefa difícil, uma vez que aspectos como o tempo de resposta dos agentes pode influenciar diretamente no seu desempenho. Isso é ainda mais preocupante quando olhamos para os simuladores de eventos discretos. São considerados simuladores de eventos discretos aqueles cuja simulação é realizada em passos e o simulador é constantemente pausado para que haja algum processamento. Durante os intervalos entre os passos, os agentes recebem as informações do simulador contendo as percepções individuais e têm até o início do próximo passo para decidir sobre suas ações e comunicá-las de volta ao simulador. Com isso, temos que por muitas vezes o tempo levado para encontrar a melhor ação é maior que o limite de tempo fixado pelo simulador, o que acarreta na perda da ação e inércia do agente durante todo o passo. Além disso, quanto mais complexos ficam os agentes, maior é o tempo utilizado para decidir

\footnotetext{
${ }^{1}$ RoboCup: http://www.robocup.org/

${ }^{2}$ MAPC: https://www.multiagentcontest.org/

${ }^{3}$ Jason: http://jason.sourceforge.net/wp/
} 
uma ação, agravando ainda mais o problema.

Segundo van Oijen e Dignum (2011), um dos problemas do paradigma BDI quando se une os agentes a ambientes virtuais é a ausência de controle sobre as percepções. Se não houver alguma forma de percepção direcionada ao objetivo, o agente pode ser inundado com informações sensoriais que podem resultar no raciocínio sobre uma enorme quantidade de informações irrelevantes. Além disso, a ausência de controle também não é realista quando olhamos para a fisiologia da percepção humana. Como a atenção é considerada um recurso limitado, não se pode atender a todos os aspectos do ambiente. Durante a execução de uma tarefa, os seres humanos, portanto, tendem a direcionar sua atenção para informações selecionadas do ambiente que podem apoiá-los na realização da tarefa selecionada. Isto sugere que uma abordagem similar deva também ser utilizada para agentes BDI.

Uma possível solução para o problema seria então a utilização de filtros de percepção de forma a reduzir o número de percepções recebidas, e assim possivelmente reduzir o tempo de processamento do agente.

\subsection{Objetivos}

O objetivo deste trabalho é construir e avaliar uma modificação do interpretador Jason que seja capaz de filtrar as percepções vindas do ambiente, para que seja possível responder a perguntas tais como:

1. Dado um certo limite de tempo de resposta do simulador, é possível para o agente processar todas as informações provenientes das percepções?

2. Ao utilizar um filtro de percepção, é possível melhorar o tempo de resposta?

3. Caso melhore, como se identificaria o filtro adequado?

4. Qual seria a influência dos filtros de percepção no valor da utilidade do agente?

Cabe neste momento ressaltar que a proposta apresentada neste trabalho tem como única finalidade prover um artifício computacional para melhorar o desempenho de um agente BDI Jason. Assim, este trabalho não tem como objetivo propor um modelo de filtro de percepção com base na psicologia ou bioinspirado, nem tampouco um modelo cognitivo mais refinado onde a decisão sobre o uso de tais filtros seja calculada. Tais questões certamente são de grande interesse e poderiam ser incorporadas a futuras extensões deste trabalho.

\subsection{Metodologia}

Neste trabalho, a integração dos filtros de percepção ao interpretador Jason foi analisada através de técnicas provenientes do domínio de análise de desempenho, em particular utilizando modelos de design de experimentos definidos por Jain (1991). Para cada experimento executado, foram definidos os fatores primários e secundários, seus diferentes níveis, a variável de resposta e o número de repetições. Dois modelos de design foram utilizados. O primeiro, mais simples, utiliza somente dois níveis para cada fator, possibilitando uma análise prévia do impacto destes fatores sobre a variável de resposta sem a necessidade de realizar uma grande quantidade de experimentos. De posse do resultado desse primeiro experimento, é possível verificar se há a necessidade de um experimento mais aprofundado. Caso seja necessário, um segundo modelo utiliza todas as combinações possíveis de níveis dos fatores escolhidos para fazer uma avaliação mais precisa do impacto de cada fator sobre a variável de resposta.

\subsection{Contribuições}

Este trabalho apresenta uma modificação do interpretador Jason que possibilita um maior controle sobre o tempo de processamento de agentes, proporcionando uma maior segurança ao desenvol- 
vedor quando existem restrições sobre o tempo de execução. Essa modificação inclui um mecanismo de filtros de percepção que, através de uma abordagem simples, torna possível que o desenvolvedor personalize seus próprios filtros conforme a aplicação. Com essa maior segurança, espera-se que haja um novo incentivo para que cresça o interesse e a utilização de linguagens orientadas a agentes nos mais diversos projetos, incluindo sistemas de simulação, acarretando em um maior desenvolvimento e popularização da área.

\subsection{Organização do trabalho}

O capítulo 2 apresenta uma base conceitual sobre Programação Orientada a Agentes, mostrando sua definição e exemplos de linguagens de programação orientadas a agentes, incluindo Jason.

No capítulo 3 são mostrados trabalhos relacionados que utilizam filtros de percepção. Em sequência, descrevem-se detalhadamente os filtros de percepção propostos neste trabalho e como eles se relacionam com os filtros apresentados anteriormente, mostrando sua incorporação no interpretador Jason e ilustrando seu uso através de exemplos.

Em 4 é definido o cenário que será utilizado para testar a aplicação dos filtros de percepção, e os métodos de avaliação utilizados.

O capítulo 5 descreve os experimentos realizados e analisa os resultados obtidos, com o objetivo de avaliar e quantificar a redução do tempo de processamento dos agentes causada pelos filtros de percepção, bem como o impacto destes filtros na função de utilidade do agente.

Por fim, o capítulo 6 apresenta as conclusões finais e os trabalhos futuros.

Nos anexos A a D, são apresentados em detalhe os resultados experimentais obtidos, que foram apresentados de forma resumida no capítulo 5 . 


\section{Capítulo 2}

\section{Programação Orientada a Agentes}

\section{$2.1 \quad$ AOP e OOP}

De acordo com Wooldridge (2009), Shoham (1993) propôs um novo paradigma para programação que foi chamado de Programação Orientada a Agentes (AOP), considerado como uma especialização da Programação Orientada a Objetos (OOP). Nesse paradigma foi proposto que agentes inteligentes fossem diretamente programados utilizando estados mentais, como crenças, desejos e intenções. O motivo para essa proposta foi a utilização desses conceitos pelos seres humanos como um mecanismo de abstração para representar as propriedades de sistemas complexos, da mesma forma que são utilizados para tentar explicar o comportamento dos seres humanos.

Segundo Shoham (1993), enquanto a OOP propõe que se veja um sistema computacional como um conjunto de módulos que se comunicam entre si, a AOP especializa esse modelo fixando um estado mental em cada um dos módulos, que são agora chamados de agentes, para que contenham mecanismos de crenças e tomada de decisão. Esses agentes podem então trocar informações, fazer solicitações, ofertas, aceitar ou rejeitar, competir e ajudar uns aos outros. A tabela 2.1 resume a relação entre AOP e OOP.

\begin{tabular}{|c|c|c|}
\hline & OOP & \multicolumn{1}{c|}{ AOP } \\
\hline \hline Unidade básica & Objeto & Agente \\
\hline $\begin{array}{c}\text { Parâmetros que definem o } \\
\text { estado de uma unidade básica }\end{array}$ & Sem restrições & $\begin{array}{l}\text { Crenças, compromissos, } \\
\text { capacidades, escolhas... }\end{array}$ \\
\hline Processo de computação & Métodos para envio de & $\begin{array}{l}\text { Métodos para envio de } \\
\text { mensagens e respostas }\end{array}$ \\
\hline Tipos de mensagem & Sem restrições & $\begin{array}{l}\text { Informar, pedir, ofertar, } \\
\text { prometer, recusar... }\end{array}$ \\
\hline Restrições sobre os métodos & Nenhuma & Honestidade, consistência... \\
\hline
\end{tabular}

Tabela 2.1: Tabela comparativa entre OOP e AOP apresentada por Shoham (1993)

De acordo com Wooldridge (1997), uma das teorias de agentes mais bem sucedidas é o modelo crença-desejo-intenção (BDI) de Rao e Georgeff (1995). As crenças de um agente representam as informações que ele tem sobre o mundo, como suas percepções, por exemplo. Os desejos de um agente podem ser pensados como as tarefas que lhe foram atribuídas. Um agente pode de fato não ser capaz de alcançar todos os seus desejos, e como em seres humanos, seus desejos podem até ser inconsistentes, no sentido de que atingir um pode inviabilizar que o agente atinja outros desejos. As intenções de um agente representam os desejos que ele se comprometeu a atingir. Como agentes não são, em geral, capazes de alcançar todos os seus desejos (mesmo aqueles consistentes), eles devem, portanto, escolher algum subconjunto destes desejos e se comprometer a alcançá-los. 
Desejos escolhidos se tornam intenções. Estas intenções serão então usadas para futuras tomadas de decisão onde, por exemplo, um agente não deve adotar intenções que entrem em conflito com aquelas que está comprometido.

Como apresentado por Bordini et al. (2006), pesquisas na área de Sistemas Multi-Agentes levaram ao desenvolvimento de uma série de ferramentas e linguagens de programação que se utilizam desse novo paradigma, como apresentado a seguir.

\section{$2.2 \quad 3 \mathrm{APL}$}

3APL (An Abstract Agent Programming Language) é uma linguagem de programação para a implementação de agentes cognitivos projetada por Hindriks et al. (1999) apud Bordini et al. (2006). Nela, os agentes têm crenças, objetivos e planos como atitudes mentais, podem gerar e rever os seus planos para atingir seus objetivos, e são capazes de interagir uns com os outros e com o ambiente que compartilham com outros agentes.

Uma das principais características de 3APL consiste na implementação de atitudes mentais de um agente bem como o processo de deliberação que as manipula. Em particular, 3APL permite a especificação direta de atitudes mentais, tais como crenças, objetivos, planos, ações e regras de raciocínio.

A linguagem de programação 3APL foi concebida de modo a respeitar uma série de princípios de engenharia de software e de programação, tais como a separação de interesses, modularidade, abstrações e reusabilidade. Ele também permite a integração com as linguagens de programação Prolog (declarativa) e Java (Orientada a Objetos).

Um exemplo de agente desenvolvido em 3APL foi apresentado em Dastani et al. (2003) e se encontra no código 1. Nesse exemplo, um robô tem como objetivo transportar caixas para um quarto específico enquanto minimiza o custo do transporte. A primeira e segunda ações dizem que o robô pode ir do quarto $R 1$ para o quarto $R 2$ se ele já estiver no quarto $R 1$ (pos $(R 1)$ ). Depois de executar o movimento, se ele estiver proibido de fazer esse movimento, seu custo é 5 , e em caso contrário seu custo é somente 1. A terceira e quarta ações representam a transição quando o agente pega ou coloca uma caixa no chão. A base de crenças mostra o estado inicial do agente, contendo sua posição inicial, a posição das caixas e quais os movimentos proibidos. Esse agente possui somente um objetivo, que é transportar caixas. Para atingi-lo, o agente utiliza sua base de regras para planejar seus movimentos.

\subsection{Jadex}

Jadex é um arcabouço de software para a criação de agentes orientados a objetivos que segue o modelo crença-desejo-intenção (BDI) e que foi desenvolvida por Braubach et al. (2003) apud Bordini et al. (2006). O arcabouço é composto por um agente racional que fica em uma camada no topo de uma infra-estrutura de agente de middleware como JADE Bellifemine et al. (1999) apud Bordini et al. (2006), e permite o desenvolvimento do agente com tecnologias bem estabelecidas, como Java e XML.

Jadex tem sido usada para construir aplicações em diferentes domínios como a simulação, planejamento de tarefas e computação móvel. Por exemplo, Jadex foi utilizado para desenvolver uma aplicação multi-agente para negociação de horários de tratamento em hospitais.

Os agentes construídos em Jadex são definidos em um arquivo chamado de "Arquivo de Definição de Agente" (ADF). Um exemplo de agente construído em Jadex foi proposto em Braubach et al. (2003) e está apresentado no código 2. Nesse exemplo, um agente faz a tradução de palavras em inglês para alemão. Os planos são instanciados através de classes escritas em Java e a base de crenças é especificada no arquivo. 


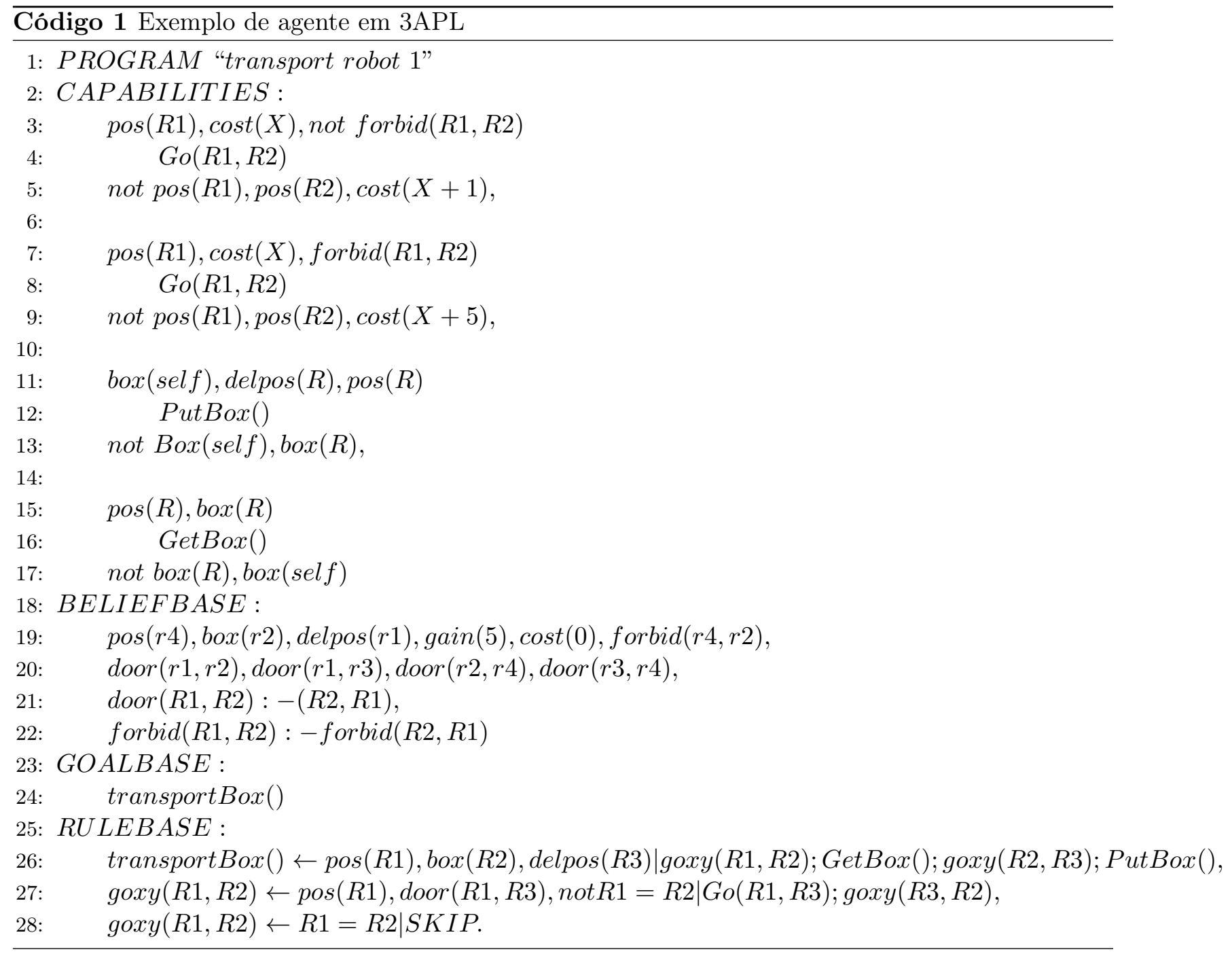

\subsection{AgentSpeak}

A linguagem AgentSpeak é uma linguagem de programação abstrata orientada a agentes baseada em uma linguagem de primeira ordem restrita com eventos e ações. Foi criada por Rao (1996) para permitir a programação do comportamento de agentes BDI e sistemas multiagentes.

Rao (1996) define que a linguagem consiste de um conjunto de crenças base (ou fatos, no contexto de programação lógica) e um conjunto de planos. Os planos são receitas invocadas por eventos e sensíveis ao contexto que permitem a decomposição hierárquica de objetivos, bem como a execução das ações. Os planos visam atingir os objetivos do agente, assim, pode-se dizer que os planos selecionados para execução seriam as intenções do agente.

No entanto, a linguagem AgentSpeak é abstrata e seus autores não construíram um compilador ou interpretador para a linguagem, não tendo utilização prática.

\subsection{Jason}

Jason é um interpretador open-source implementado na linguagem Java para uma versão estendida da linguagem AgentSpeak, desenvolvido por Bordini, Hübner, e Wooldridge (2007), que implementa a semântica operacional da linguagem e fornece uma plataforma para o desenvolvimento de sistemas multi agentes.

Segundo Bordini et al. (2006), além daquelas definidas pela linguagem AgentSpeak, algumas das funcionalidades disponíveis no Jason são: 


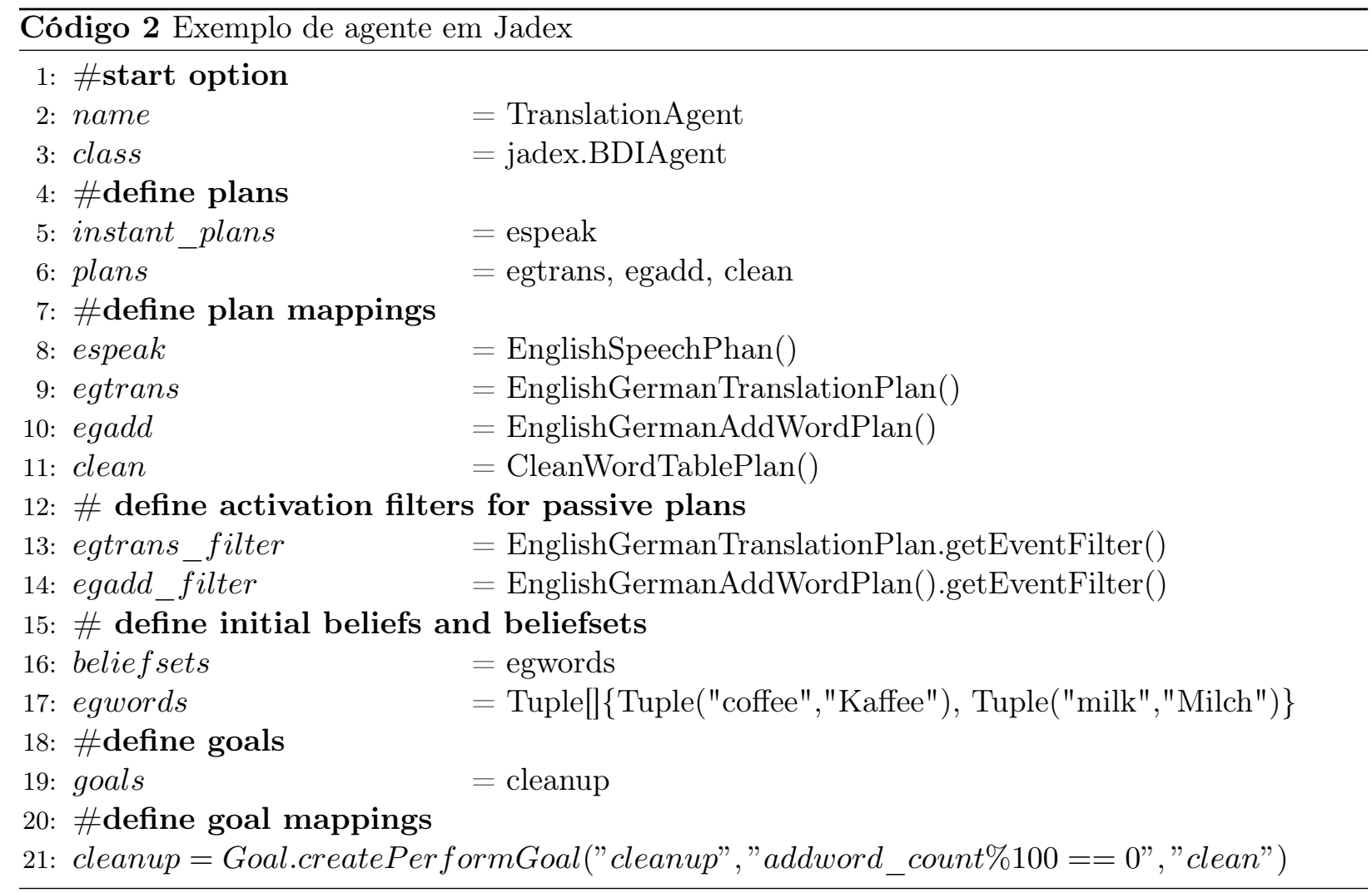

1. Comunicação entre agentes baseada em atos de fala (e anotações nas crenças sobre as fontes de informação);

2. Anotações nos rótulos dos planos, que podem ser usados por funções de seleção mais elaboradas;

3. Funções de seleção, funções de confiança e arquitetura geral do agente (percepção, revisão de crenças, comunicação entre agentes e ações) inteiramente customizáveis (em Java);

4. Capacidade de extensão (e utilização de código legado) por meio de "ações internas"definidas pelo usuário;

5. Uma noção clara de um ambiente multi-agente, que é implementado em Java (este pode ser uma simulação de um ambiente real, por exemplo, para fins de teste antes do sistema ser realmente implantado).

\subsubsection{Ciclo de raciocínio}

Em Jason, os agentes são executados por meio de um ciclo de raciocínio que pode ser dividido em 10 passos principais, como pode ser visto na figura 2.1. Durante cada ciclo de raciocínio, o agente recebe as percepções do ambiente, as mensagens de outros agentes, delibera, escolhe uma intenção e executa uma ação.

O processo interno é descrito por Bordini et al. (2007) da seguinte forma:

\section{Percepção do ambiente}

O primeiro passo na execução do agente é perceber o ambiente. As percepções são um conjunto de literais onde cada literal representa uma propriedade no atual estado do ambiente.

\section{Atualização da Base de Crenças}

A base de crenças é atualizada para refletir as mudanças do ambiente. Isso é feito através de uma função de atualização personalizável. Na implementação padrão do Jason, assume-se que 


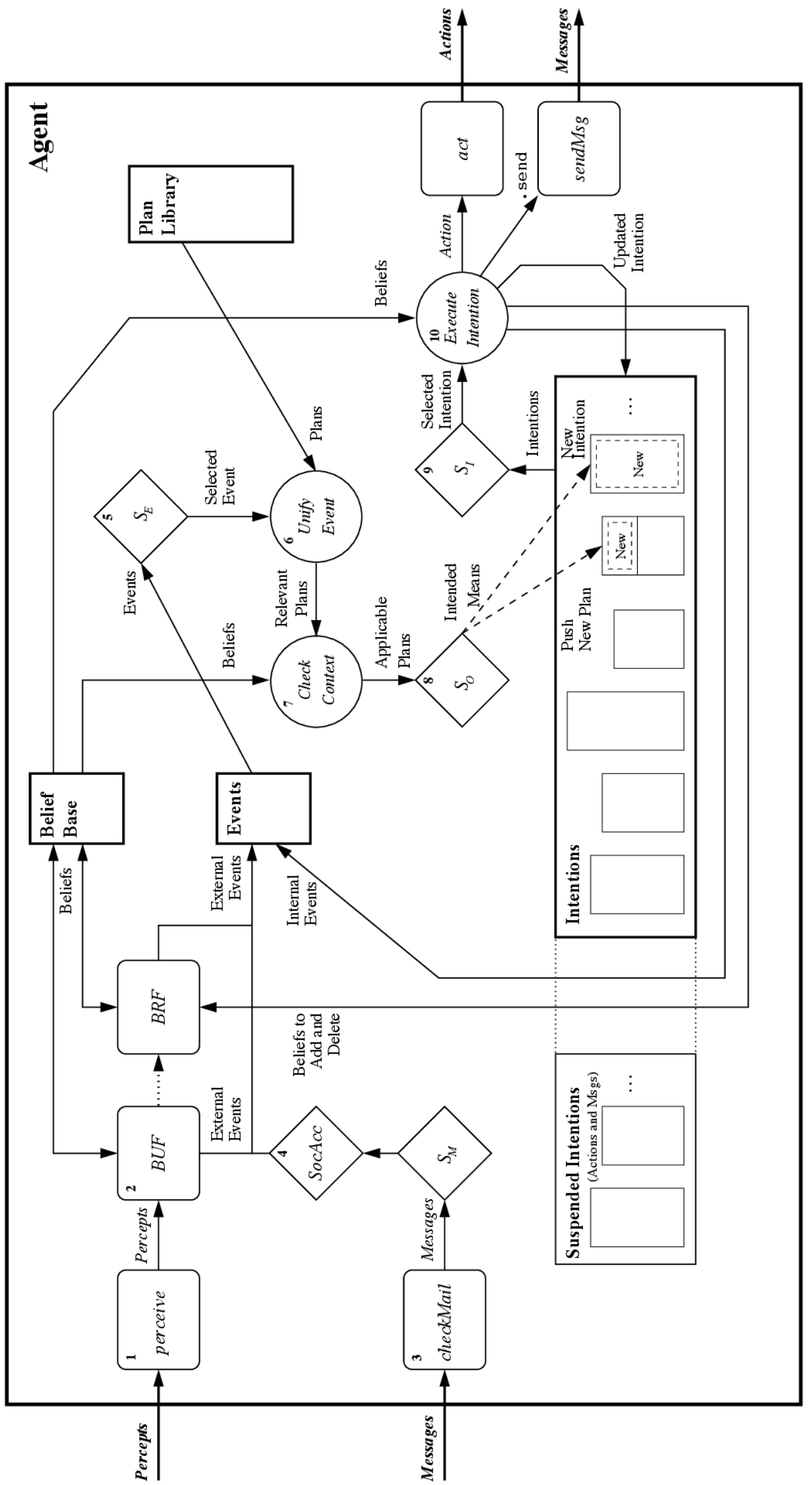

Figura 2.1: Ciclo de raciocinio de um agente Jason apresentado por Bordini et al. (2007). 
tudo o que pode ser percebido no ambiente está listado no conjunto de percepções. Assim, o método padrão percorre a base de crenças e a lista de percepções para incluir os literais novos, remover os literais que não foram mais percebidos e manter aqueles que já eram conhecidos. Cada inclusão ou exclusão de literais gera um evento, que é adicionado à uma lista que será utilizada posteriormente.

\section{Recebendo comunicação de outros agentes}

Neste estágio, o interpretador verifica se o agente recebeu alguma mensagem de outro agente. Caso afirmativo, é selecionada uma delas para ser processada.

\section{Selecionando mensagens "Socialmente Aceitáveis"}

Antes de processada, a mensagem passa por uma verificação para determinar se ela deve ou não ser aceita pelo agente, verificando o remetente e o conteúdo através de uma função personalizável.

\section{Selecionando um Evento}

A partir da lista de eventos criada na fase de atualização das crenças, é selecionado um evento para ser executado. Caso não haja alteração da função de seleção, o primeiro evento da lista é escolhido.

\section{Recuperando os planos relevantes}

Selecionado um evento, é necessário encontrar um plano que permita ao agente agir de forma a lidar com o evento. O primeiro passo é percorrer a lista de planos e encontrar todos aqueles invocados pelo evento selecionado.

\section{Determinando os planos aplicáveis}

Com a lista de planos relevantes, é preciso verificar quais deles podem realmente ser executados, ou seja, cujas precondições são válidas.

\section{Selecionando um dos planos aplicáveis}

Neste ponto, já foram determinados todos os planos que podem ser utilizados para lidar com o evento selecionado. Assim, teoricamente, qualquer um dos planos pode ser utilizado para esse fim. Para decidir então qual deles executar, é utilizada uma outra função de seleção personalizável que o adiciona à lista existente de intenções.

\section{Selecionando uma intenção para posterior execução}

Durante a execução, tipicamente um agente possui mais de uma intenção para executar, cada uma representando um foco de atenção diferente. No entanto, somente uma intenção pode ser executada por vez. Assim, é necessário escolher uma única intenção para ser executada.

\section{Executando um passo da intenção}

Neste último estágio, o agente já atualizou suas informações sobre o ambiente, lidou com um dos eventos gerados e deve agora, efetuar uma ação. Da intenção escolhida, é selecionada a primeira ação que ainda não foi executada e esta é efetuada.

\subsubsection{Exemplo de código}

Um exemplo de agente construído em Jason pode ser visto no código 3. Nesse exemplo, disponibilizado junto ao código fonte do $\mathrm{Jason}^{1}$, um agente é responsável por efetuar a limpeza de uma sala. Ele realiza essa tarefa percorrendo todos os quadrados do grid e ao encontrar lixo em um dos quadrados, carrega esse lixo até o incinerador. O agente irá perceber o ambiente a cada passo e obterá informações sobre sua atual posição " $\operatorname{pos}(r 1,0,0)$ ", a posição do incinerador " $\operatorname{pos}(r 2,10,10)$ " e se existe lixo no espaço onde se encontra "garbage $(r 1)$ ". No início da execução, o agente possui o objetivo de percorrer o grid em busca de lixo. O único plano que pode ser usado verifica se há lixo

\footnotetext{
${ }^{1}$ http://jason.sourceforge.net/wp/
} 
no mesmo espaço do agente. Se não houver, o agente se movimenta para o próximo espaço. Caso o agente perceba que há lixo no mesmo espaço que ocupa, ele pega o lixo, o carrega até o incinerador e volta para a mesma posição onde se encontrava anteriormente.

Dado que o interpretador Jason é implementado na linguagem Java, é possível utilizar conjuntamente com o AgentSpeak métodos desenvolvidos na linguagem Java para tarefas como cálculos matemáticos ou leituras de arquivos, onde o uso de uma abstração BDI tornariam sua execução ineficiente.

Utilizando então estes mecanismos, o Jason é capaz de executar os agentes de forma que interajam com o ambiente quando necessário e realizem as tarefas especificadas.

\subsection{Análise de desempenho de Jason}

Para identificar com maior precisão os pontos críticos de processamento do interpretador Jason, numa primeira etapa do trabalho conduzimos uma análise preliminar da complexidade computacional de seu código, analisando as principais funções de seu ciclo de raciocínio. Esta análise sugeriu que um dos métodos com maior complexidade seria a função de Atualização da Base de Crenças. Para verificar quais crenças foram adicionadas, quais foram mantidas e quais devem ser removidas, é feita uma comparação entre todas as $b$ crenças existentes na base e as novas $p$ percepções. No pior caso, essa comparação pode apresentar uma complexidade $O(b * p)$. Sendo que a base de crenças é altamente dependente das percepções, essa função tem comportamento quadrático no número de percepções, apresentando uma complexidade maior que o restante dos métodos do ciclo de raciocínio que apresentam complexidade linear.

A fim de verificar o comportamento da função de Atualização da Base de Crenças e identificar outros pontos críticos no desempenho do ciclo de raciocínio apresentado na seção 2.5, usamos o JProfiler ${ }^{2}$ para avaliar a execução do Jason e monitorar o uso de memória e de CPU.

Monitoramos inicialmente a execução de uma versão prévia do primeiro experimento descrito em detalhes no capítulo 5. Resumidamente, o experimento se tratava de um agente em um grid que devia capturar o maior número de insetos que se moviam aleatoriamente. Nessa versão o agente não utilizava informações de ciclos de raciocínio anteriores e se movimentava em direção à maior concentração de insetos. O cálculo era realizado dividindo o grid horizontalmente e verticalmente em 4 setores, e o agente se movia para o setor que apresentava o maior número de insetos.

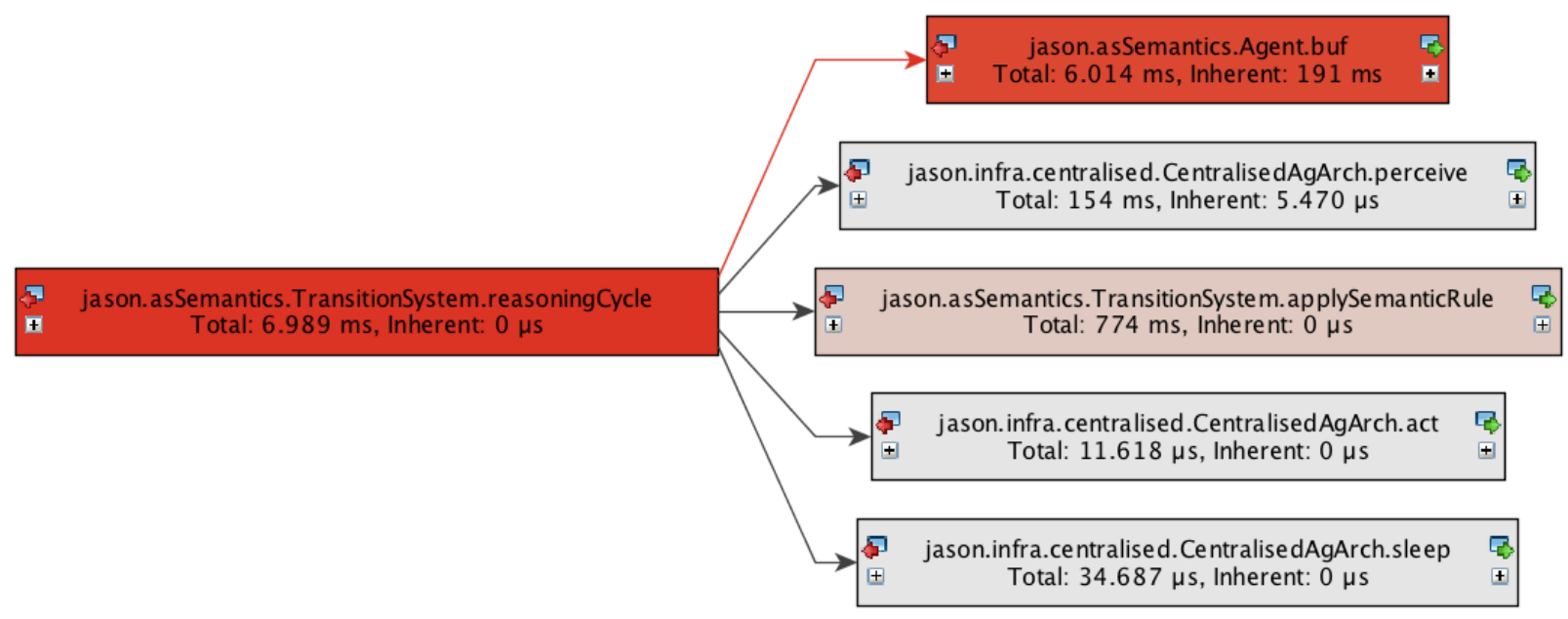

Figura 2.2: Tempo de execução dos métodos do ciclo de raciocínio do Jason no primeiro experimento.

O resultado do profiling é mostrado na figura 2.2. Nele é possível ver que $86 \%$ do tempo de execução do ciclo de raciocínio (reasoningCycle) é utilizado na função de Atualização da Base de Crenças (buf). É possível ver também que uma segunda função se sobressai: a função responsável

\footnotetext{
${ }^{2}$ JProfiler está disponível em https://www.ej-technologies.com.
} 


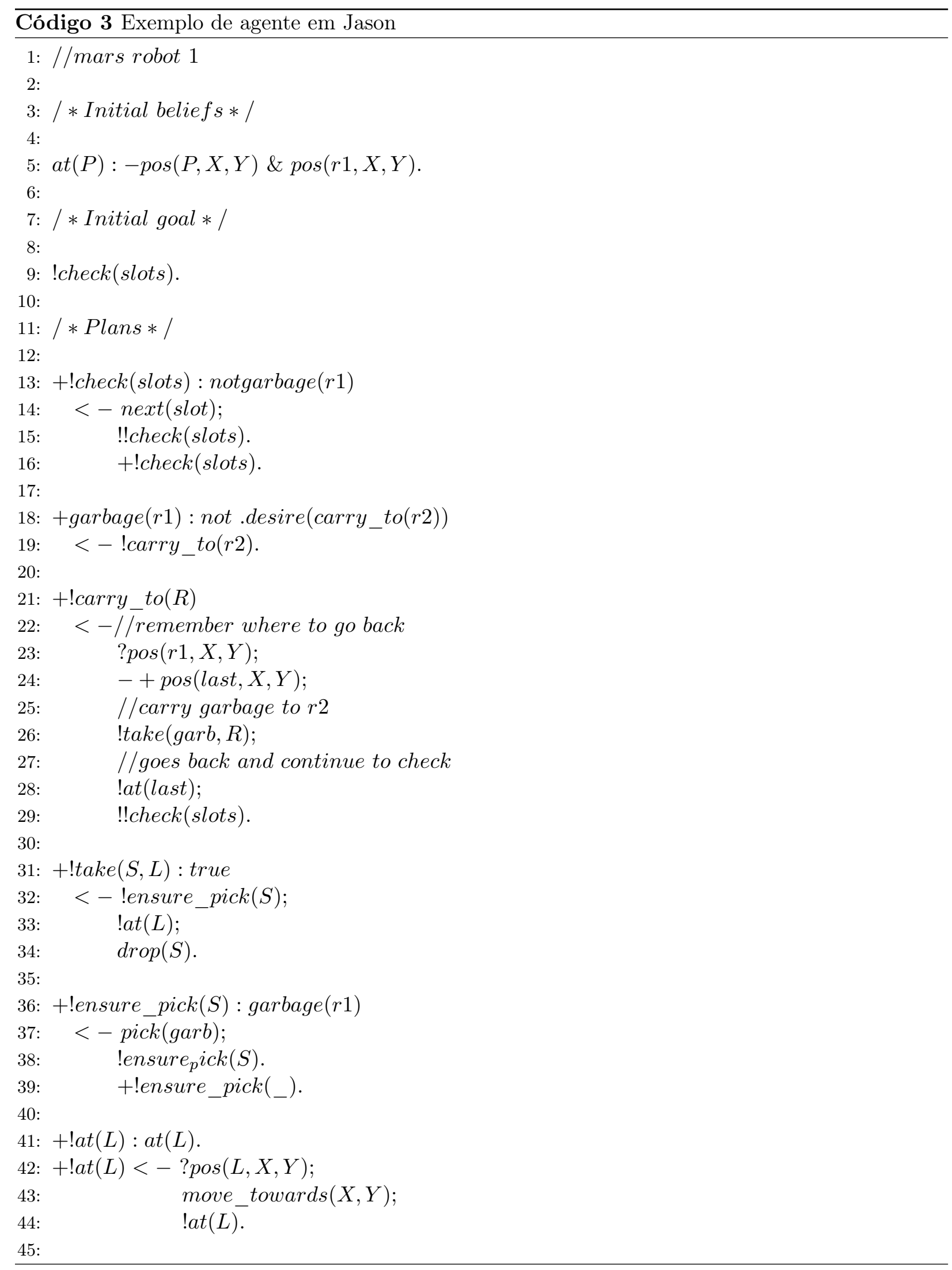


pela unificação de variáveis nos planos e regras (applySemanticRule) ocupa cerca de $11 \%$ do tempo de processamento, fazendo com que juntas, essas duas funções sejam responsáveis por praticamente todo o tempo de processamento do ciclo de raciocínio. Outra importante informação que foi obtida no experimento é que o tempo de resposta do agente se deve ao processamento dos métodos, já que a quantidade de memória utilizada pelo interpretador não causou perda de desempenho.

Monitoramos em seguida a execução do primeiro experimento descrito no capítulo 5. Nessa versão, o agente já baseia seus movimentos na localização prévia dos insetos, fazendo necessário um maior processamento das percepções.

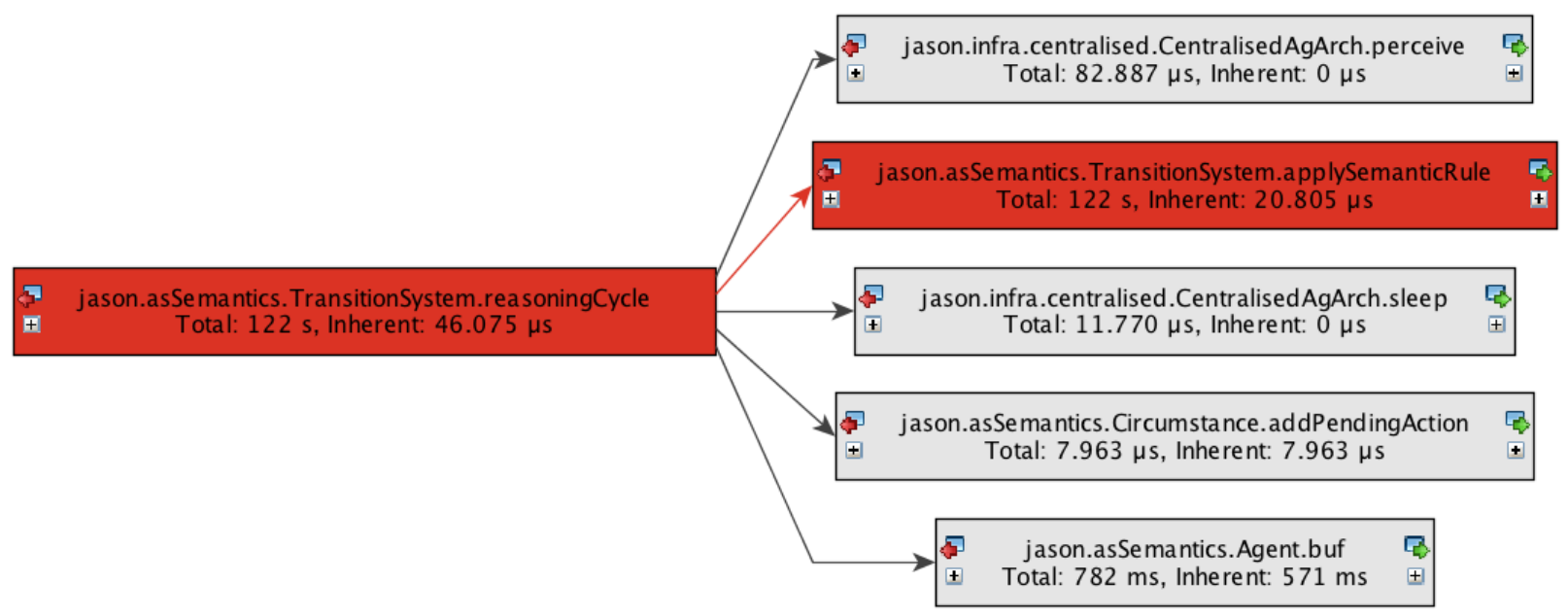

Figura 2.3: Tempo de execução dos métodos do ciclo de raciocínio do Jason no segundo experimento.

O resultado do segundo profiling é mostrado na figura 2.3. Nele é possível ver que o tempo de processamento da função de Atualização da Base de Crenças (buf) ainda é maior que o das outras funções, com exceção da função responsável pela unificação de variáveis nos planos e regras (applySemanticRule), que neste experimento é responsável por $99 \%$ do tempo de processamento. Esse comportamento foi justificado por uma análise posterior, que verificou que essa função era chamada recursivamente diversas vezes, causando o impacto no tempo de processamento.

Esses testes de profiling foram úteis para mostrar que estas duas funções representam pontos problemáticos dentro do ciclo de raciocínio. É interessante verificar que estas duas funções compartilham uma mesma característica: quanto mais as crenças do agente tiver, mais demorada é a sua execução.

Com base nesse fato, seria promissora uma modificação que tornasse possível exercer um maior controle sobre a quantidade de percepções. Como dito anteriormente, na implementação padrão do Jason assume-se que tudo o que pode ser percebido no ambiente está listado no conjunto de percepções recebido pelo agente.

Nas aplicações que nos interessam, como nem sempre é viável para os agentes perceber todo o ambiente e ainda manter um alto nível de desempenho, fornecendo uma ação dentro de um limite de tempo de resposta, é importante ser capaz de reconhecer as mudanças relevantes que ocorrem no ambiente. Tal comportamento é possível através do uso de filtros de percepção, como mostrado a seguir. 


\section{Capítulo 3}

\section{Filtros de Percepção em Jason}

\subsection{Trabalhos relacionados}

Os trabalhos de van Oijen e Dignum (2011) e Bordeux et al. (1999) sobre filtros de percepção sugerem uma possível solução para esse problema. Os filtros de percepção fazem com que seja possível selecionar previamente e enviar ao agente somente aquilo que é interessante para ele naquele determinado momento.

van Oijen e Dignum (2011) têm como objetivo a integração de agentes criados em plataformas multi-agentes como 2APL de Dastani (2008), Jadex de Braubach et al. (2003) e Jason de Bordini et al. (2007) com ambientes virtuais em tempo real, mais especificamente jogos de computador. Nesse artigo foi proposto um middleware para fazer a integração entre os dois sistemas. Esse middleware é responsável por receber sinais do ambiente virtual e fazer todo o processamento para entregar ao agente somente o conjunto de percepções que sejam de seu interesse. Como descrito no artigo e na seção 1.1, um dos problemas do paradigma BDI quando se integram agentes a ambientes virtuais é a ausência de controle sobre as percepções, resultando no raciocínio sobre informações irrelevantes.

Table I

ObJect ATtribute SubSCRIPTION EXAMPLES

\begin{tabular}{|l|l|l|l|l|l|}
\hline OBJECT CLASS & PROPERTY & CONDITION & SOURCE & UPDATE POLICY & DESCRIPTION \\
\hline \hline PHYSICALOBJECT & LOCATION & - & - & FREQUENCY-1 & LOCATION ALL OBJECTS AT 1 HZ. \\
\hline HUMAN & LOCATION & - & - & FREQUENCY-5 & LOCATION OF ALL HUMANS AT 5 HZ. \\
\hline CAR & LOCATION & {$[$ COLOR=RED $]$} & - & FREQUENCY-2 & LOCATION OF RED CARS AT 2 HZ. \\
\hline CAR & MODEL & - & & ONE-TIME & MODEL OF A CAR \\
\hline DOOR & STATUS & - & & VALUE-CHANGE & DOORS OPENING/CLOSING \\
\hline HUMAN & GENDER & - & HUMAN21 & ONE-TIME & GENDER OF ONE SPECIFIC PERSON \\
\hline
\end{tabular}

Table II

EVENT SUBSCRIPTION EXAMPLES

\begin{tabular}{|l|l|l|l|l|}
\hline EVENT CLASS & PARAMETER & CONDITION & SOURCE & DESCRIPTION \\
\hline \hline COMMUNICATION & - & - & - & ALL COMMUNICATION EVENTS \\
\hline COMMUNCIATION & - & - & HUMAN21 & COMMUNICATIONS FROM ONE SPECIFIC PERSON \\
\hline COMMUNICATION & RECEIVER & HUMAN22 & HUMAN21 & COMMUNICATIONS BETWEEN TWO SPECIFIC SPEECH PARTNERS \\
\hline PHONERINGING & - & - & CELLPHONE1 & RINGING OF A SPECIFIC PHONE \\
\hline
\end{tabular}

Figura 3.1: Tabela de inscrições utilizada por van Oijen e Dignum (2011).

Para atacar esse problema, foi criado um Gerenciador de Assinaturas de Interesse que contém assinaturas para informações específicas do ambiente. Quando um agente adota um objetivo, o sistema cria automaticamente um conjunto de inscrições de informações sobre o ambiente usando o Gerenciador de Assinaturas de Interesse. Assim, quando um objetivo é alcançado ou descartado, o sistema automaticamente cancela a inscrição da informação correspondente. Para efetuar tal procedimento, o sistema utiliza uma tabela off-line previamente criada que mapeia os objetivos do agente para conjuntos de assinaturas. Um exemplo de tabela pode ser visto na figura 3.1. Nela é 
possível ver que existem condições específicas de quando e com que frequência se deve perceber determinados objetos como pessoas e carros.

O objetivo de Bordeux et al. (1999) é criar uma extensão para uma arquitetura de software para a gestão de ações chamada AGENTlib, criada por Boulic et al. (1997), para implementar um mecanismo de percepção. Esse mecanismo de percepção conta com um filtro de percepções que tem como objetivo filtrar eficientemente informações valiosas da cena onde se encontra o agente. No artigo, o filtro de percepção representa a entidade básica do mecanismo de percepção. Esse filtro recebe entidades perceptíveis a partir da cena como entrada, extrai informações específicas sobre elas, e, finalmente, decide se envia a percepção referente a essa entidade ao agente ou não. Para diferentes finalidades, foram criados alguns tipos de filtro. Entre eles os que se destacam são:

- Filtro de intervalo: Este filtro seleciona somente os objetos que estão fisicamente ao redor do agente em um determinado intervalo de espaço;

- Filtro de campo de visão: Este filtro simula um campo de visão de um agente com uma determinada abertura angular;

- Filtro de colisão: Este filtro detecta os objetos sujeitos a potenciais impactos com o agente de acordo com sua trajetória;

- Filtro detector de tipo: Este filtro procura ao redor do agente por objetos com tipos e propriedades específicas.

Também é possível combinar diferentes filtros para atingir o objetivo desejado. Com isso, foi possível alcançar o objetivo inicial e permitir aos agentes perceber os objetos de interesse no ambiente.

\subsection{Proposta}

Com base nesses dois trabalhos e no funcionamento do Jason, foi então idealizado um modo de incluir filtros de percepção no mecanismo de percepção do agente Jason.

Da abordagem de van Oijen e Dignum (2011), utilizamos a idéia de especificar documentos indicando as percepções a serem descartadas. Entretanto, em nosso caso não é adequado a construção de um middleware específico para esta tarefa, já que desejamos incorporar tais filtros ao Jason. Assim, para tal nos inspiramos na abordagem de Bordeux et al. (1999).

Também baseados em Bordeux et al. (1999), definimos dois tipos de filtros distintos:

- Filtro de intervalo, que descarta percepções de regiões do ambiente localizadas além de um determinado intervalo de espaço;

- Filtro de propriedade, que descarta percepções de objetos do ambiente com tipos e propriedades diferentes daqueles nos quais o agente deve focar sua atenção.

Os filtros de intervalo podem ser utilizados em quaisquer ambientes topológicos que tenham uma noção de distância. Já os filtros de propriedade são dependentes do domínio de aplicação. Em particular, como mostrado nos experimentos relatados no capítulo 5, implementamos e analisamos o efeito destes dois tipos de filtros.

Um agente Jason recebe as percepções na forma de uma lista de literais em linguagem lógica no passo 1 do seu ciclo de raciocínio. Além disso, Jason permite a adição de anotações aos literais, de forma que é possível adicionar informações extras às percepções. Por padrão, é adicionada a cada percepção a anotação source para que seja possível saber se uma crença na base de crenças do agente surgiu de uma percepção, do raciocínio do próprio agente ou se foi uma informação vinda de outro agente. As anotações são, assim como as percepções, compostas por um predicado e parâmetros. Um exemplo de base de crenças é apresentada no código 4. 


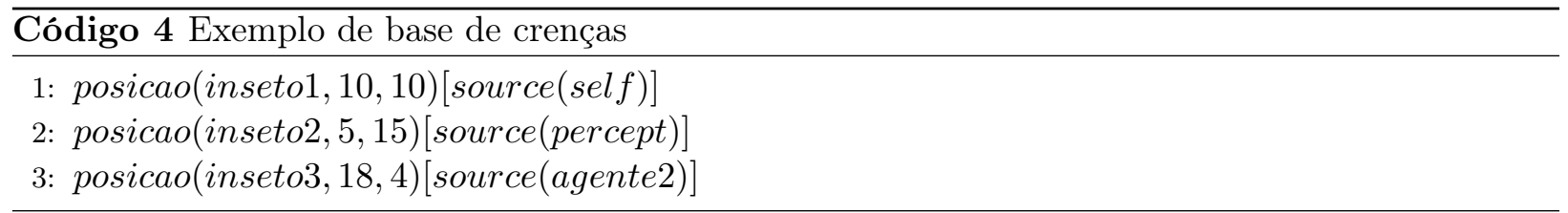

Nesse exemplo, o agente teria deduzido através de algum mecanismo interno a posição do inseto1, percebido através de seus sensores a posição do inseto2 e teria sido informado pelo agente2 onde se encontra o inseto3. Desta forma, possuímos todas essas informações que podem ser utilizadas na hora de decidir se uma percepção deve ou não ser avaliada.

De forma semelhante ao realizado com as tabelas em van Oijen e Dignum (2011), para cada agente são criados documentos de restrição, que informam ao interpretador quais percepções devem ser descartadas. Estes documentos de restrição são construídos em formato xml, como mostra o código 5. Este exemplo utiliza um documento de restrição similar àquele utilizado nos experimentos do capítulo 5, e descreve um filtro de intervalo.

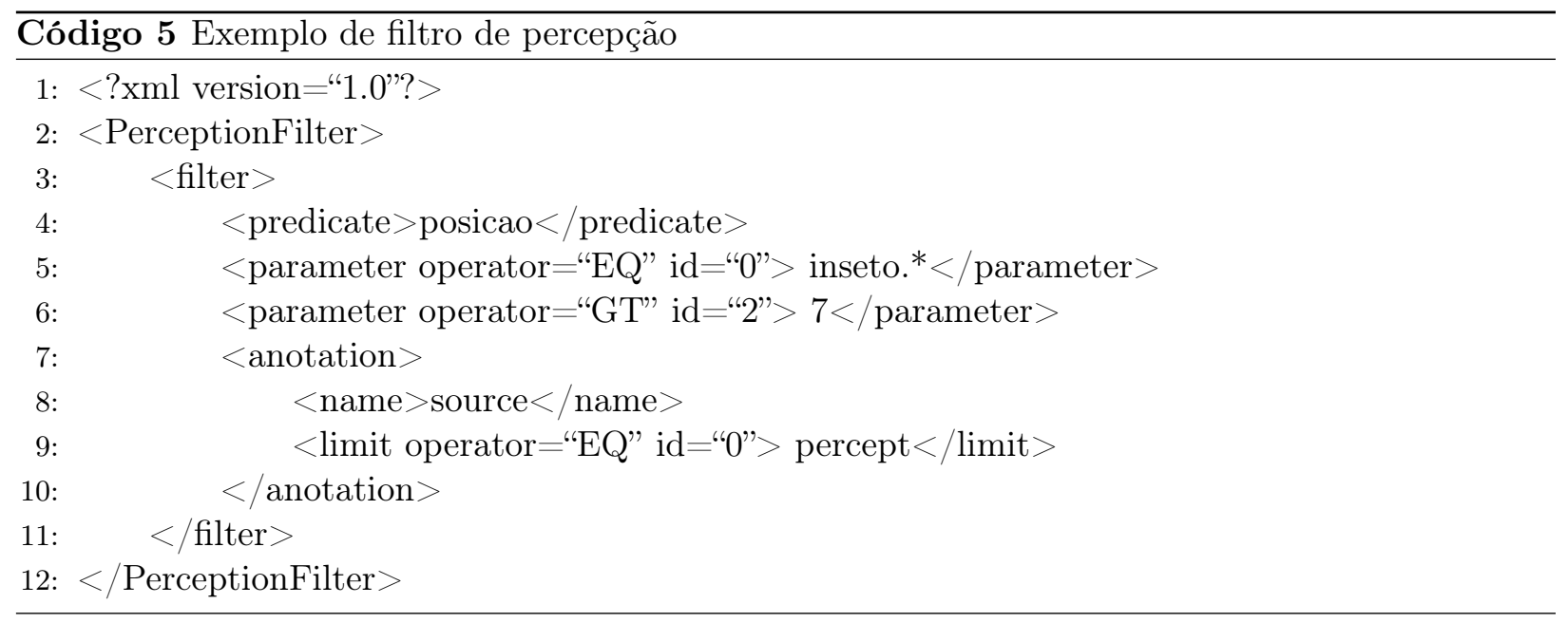

Cada arquivo desse pode conter inúmeras tags filter para filtrar os diferentes predicados utilizados. Para que uma percepção seja descartada ela deve obedecer a todos os critérios especificados no filtro. Em cada filtro existem três critérios: o predicado, os parâmetros e as anotações, sendo que o único critério obrigatório é o predicado, dado que não é possível que exista um literal sem um predicado associado.

A restrição para o predicado é direta, verificando-se se o predicado associado ao literal é o mesmo predicado especificado no filtro. Já para os parâmetros, existem duas informações necessárias: a primeira é o id que informa qual dos parâmetros deve ser comparado, e a segunda é o operator, que indica como deve ser feita a comparação do valor dentro da tag com o valor no literal vindo da percepção. Operator pode assumir seis valores:

- EQ: O valor do parâmetro na percepção deve ser igual ao valor dentro da tag. Este último pode ser uma expressão regular para a linguagem Java.

- NE: O valor do parâmetro na percepção deve ser diferente do valor dentro da tag. Este último pode ser uma expressão regular para a linguagem Java.

- GT: O valor do parâmetro na percepção deve ser maior do que o valor dentro da tag (inteiro ou de ponto flutuante).

- GE: O valor do parâmetro na percepção deve ser maior ou igual ao valor dentro da tag (inteiro ou de ponto flutuante).

- LT: O valor do parâmetro na percepção deve ser menor do que o valor dentro da tag (inteiro ou de ponto flutuante). 
- LE: O valor do parâmetro na percepção deve ser menor ou igual ao valor dentro da tag (inteiro ou de ponto flutuante).

Dado que as anotações também são literais em linguagem lógica, é necessário que sejam comparados seu predicado e seus parâmetros. Assim, o valor dentro da tag name é comparado ao predicado da anotação para ver se são iguais. A tag limit funciona da mesma forma que a tag parameter, comparando os parâmetros contidos na anotação.

Mesmo com a possibilidade de se selecionar exatamente as informações que se deseja restringir, pode ser que dependendo da situação e do objetivo atual do agente seja interessante que os filtros sejam alterados. Com essa finalidade, foi incluída uma ação interna change filter que pode ser incluída como parte de um plano para que o filtro atual seja alterado.

A ação interna pode ser incluída em qualquer plano, como mostra o exemplo no código 6:

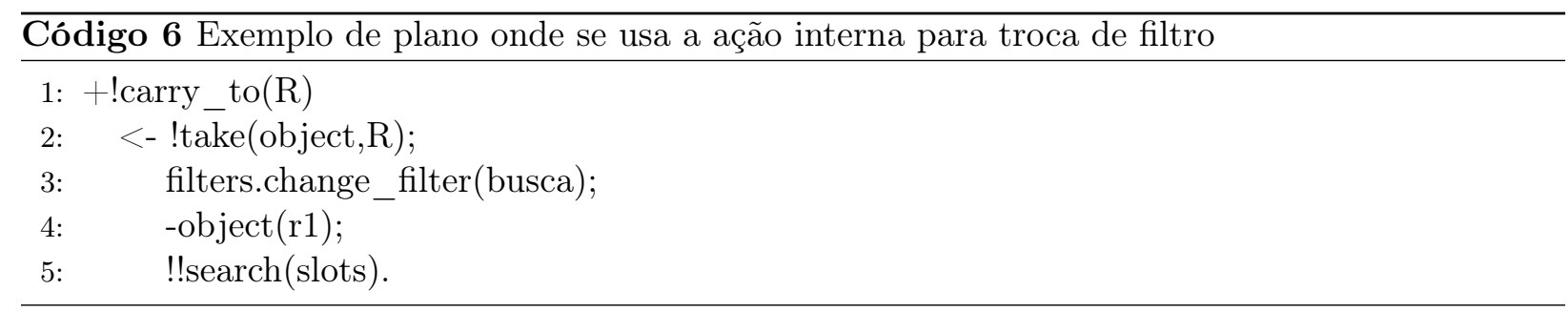

Assim, depois que o agente executou o objetivo de pegar o objeto, o filtro é alterado para que haja o controle das percepções nos ciclos de raciocínio futuros. A palavra "busca"utilizada como parâmetro se refere ao nome do arquivo XML onde se encontra o filtro desejado. Assim, é possível ter diversos filtros para diversas situações.

Enquanto um filtro previamente selecionado não for alterado, sempre que o agente receber uma lista de percepções cada uma delas será analisada e eventualmente apagada caso corresponda aos critérios do filtro ativo. Sabendo qual o filtro a ser utilizado, foi inserido entre os passos 1 e 2 do ciclo de raciocínio (Figura 2.1) o mecanismo de filtragem. Dessa forma, é possível verificar quais percepções recebidas pelo agente no passo 1 devem ser enviadas à função de atualização de crenças no passo 2 .

Uma versão inicial do modelo dos filtros de percepção, bem como alguns resultados preliminares, encontra-se descrito em Stabile Jr. e Sichman (2015a). 


\section{Capítulo 4}

\section{Estudo de Caso}

\subsection{Simulador}

Para tentar encontrar as respostas para as perguntas propostas na seção 1.2, foi implementado um ambiente onde um agente Jason deve perseguir, capturar insetos que se movem aleatoriamente e levá-los de volta para sua base em um grid, como mostrado na Figura 4.1.

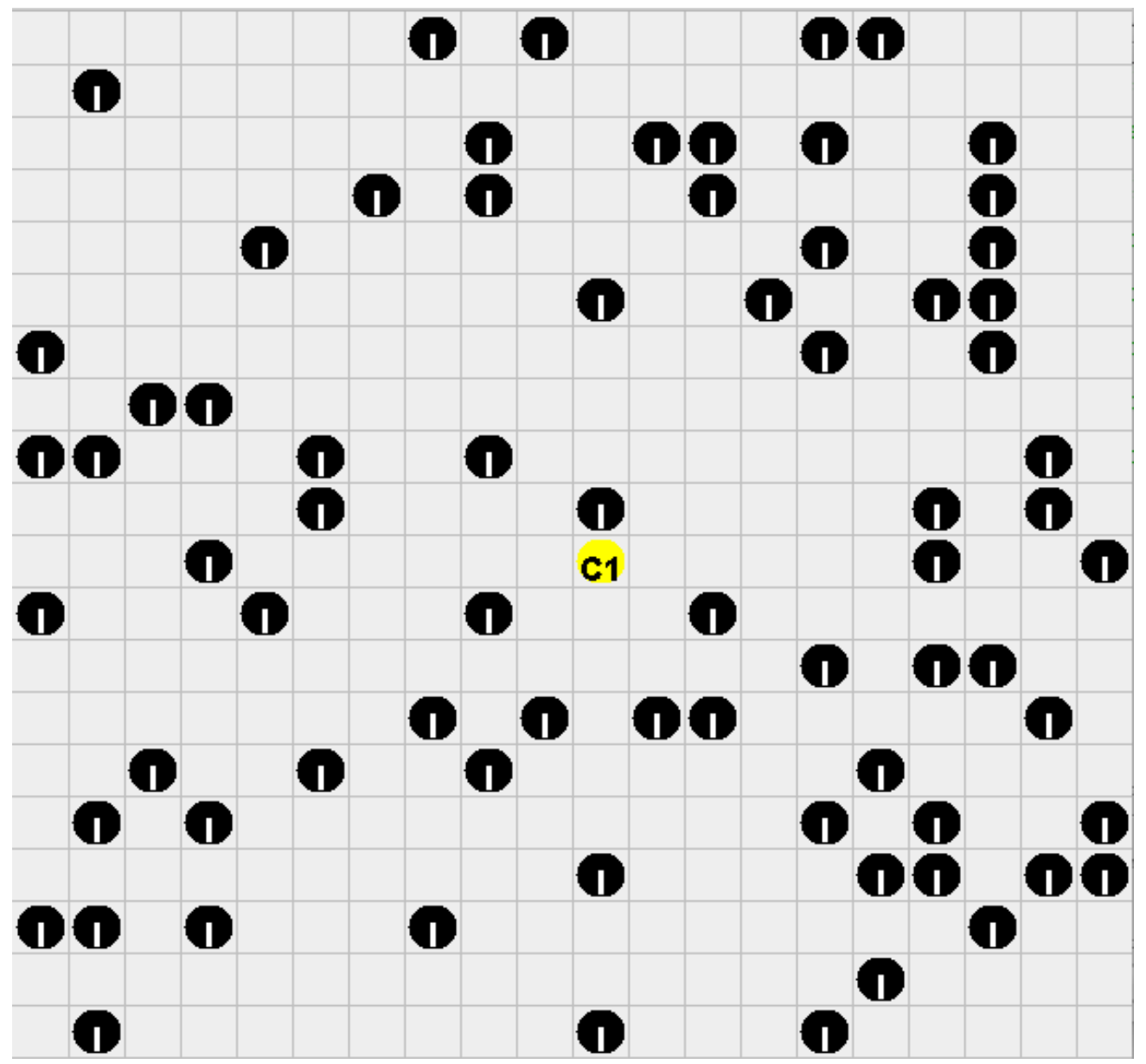

Figura 4.1: Ambiente utilizado para os testes de desempenho.

Da mesma forma que nos simuladores mencionados na seção 1.1, a execução do simulador é feita em passos:

1. O simulador envia dados perceptuais do estado atual do ambiente para o agente;

2. O agente processa a informação perceptual através do ciclo de raciocínio e informa ao simu- 
lador a ação que deseja executar;

3. O simulador recebe a ação pretendida do agente e, se possível, executa-a no ambiente;

4. O simulador atualiza a posição dos insetos (movimentando-os aleatoriamente para os lados, para cima ou ficando parados), adiciona insetos se algum deles foi capturado ${ }^{1}$ e registra o tempo decorrido para a ação do agente e o número de insetos capturados;

5. Finalmente, um novo ciclo é iniciado.

Definimos como $n$ a dimensão do grid, que representa a sua largura e altura (o grid contém $n^{2}$ espaços). Os experimentos aqui mostrados apresentam o valor de $n=20$, permitindo uma variação significativa na quantidade de insetos.

\subsection{Agente}

O objetivo do agente é capturar o maior número possível de insetos durante a simulação. Se o agente está localizado na mesma posição que um inseto, ele precisa executar a ação pick up para capturá-lo. Em seguida, o agente deve retornar à sua base, localizada no centro do grid, para armazenar o inseto e então poder começar a perseguir outro inseto.

Uma vez recebida a sua lista de percepções do simulador, o agente delibera e decide qual a ação a tomar. Seu comportamento pode ser descrito por um conjunto de planos:

- Quando o agente está segurando um inseto, ele vai para a base;

- Quando o agente está na base segurando um inseto, o agente o armazena;

- Quando o agente está localizado na mesma posição de um inseto e não está segurando um inseto, ele executa a ação pick up;

- Quando o agente não está segurando um inseto e percebe um em um quadrado adjacente, o agente se move nessa direção;

- Quando o agente não está segurando um inseto e não percebe insetos em quadrados adjacentes, ele compara a posição atual de todos os insetos que pode perceber com suas posições no ciclo anterior. $\mathrm{O}$ agente então se move para a direção onde mais insetos vieram em sua direção.

O código Jason do agente se encontra apresentado no código 7.

\subsection{Design de experimentos}

Nossos experimentos foram conduzidos utilizando técnicas provenientes do domínio de análise de desempenho, seguindo as diretrizes de design experimental apresentadas em Jain (1991). Segundo o autor, o objetivo de um design de experimento adequado é obter o máximo de informação com o número mínimo de experimentos. O processo separa os efeitos de vários fatores que podem afetar o desempenho e permite determinar se um fator tem um efeito significante sobre o desempenho ou se a diferença observada é simplesmente devido a variações aleatórias causadas por erros de medição e/ou parâmetros que não foram controlados.

É importante definir o significado de quatro termos:

- Variável de resposta é o resultado de um experimento. Nos experimentos realizados neste trabalho, as variáveis de resposta são o tempo de resposta das ações dos agentes e a quantidade de insetos capturados.

\footnotetext{
${ }^{1}$ Isto foi feito a fim de manter o mesmo número de percepções através de todo o experimento.
} 


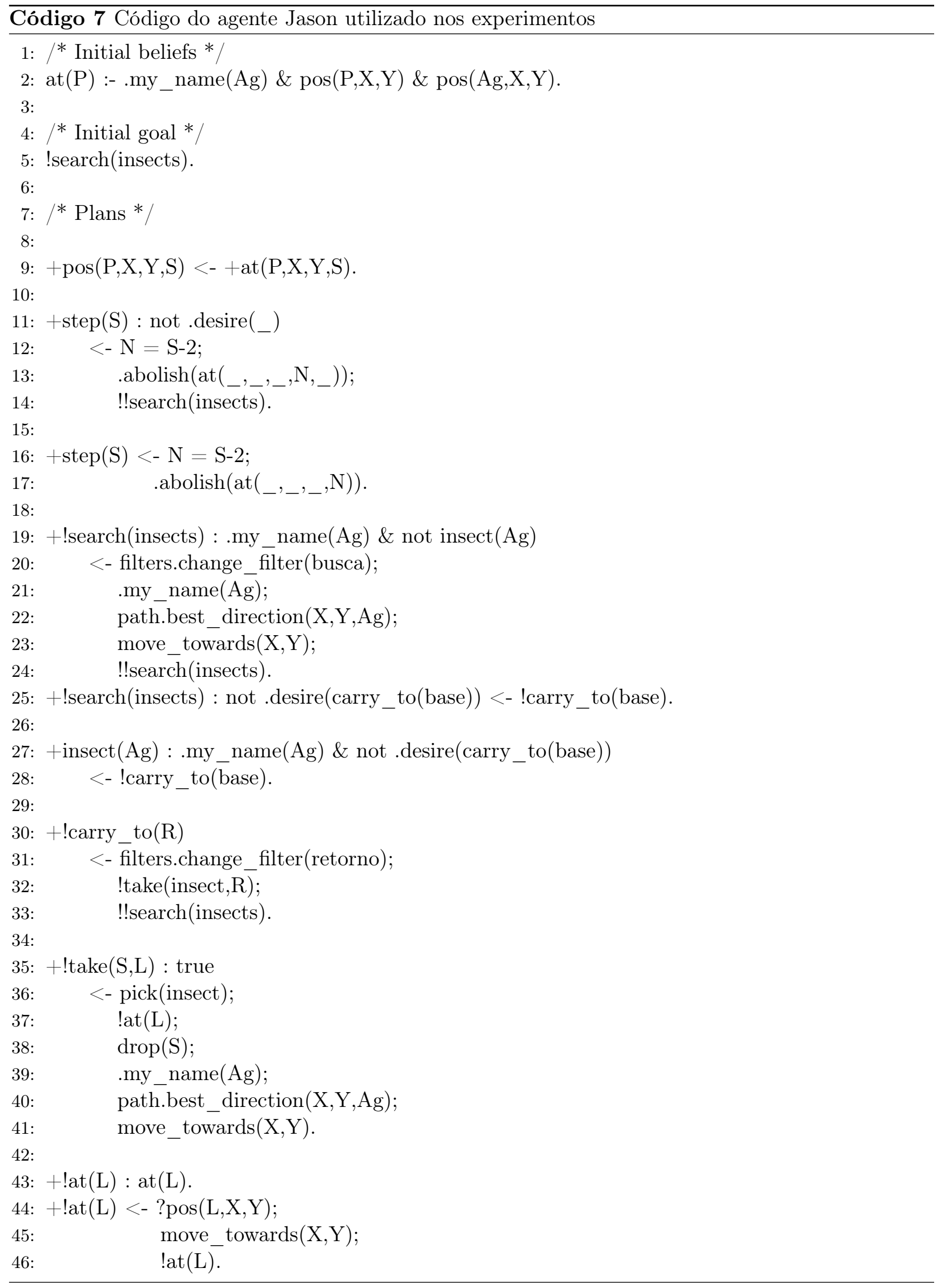


- Fatores são as variáveis que afetam a variável de resposta. Como um exemplo, o número de percepções afeta o tempo necessário para que um agente possa responder para o servidor. Fatores podem ser primários ou secundários. Fatores primários são aqueles cujos efeitos devem ser quantificados, enquanto fatores secundários são aqueles que impactam o desempenho, mas cujo impacto não estamos interessados em quantificar.

- Níveis são os valores que um fator pode assumir. No caso acima, os níveis do fator "número de percepções"são os números de percepções utilizados no experimento, como por exemplo 40 percepções ou 360 percepções.

- Repetição é uma nova execução de alguns ou de todos os experimentos. Se são realizadas três execuções de um mesmo experimento, é dito que o estudo teve três repetições.

Dois tipos de experimentos foram utilizados para fazer a avaliação dos filtros de percepção: o design fatorial completo e o design fatorial $2^{k} r$, explicados a seguir.

\subsubsection{Design fatorial completo}

A vantagem deste design é que todas as combinações possíveis dos níveis dos diversos fatores são examinadas. É possível com isso encontrar tanto os efeitos de todos os fatores individualmente, bem como a interação entre eles. Normalmente, os estudos envolvem frequentemente um grande número de possíveis fatores e cada um deles pode também ter vários níveis. O principal problema da utilização deste tipo de projeto é a quantidade de experimentos que precisam ser realizados uma vez que cada associação deve ser analisada. Executar experiências para todas as combinações possíveis e, eventualmente, repetir cada uma destas experiências várias vezes é frequentemente demasiado caro, tornando impraticável o estudo.

A fim de resolver este problema, Jain (1991) aconselha que com a redução do número de níveis em cada fator é possível verificar se algum dos fatores não apresenta um efeito significativo sobre a variação, permitindo assim a remoção deste fator dos estudos mais detalhados.

Jain (1991) propõe então que um estudo seja dividido em duas etapas. Como um primeiro passo, o design fatorial $2^{k}$ é indicado. Este tipo de design reduz o número de níveis para que um estudo seja realizado considerando apenas dois níveis para cada um dos $k$ fatores. Sugere-se que estes dois níveis devem ser os níveis máximo e mínimo deste fator. Tal redução permite uma avaliação preliminar dos fatores com uma quantidade mínima de experimentos.

\subsubsection{Design fatorial $2^{k} r$}

A fim de melhor apresentar o conceito do design fatorial $2^{k} r$, um caso mais simples, com apenas dois fatores $(k=2)$ e uma única repetição $(r=1)$ é útil como um caso ilustrativo. Tomando como base o exemplo contido em Jain (1991), é possível alterar os fatores para gerar um exemplo mais próximo do caso analisado neste trabalho.

Suponha que queremos avaliar a eficiência de dois agentes (Agente A e Agente B) em capturar insetos com duas ferramentas diferentes (Rede de Borboleta e Pinça) durante um minuto. Os resultados dos experimentos estão apresentados na Tabela 4.1.

\begin{tabular}{|c|c|c|}
\hline & Pinça & Rede de Borboleta \\
\hline Agente A & 15 & 45 \\
\hline Agente B & 25 & 75 \\
\hline
\end{tabular}

Tabela 4.1: Número de insetos capturados após um minuto.

Devemos, então, definir as variáveis $x_{A}$ e $x_{B}$ da seguinte forma: 


$$
\begin{aligned}
& x_{A}=\left\{\begin{aligned}
-1, & \text { se Pinça } \\
1, & \text { se Rede de Borboleta }
\end{aligned}\right. \\
& x_{B}=\left\{\begin{aligned}
-1, & \text { se Agente A } \\
1, & \text { se Agente B }
\end{aligned}\right.
\end{aligned}
$$

A eficiência do agente agora pode ser regredida sobre $x_{A}$ e $x_{B}$ usando um modelo de regressão da forma:

$$
\begin{aligned}
& 15=q_{0}-q_{A}-q_{B}+q_{A B} \\
& 45=q_{0}+q_{A}-q_{B}-q_{A B} \\
& 25=q_{0}-q_{A}+q_{B}-q_{A B} \\
& 75=q_{0}+q_{A}+q_{B}+q_{A B}
\end{aligned}
$$

A primeira equação, por exemplo, representa que quando o agente $\mathrm{A}$ (valor $-1 \mathrm{em} x_{A}$ ) utiliza a Pinça (valor -1 em $x_{B}$ ) ele captura 15 insetos. O valor $q_{0}$ representa a média das capturas, sendo a base ao redor da qual os valores vão variar, e $q_{A B}$ representa a interação entre os dois fatores, e seu valor é sempre multiplicado pelo valor de $x_{A} * x_{B}$

Estas equações podem ser resolvidas de forma única para as quatro variáveis desconhecidas. A equação de regressão é:

$$
y=40+20 x_{A}+10 x_{B}+5 x_{A} x_{B}
$$

O resultado é interpretado da seguinte forma: a captura média é de 40 insetos, onde o efeito devido às ferramentas é de 20 insetos, o efeito devido aos agentes é de 10 insetos e a interação entre agentes e ferramentas responde por 5 insetos.

A fim de medir a importância de um fator, precisamos calcular a proporção da variância total por ele gerada. O primeiro passo é calcular a variação total dos valores de resposta, chamada Soma Total dos Quadrados (SST),

$$
\text { Variação total de } y=S S T=\sum_{i=1}^{2^{2}}\left(y_{i}-\bar{y}\right)^{2}
$$

onde $\bar{y}$ é a média de todas as respostas dos quatro experimentos. Por outro lado, considerando o design $2^{2}$, a variação pode ser dividida em três partes, devida a cada um dos fatores isoladamente e à sua combinação:

$$
S S T=2^{2} q_{A}^{2}+2^{2} q_{B}^{2}+2^{2} q_{A B}^{2}
$$

É possível então separar a equação e explicar a variação de cada um dos fatores através de uma fração. Por exemplo:

$$
\text { Fração da variação explicada por } A=\frac{S S A}{S S T}=\frac{2^{2} q_{A}^{2}}{S S T}
$$

Utilizando essas equações, podemos calcular o total de variação $S S T=2100$, e, em seguida, calcular cada variação individual $S S A, S S B$ e $S S A B$. Assim, podemos afirmar que a variação atribuída à Ferramenta é 1600 (76\%), a variação atribuída ao Agente é de 400 (19\%) e a variação atribuída à interação destes fatores é 100 (5\%). Estes números mostram que a quantidade de insetos capturados, portanto, é mais dependente da ferramenta do que do agente.

Um problema com o design fatorial $2^{k}$ (quando $r=1$ ) é que não é possível estimar erros experimentais. Estes erros podem ser quantificados apenas quando as medições são repetidas nas mesmas combinações de níveis de fatores. $\mathrm{O}$ design $2^{k} r$ pode então ajudar a classificar o impacto 
dos níveis e quantificar os erros experimentais com um pequeno número de experimentos. Para este projeto, em vez de ter apenas um valor para cada combinação fator/nível, devemos ter $R$ valores, um para cada repetição. Os valores usados por $y$ são, então, a média dos resultados das $r$ repetições. Isso nos permite adicionar um termo devido a erros experimentais ao modelo e medir a variação a ele atribuída, através da seguinte equação:

$$
y=q_{0}+q_{A} x_{A}+q_{B} x_{B}+q_{A B} x_{A} x_{B}+e
$$

Por fim, a utilização desse tipo de modelo de regressão deve ser validado pelos testes visuais apresentados por Jain (1991). Dois testes devem ser realizados. O primeiro é a construção de um gráfico quantil-quantil normal como os mostrados da figura 4.2. Esse gráfico tem como objetivo verificar se o erro está normalmente distribuído. Para que ele esteja, os pontos do gráfico deve apresentar uma linearidade, como no gráfico (a). Caso os pontos não formem uma linearidade como no gráfico (b), deve-se aplicar uma transformação nos dados de forma a tornar normal a distribuição dos erros.
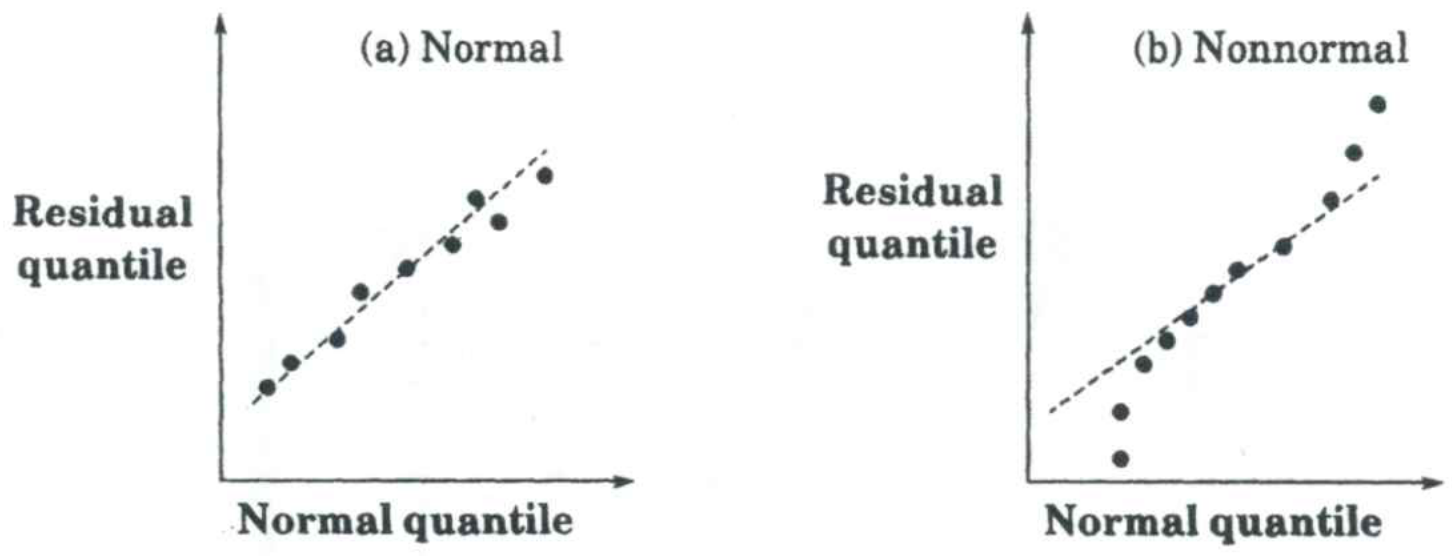

Figura 4.2: Gráficos quantil-quantil normal construídos por Jain (1991).

O segundo teste visual busca verificar se o desvio padrão dos erros é constante. Para isso, é feito um gráfico de dispersão como os da figura 4.3. Para que o desvio padrão dos erros seja constante, o gráfico não pode apresentar tendências, assim como o gráfico (a). No gráfico (b) existe uma tendência de crescimento dos erros conforme cresce a resposta. Isso significa que o modelo não incorpora corretamente os efeitos dos fatores e a distribuição dos erros não é independente. Novamente, caso os pontos não formem um gráfico sem tendência é necessário efetuar uma transformação nos dados.
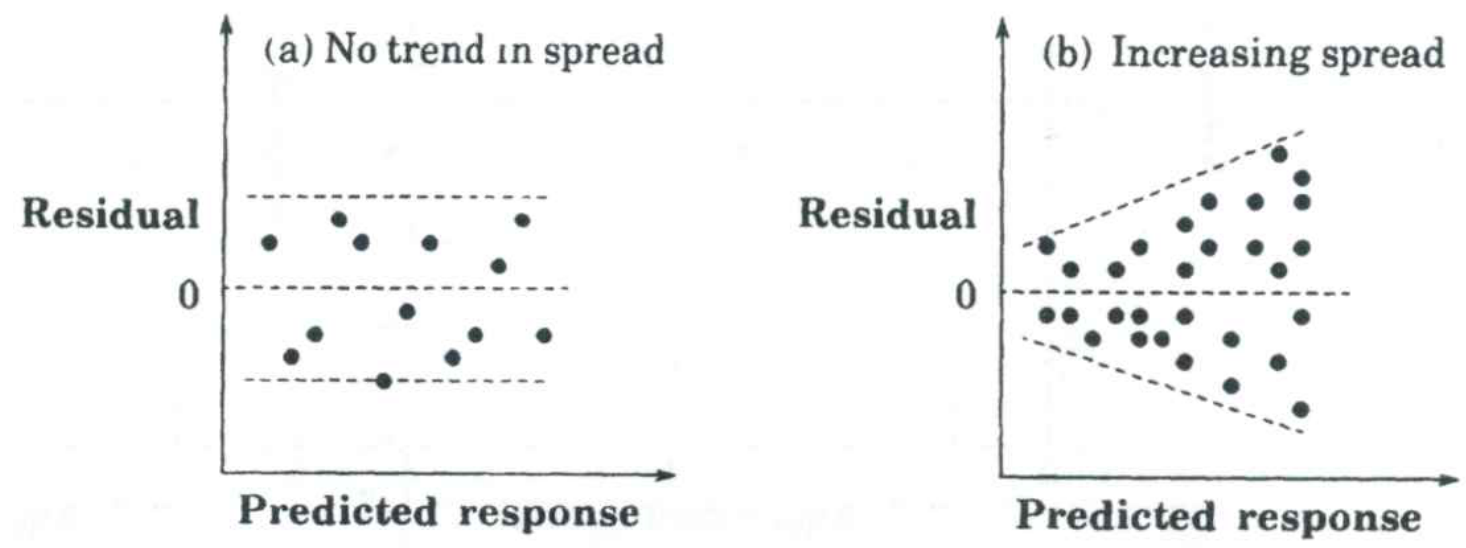

Figura 4.3: Gráficos de dispersão construídos por Jain (1991).

Uma das possíveis transformações nos dados que pode solucionar os problemas do erro não estar normalmente distribuído e desvio padrão dos erros não ser constante é a transformação logarítmica. 
Para efetuá-la, basta calcular o log dos valores de resposta dos experimentos. Outra possível transformação é utilizar a raiz quadrada dos resultados obtidos. Essas transformações são bastante úteis quando os valores dos dados estão em ordens de magnitude diferentes, como é o caso da maioria dos resultados por nós obtidos, apresentados a seguir. 


\section{Capítulo 5}

\section{Experimentos e Resultados}

\subsection{Descrição}

Nos experimentos descritos neste capítulo, para cada combinação de níveis foram executadas 3 repetições de 300 iterações do ciclo descrito na subseção 4.1. Tais repetições permitem identificar possíveis erros de medição e quantificá-los.

Nos estudos cuja variável de resposta é o tempo de processamento do agente, para cada iteração foi marcado o tempo que o agente levou processando, isto é, o tempo necessário para que o agente recebesse as percepções vindas do simulador, executasse quantos ciclos de raciocínio fossem necessários (figura 2.1) e enviasse a ação que gostaria de executar para o simulador. Com esses valores, foi selecionado o 95-percentil como valor da variável de resposta da execução.

Já nos estudos onde a variável de resposta é a quantidade de insetos capturados, o valor da variável foi considerado como a quantidade de capturas ao final do ciclo de número 300.

Todos os experimentos utilizaram a versão 1.4.2 do interpretador Jason.

\subsection{Filtro de intervalo}

Neste primeiro conjunto de experimentos, o objetivo era avaliar o possível ganho de desempenho aos utilizar filtros de intervalo. Para este cenário, foram criadas duas regras diferentes:

R1 Quando o agente estiver perseguindo os insetos, o filtro irá excluir os insetos que estão mais longe do que um determinado valor expresso no parâmetro;

R2 Quando o agente estiver voltando para a base carregando um inseto, o filtro elimina todas as percepções que contém as posições de insetos.

Deste modo, ao perseguir os insetos, o agente somente percebe os insetos que estão mais próximos a ele. Por outro lado, quando está voltando para a base carregando um inseto, o agente não precisa perceber inseto algum já que não pode realizar uma captura no momento. Embora esta segunda regra não se altere o comportamento do agente, ela exerce impacto no tempo de processamento.

Dado que as modificações realizadas no ciclo de raciocínio estavam focadas em reduzir a quantidade de percepções através de filtros de percepção, os fatores escolhidos para a avaliação, e seus respectivos níveis, foram:

P Número de percepções. Representa o número de insetos que estão presentes no grid. Os níveis escolhidos são proporcionais ao tamanho do grid:

P10 $10 \%$ do grid (40 insetos);

P20 20\% do grid (80 insetos);

P30 30\% do grid (120 insetos); 
P40 40\% do grid (160 insetos);

P50 50\% do grid (200 insetos);

P60 60\% do grid (240 insetos);

P70 $70 \%$ do grid (280 insetos);

P80 80\% do grid (320 insetos);

P90 90\% do grid (360 insetos);

F Tamanho do filtro. Representa a máxima distância ao redor do agente, em espaços, onde os insetos podem ser percebidos pelo agente. Supondo que inicialmente o agente estivesse no meio do grid e tivesse uma percepção completa do mesmo, ele poderia perceber objetos em até 10 espaços de distância para cada lado. Chamando este valor de raio do grid, os níveis do filtro foram definidos percentualmente em função deste raio:

F2 'Filtro 2', que corresponde a uma percepção máxima de $20 \%$ do raio;

F5 'Filtro 5', que corresponde a uma percepção máxima de 50\% do raio;

F7 'Filtro 7', que corresponde a uma percepção máxima de $70 \%$ do raio;

F0 'Sem filtro', que corresponde à percepção de todo o grid.

Isto significa que quando o filtro de intervalo estiver ativo, o agente só pode perceber insetos a uma distância de dois quadrados, cinco quadrados e sete quadrados respectivamente. 'Sem filtro' representa a execução padrão do Jason, percebendo assim todos os insetos e não fazendo uso dos filtros de percepção.

O código do filtro de intervalo N1, cuja percepção máxima é de $20 \%$ do raio, está apresentado no código 8. Dependendo do nível escolhido, é alterado o valor do parâmetro para definir a distância correta.

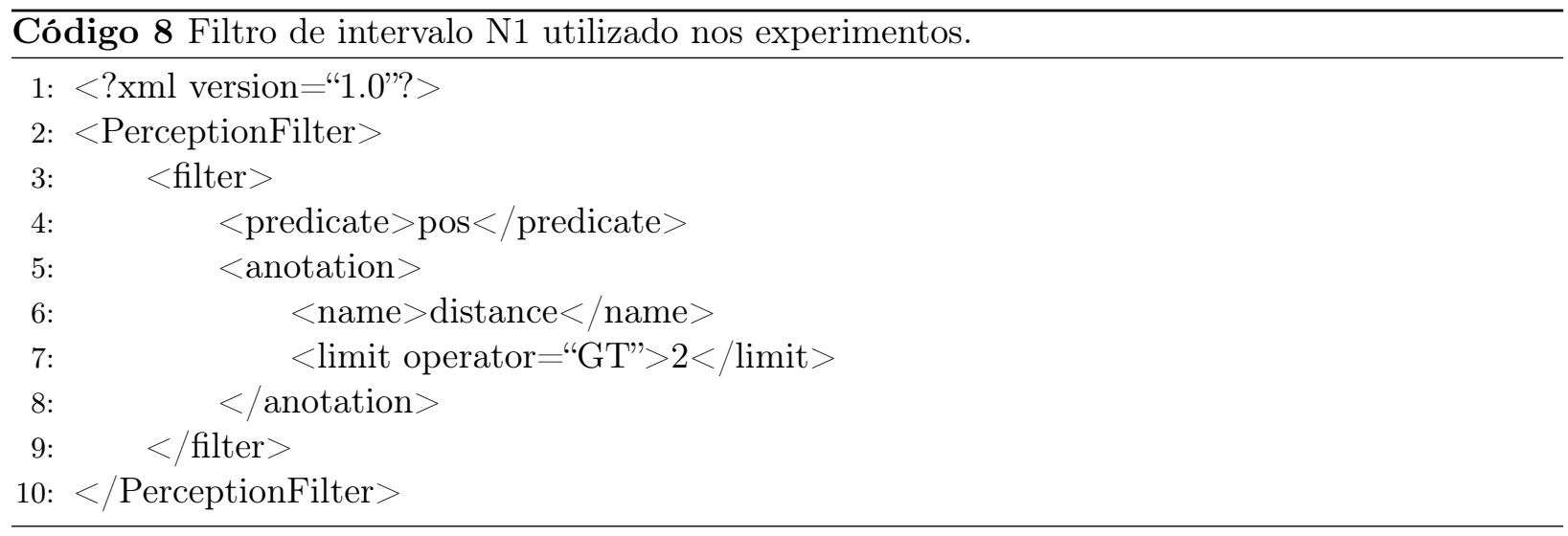

Três estudos foram conduzidos sobre o efeito do filtro de intervalo, descritos a seguir. Esses estudos foram inicialmente apresentados em Stabile Jr. e Sichman (2015b), mas foram aqui refeitos utilizando o método de geração aleatória de sementes apresentado por Jain (1991). Os novos resultados são apresentados abaixo.

\subsubsection{Estudo reduzido sobre o tempo de processamento}

O primeiro estudo teve como objetivo identificar a variação atribuída ao número de percepções e aos filtros de percepção sobre o tempo de processamento do agente, medido do momento da recepção da lista de percepções até o momento em que a ação é enviada para o simulador. Seguindo o conselho de Jain (1991), esse primeiro estudo foi do tipo fatorial reduzido $2^{k} r$, onde foram comparadas combinações de execuções considerando os níveis extremos dos fatores tamanho do filtro (filtro de tamanho 2 e sem filtro) e número de percepções (40 insetos e 360 insetos), como mostra a tabela 5.1 . 


\begin{tabular}{|c|c|c|}
\hline & \multicolumn{2}{|c|}{ Fatores } \\
\hline Experimento & P & F \\
\hline EXP 1.1 & P40 & F2 \\
\hline EXP 1.2 & P40 & F0 \\
\hline EXP 1.3 & P360 & F2 \\
\hline EXP 1.4 & P360 & F0 \\
\hline
\end{tabular}

Tabela 5.1: Níveis dos fatores para o estudo reduzido sobre filtros de intervalo.

Como já discutido na seção 4.3.1, um primeiro estudo reduzido permite identificar o impacto que os fatores selecionados possuem no tempo de resposta, e principalmente se certificar de que o filtro de percepção possui impacto significativo sem haver a necessidade de um grande número de execuções.

\begin{tabular}{|c|c|c|r|r|r|}
\hline Experimento & Percepções & Filtro & \multicolumn{3}{|c|}{ 95 percentil } \\
\hline EXP 1.1 & P40 & F2 & 3704410 & 3582008 & 3636800 \\
\hline EXP 1.2 & P40 & F0 & 7142134 & 7258794 & 7572025 \\
\hline EXP 1.3 & P360 & F2 & 4937115 & 4667631 & 5133402 \\
\hline EXP 1.4 & P360 & F0 & 26828704 & 24089467 & 25982379 \\
\hline
\end{tabular}

Tabela 5.2: Filtros de intervalo: Tempos de processamento (ns) obtidos no estudo reduzido.

A tabela 5.2 apresenta os tempos de resposta encontrados para cada execução do experimento, medidos em nanosegundos.

Ao aplicar esses valores, descobrimos que o modelo resultante não era válido, uma vez que os testes visuais utilizados para a validação falharam como pode ser visto na figura 5.1. Nela nota-se que na Figura 5.1a os valores residuais possuem claramente uma tendência de crescimento conforme se aumenta a resposta predita; já na figura $5.1 \mathrm{~b}$ os pontos formam uma curva que se distancia bastante da reta esperada. Isto implica que a distribuição dos erros não é independente, fazendo com que o modelo linear aplicado não incorpore totalmente os efeitos estudados.

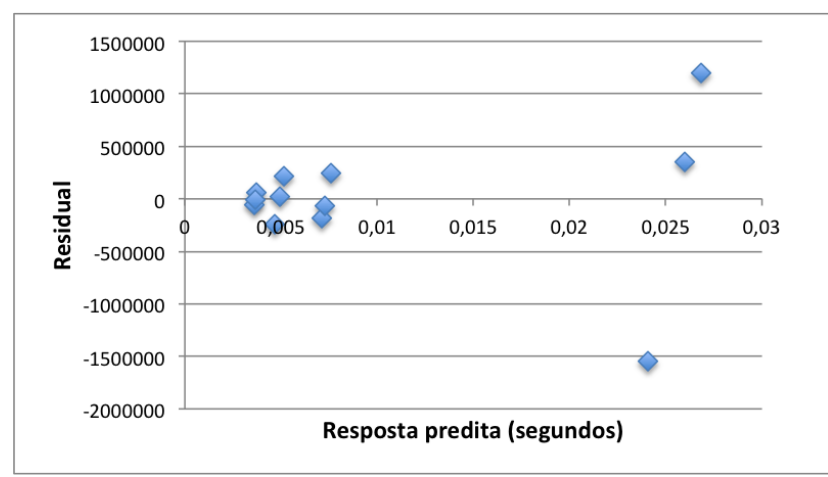

(a) Gráfico de dispersão.

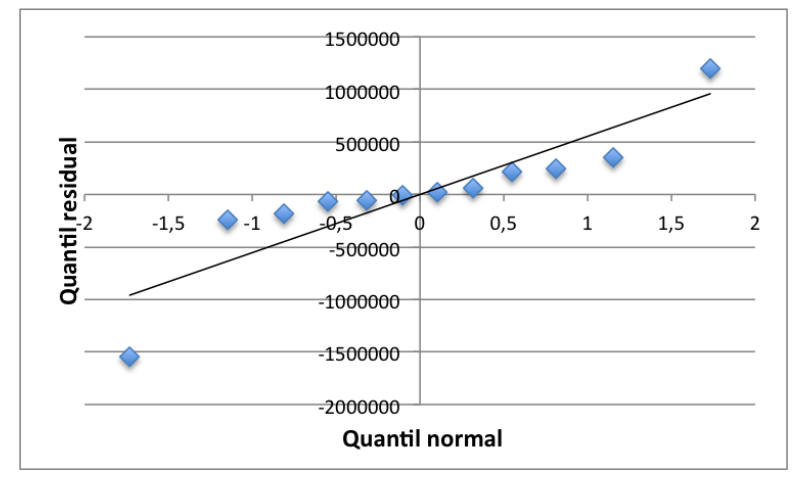

(b) Gráfico do quantil-quantil normal.

Figura 5.1: Filtros de intervalo: Testes visuais do estudo reduzido sobre tempos de processamento.

A fim de avaliar adequadamente a variação de cada fator, tivemos que aplicar uma transformação logarítmica no modelo, convertendo-o de um modelo aditivo para um modelo multiplicativo. Isto foi realizado por meio do cálculo do $\log$ de todos os valores de resultados medidos. A tabela 5.3 apresenta os logs dos valores originais.

Com estes novos valores, é possível efetuar novamente os cálculos de variação atribuídos aos fatores. É possível verificar na figura 5.2 que a transformação soluciona os problemas apresentados nos testes visuais anteriores, permitindo uma avaliação correta dos efeitos dos fatores.

A variação atribuída a cada fator isolado e à sua interação é apresentada na tabela 5.4. Nela é possível ver que o filtro de intervalo exerce uma grande variação sobre o tempo de resposta do 


\begin{tabular}{|c|c|c|c|c|c|}
\hline Experimento & Percepções & Filtro & \multicolumn{3}{|c|}{ Valores calculados } \\
\hline EXP 1.1 & P40 & F2 & 6.568 & 6.554 & 6.560 \\
\hline EXP 1.2 & P40 & F0 & 6.853 & 6.860 & 6.879 \\
\hline EXP 1.3 & P360 & F2 & 6.693 & 6.669 & 6.710 \\
\hline EXP 1.4 & P360 & F0 & 7.428 & 7.381 & 7.414 \\
\hline
\end{tabular}

Tabela 5.3: Filtros de intervalo: Logs dos tempos de processamento do estudo reduzido.

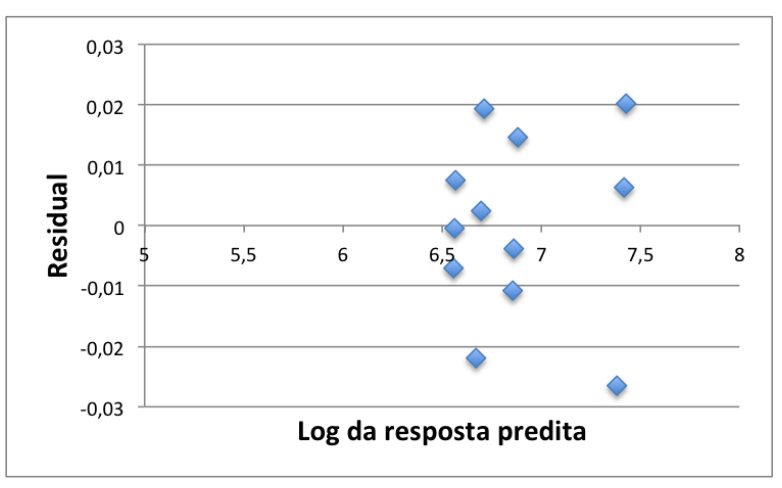

(a) Gráfico de dispersão.

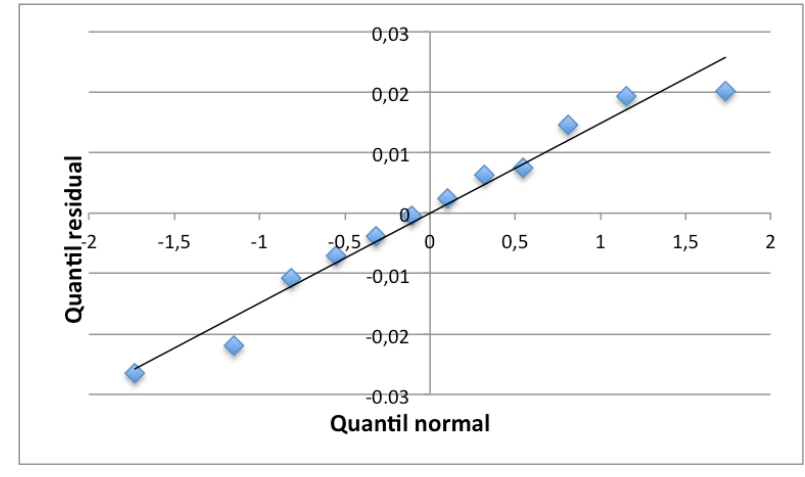

(b) Gráfico do quantil-quantil normal.

Figura 5.2: Filtros de intervalo: Testes visuais do estudo reduzido transformado sobre tempos de processamento.

agente, mostrando que o filtro é responsável por aproximadamente $63 \%$ da redução no tempo de processamento.

\begin{tabular}{|l|c|}
\hline Fator & Variação atribuída \\
\hline Número de percepções (P) & $27,16 \%$ \\
\hline Tamanho do Filtro (F) & $62,38 \%$ \\
\hline Interação entre P e F & $10,26 \%$ \\
\hline Erro de medição & $0,2 \%$ \\
\hline
\end{tabular}

Tabela 5.4: Filtros de intervalo: Variação atribuída a cada fator do estudo reduzido transformado no tempo de processamento.

A figura 5.3 apresenta um comparativo entre os tempos de processamento dos agentes nos diferentes experimentos. Os valores apresentados em cada coluna são a média dos tempos das três execuções. É possível visualizar que com 40 insetos no grid (experimentos 1.1 e 1.2), houve uma redução média de aproximadamente $50 \%$, enquanto no caso com 360 insetos no grid (experimentos 1.3 e 1.4), houve uma redução média de mais de $80 \%$.

Sabendo que o filtro de intervalo causa uma redução significativa, é interessante agora avaliar os outros filtros de intervalo menos restritivos e também cenários com números mais variados de insetos. Para isso, foi conduzido o estudo completo a seguir.

\subsubsection{Estudo completo sobre o tempo de processamento}

O segundo estudo ampliou a análise dos resultados do primeiro estudo por meio da execução de um estudo fatorial completo de dois fatores com variação nos filtros e na quantidade de insetos.

Todos os filtros de intervalo descritos anteriormente foram utilizados em combinação com quantidades de percepções que variavam de 10\% (40 insetos) a 90\% (360 insetos) do grid, com intervalos de $10 \%$, totalizando assim 36 experimentos distintos.

Os valores de tempo medidos em cada execução destes experimentos podem ser encontrados no apêndice A. Com a experiência do estudo anterior, já é conhecido que os dados devem ser transformados através do cálculo do $l o g$. O resultado deste cálculo pode ser visto no apêndice B. O 


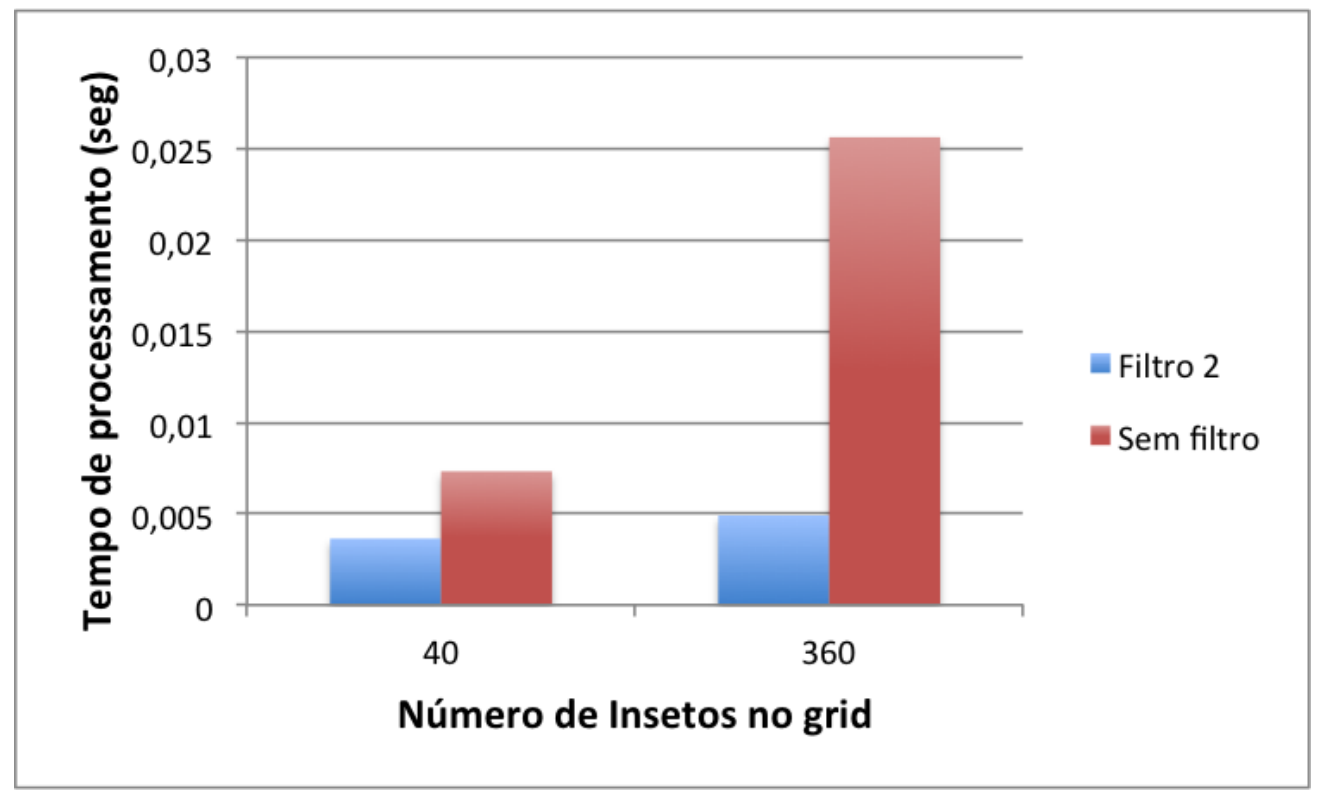

Figura 5.3: Filtros de intervalo: 95 percentil do tempo de processamento do agente.

emprego da transformação logarítmica novamente apresentou o resultado desejado, como pode ser visto na figura 5.4.

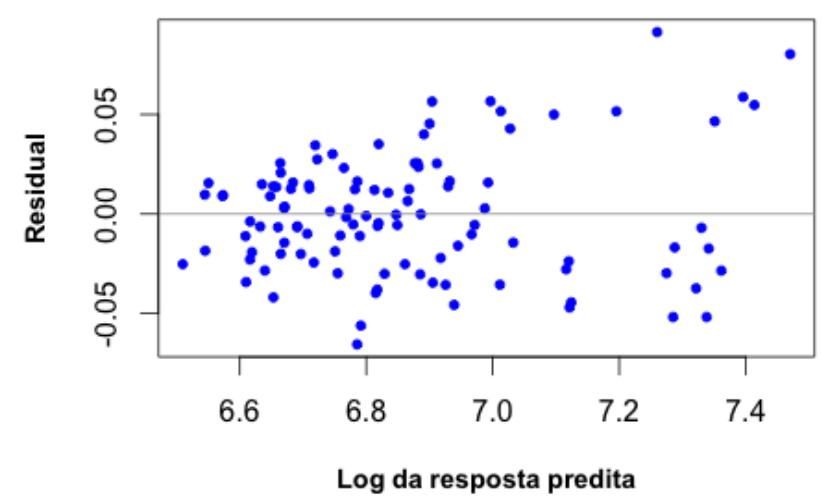

(a) Gráfico de dispersão.

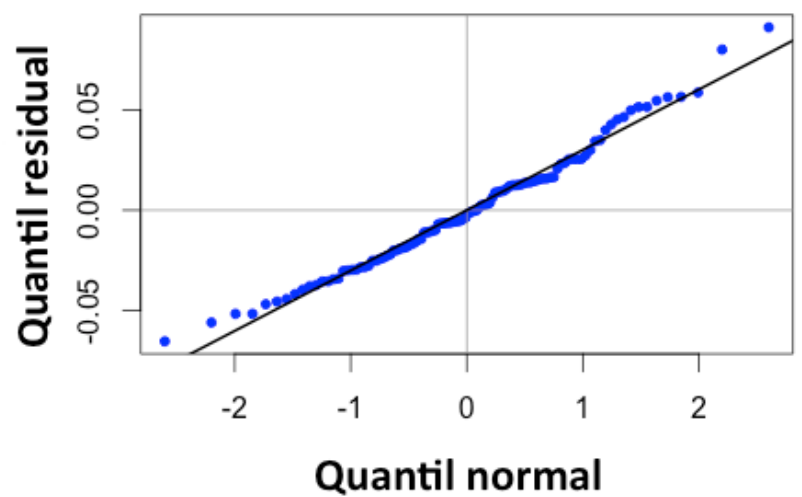

(b) Gráfico do quantil-quantil normal.

Figura 5.4: Filtros de intervalo: Testes visuais do estudo completo transformado sobre tempos de processamento.

A variação atribuída a cada fator e interação calculada para o conjunto de experimentos completo é apresentada na tabela 5.5. Nela é possível ver que o filtro de intervalo exerce uma variação ainda maior sobre o tempo de resposta do agente que do que no estudo reduzido, certificando que o filtro é responsável agora por aproximadamente $76 \%$ da redução do tempo de processamento do agente.

Para completar a análise do efeito dos filtros de intervalo, deve-se verificar o impacto de cada filtro individualmente de forma a poder identificar suas vantagens e desvantagens. Para verificar a aplicabilidade de cada filtro, foi analisada a capacidade de resposta do agente variando o tempo limite do simulador. A figura 5.5 apresenta essa análise. Nessa figura foram comparados os tempos de execução dos filtros nos experimentos com 360 insetos. O eixo horizontal representa o tempo limite do simulador em segundos e o eixo vertical representa a porcentagem das ações que foram executadas em um tempo menor ou igual ao tempo limite. 


\begin{tabular}{|l|c|}
\hline Fator & Variação atribuída \\
\hline Número de percepções $(\mathrm{P})$ & $17.08 \%$ \\
\hline Tamanho do Filtro (F) & $76.18 \%$ \\
\hline Interação entre P e F & $4.97 \%$ \\
\hline Erro de medição & $1.77 \%$ \\
\hline
\end{tabular}

Tabela 5.5: Filtros de intervalo: Variação atribuída a cada fator do estudo completo.

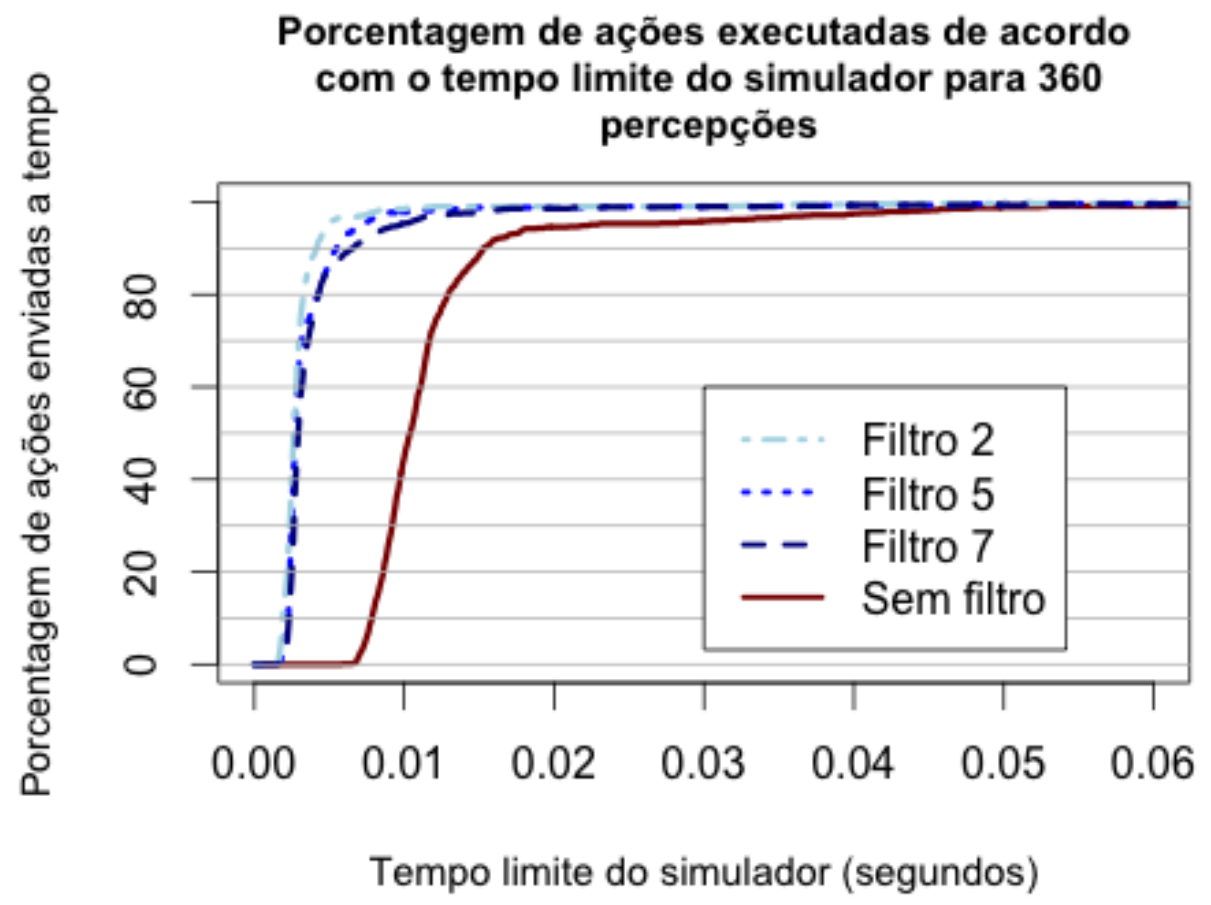

Figura 5.5: Filtros de intervalo: Porcentagem de ações executadas no tempo limite do simulador.

Como o agente necessita de um tempo mínimo de execução maior sem o uso de filtros, é possível notar que a porcentagem de vezes em que o agente consegue enviar uma ação ao simulador no tempo limite é significativamente inferior quando comparada aos casos em que filtros são utilizados, principalmente quando este tempo de limite é baixo. Além disto, quanto mais restritivo é o filtro, menor é o tempo limite do simulador no qual o agente consegue responder em $100 \%$ das vezes. Esses tempos estão apresentados na tabela 5.6 para melhor visualização.

\begin{tabular}{|c|c|}
\hline Filtro & Tempo mínimo \\
\hline F2 & 0.0427 \\
\hline F5 & 0.0500 \\
\hline F7 & 0.0609 \\
\hline F0 & 0.0902 \\
\hline
\end{tabular}

Tabela 5.6: Tempo mínimo necessário (seg) para que o agente consiga executar todas as ações.

Os resultados obtidos através destas duas experiências permitiram então avaliar o impacto de diferentes filtros de percepção no tempo raciocínio do agente. Os filtros de percepção foram responsáveis nesse estudo de caso por uma redução bastante significativa no tempo de processamento do agente, tornando possível a sua utilização em um simulador com o tempo limite bem menor do que seria possível anteriormente sem o uso destes filtros. 


\subsubsection{Estudo reduzido sobre o impacto na função de utilidade}

Apesar de os estudos anteriores terem mostrado que o filtro de intervalo propicia uma redução bastante significativa no tempo de processamento dos agentes, isso só é útil se o agente não perder a sua capacidade de tomar boas decisões. A fim de medir a interferência dos filtros de percepção na função de utilidade do agente, um terceiro estudo foi realizado. Este terceiro estudo é um design fatorial $2^{k} r$ usando novamente os mesmos fatores e níveis do primeiro estudo. Neste estudo, entretanto, a variável de resposta é agora a quantidade de insetos capturados durante toda a simulação, considerada como um valor de utilidade. A tabela 5.7 mostra o número de insetos capturados pelo agente em cada execução dos experimentos.

\begin{tabular}{|c|c|c|c|c|c|}
\hline Experimento & Percepções & Filtro & \multicolumn{3}{|c|}{ Insetos capturados } \\
\hline EXP 3.1 & P40 & F2 & 22 & 20 & 17 \\
\hline EXP 3.2 & P40 & F0 & 25 & 28 & 20 \\
\hline EXP 3.3 & P360 & F2 & 41 & 41 & 38 \\
\hline EXP 3.4 & P360 & F0 & 45 & 51 & 50 \\
\hline
\end{tabular}

Tabela 5.7: Filtros de intervalo: Valores de utilidade (número de insetos capturados) obtidos no estudo reduzido.

Para este conjunto de experimentos, não foi necessário efetuar a transformação logarítmica, uma vez que os testes visuais apresentados na figura 5.6 já atestam a corretude do modelo.

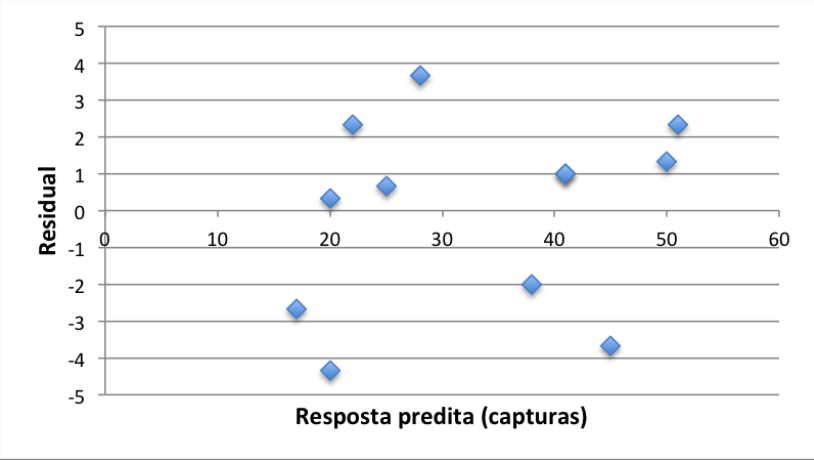

(a) Gráfico de dispersão.

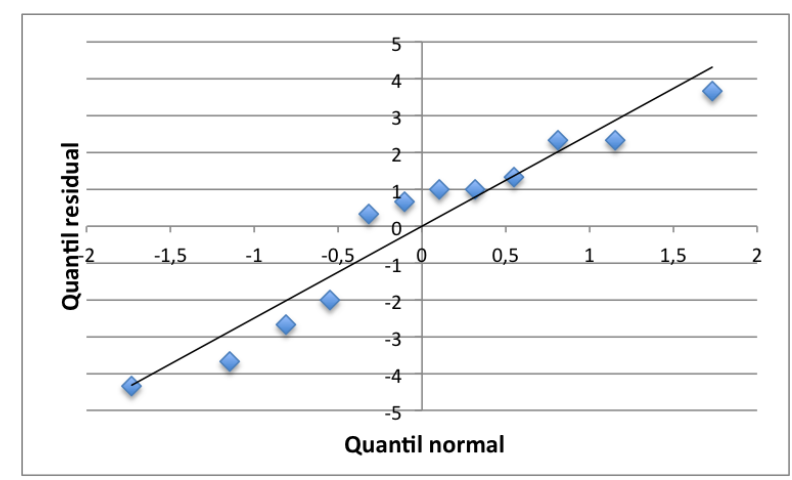

(b) Gráfico do quantil-quantil normal.

Figura 5.6: Filtros de intervalo: Testes visuais do estudo reduzido sobre valores de utilidade.

A variação atribuída a cada fator e interação encontra-se apresentada na tabela 5.8. Nela é possível ver que o filtro de intervalo exerce uma baixa variação sobre o valor de utilidade do agente, ao redor de $8 \%$. Essa variação se torna menos significante ao se notar que se está comparando a execução padrão (sem filtro) com o filtro mais restritivo. No entanto, o uso do filtro de intervalo está causando no agente uma pequena perda na sua capacidade de tomar boas decisões.

\begin{tabular}{|l|c|}
\hline Fator & Variação atribuída \\
\hline Número de percepções $(\mathrm{P})$ & $87,32 \%$ \\
\hline Tamanho do Filtro $(\mathrm{F})$ & $7,78 \%$ \\
\hline Interação entre P e F & $0,70 \%$ \\
\hline Erro de medição & $4,20 \%$ \\
\hline
\end{tabular}

Tabela 5.8: Filtros de intervalo: Variação atribuída a cada fator do estudo sobre o valor de utilidade.

Estes três conjuntos de experimentos mostraram então que foi possível construir um filtro de percepção para o problema tratado que reduziu de forma extremamente significativa o tempo de processamento necessário para o agente responder ao simulador, com o custo de uma pequena redução na utilidade obtida pelo seu processo de tomada de decisão. Apesar dessa perda, a grande 
redução no tempo de processamento ainda faz com que ainda seja bastante interessante o uso desse tipo de filtro, já que permite transformar uma situação onde um agente não teria tempo hábil para executar uma ação no limite de tempo fixado pelo simulador para outra, onde o agente executaria uma ação subótima.

\subsection{Filtro de propriedade}

Neste segundo conjunto de experimentos, o objetivo era avaliar o possível ganho de desempenho aos utilizar filtros de propriedade. O cenário do simulador foi então alterado para incluir um segundo tipo de inseto. Os insetos desse novo tipo se comportam da mesma maneira que os do outro tipo, no entanto, devem ser ignorados pelo agente já que ele não deve capturar esse tipo de inseto. Para este cenário, foram novamente criadas duas regras diferentes:

R1 Quando o agente estiver perseguindo os insetos, o filtro irá excluir os insetos que possuem a propriedade especificada (ser do segundo tipo);

R2 Quando o agente estiver voltando para a base carregando um inseto, o filtro elimina todas as percepções que contém as posições de insetos.

Desse modo, o agente somente percebe os insetos que são do tipo que o interessa, e quando está voltando para a base carregando um inseto não percebe quaisquer insetos no grid.

Para este conjunto de experimentos, os fatores e níveis escolhidos para a avaliação foram:

P Número de percepções. Representa novamente o número de insetos que estão presentes no grid. Os níveis escolhidos são proporcionais ao grid:

P10 10\% do grid (40 insetos);

P20 20\% do grid (80 insetos);

P30 30\% do grid (120 insetos);

P40 40\% do grid (160 insetos);

P50 50\% do grid (200 insetos);

P60 60\% do grid (240 insetos);

P70 $70 \%$ do grid (280 insetos);

P80 $80 \%$ do grid (320 insetos);

P90 90\% do grid (360 insetos);

F Uso do filtro. Neste conjunto de experimentos, somente um tipo de filtro de propriedade foi avaliado, responsável por excluir todos os insetos que não interessavam ao agente. Assim, o fator uso do filtro pode assumir somente dois valores, se o filtro está sendo utilizado ou se a execução está sendo realizada sem filtro.

FC 'Com filtro', que corresponde ao uso do filtro de propriedade;

FS 'Sem filtro', que corresponde à execução padrão do Jason;

I Percentual de interesse. Representa a proporção entre os insetos que são de interesse do agente e o número total de insetos. Os níveis escolhidos são:

I10 $10 \%$ dos insetos;

I25 25\% dos insetos;

I50 $50 \%$ dos insetos;

I75 $75 \%$ dos insetos; 
I90 $90 \%$ dos insetos;

Conforme justificado adiante, somente dois estudos foram conduzidos para esse cenário. Ambos os estudos foram do tipo fatorial reduzido $2^{k} r$, onde foram comparadas combinações de execuções considerando os níveis extremos dos fatores uso do filtro (com e sem filtro), número de percepções (40 insetos e 360 insetos) e percentual de interesse (10\% e 90\%), como mostra a tabela 5.9.

\begin{tabular}{|c|c|c|c|}
\hline & \multicolumn{3}{|c|}{ Fatores } \\
\hline Experimento & F & P & I \\
\hline EXP 4.1 & FS & P40 & I10 \\
\hline EXP 4.2 & FS & P40 & I90 \\
\hline EXP 4.3 & FS & P360 & I10 \\
\hline EXP 4.4 & FS & P360 & I90 \\
\hline EXP 4.5 & FC & P40 & I10 \\
\hline EXP 4.6 & FC & P40 & I90 \\
\hline EXP 4.7 & FC & P360 & I10 \\
\hline EXP 4.8 & FC & P360 & I90 \\
\hline
\end{tabular}

Tabela 5.9: Niveis dos fatores para o estudo reduzido sobre filtros de propriedade.

O primeiro estudo teve como objetivo identificar a variação atribuída ao número de percepções, ao percentual de interesse e ao uso do filtro de propriedade sobre o tempo de processamento do agente.

O segundo estudo utilizou então os mesmos fatores e níveis do primeiro estudo, mas sua variável de resposta foi a quantidade de insetos capturados durante a simulação, de forma a avaliar o impacto da utilização do filtro de propriedade sobre a utilidade do agente.

Este conjunto de experimentos foi executado duas vezes, com implementações diferentes do filtro de propriedade, para melhor avaliar se as implementações teriam impacto significativo nos resultados. A primeira implementação foi baseada em expressões regulares, enquanto a segunda somente realizou uma comparação simples entre variáveis. Como a implementação do filtro foi realizada na linguagem Java, poderia haver algum impacto no tempo de processamento dada a complexidade do tratamento de expressões regulares.

\subsubsection{Filtro com expressões regulares}

A primeira implementação foi realizada através do uso de expressões regulares. O filtro utilizado está apresentado no código 9.

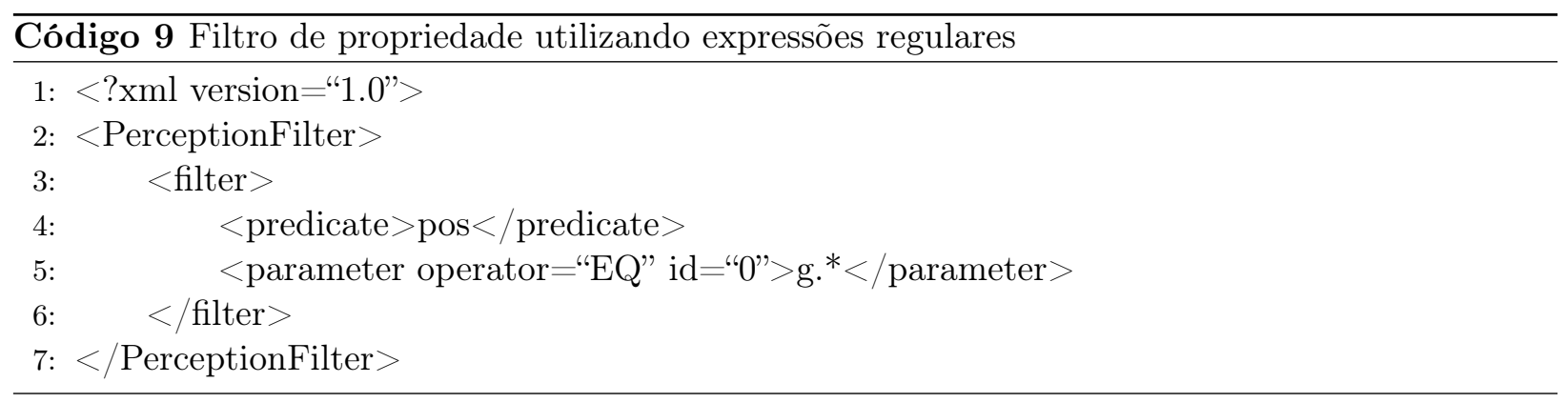

Esse filtro se baseia no fato de que os insetos que são interessantes para o agente tem seu nome iniciado pela letra $i$. Já os insetos que não são do interesse do agente, começam com a letra $g$. Esse filtro se utiliza então dessa informação para excluir todas as percepções dos insetos cujos nomes correspondem à expressão regular ' $g$.*', ou seja, começam com a letra $g$. 


\subsubsection{Estudo reduzido sobre o tempo de processamento}

A tabela 5.10 apresenta os tempos de resposta encontrados para cada execução dos experimentos, medidos em nanosegundos.

\begin{tabular}{|c|c|c|c|c|c|c|}
\hline Experimento & Uso do filtro & Num. Perc. & Perc. Interesse & \multicolumn{3}{|c|}{ 95 percentil } \\
\hline EXP 4.1 & FS & P40 & I10 & 6806118 & 7291754 & 7283728 \\
\hline EXP 4.2 & FS & P40 & I90 & 6892990 & 7362790 & 7204731 \\
\hline EXP 4.3 & FS & P360 & I10 & 34253660 & 27150407 & 28231143 \\
\hline EXP 4.4 & FS & P360 & I90 & 26724287 & 26866745 & 27125272 \\
\hline EXP 4.5 & FC & P40 & I10 & 4318976 & 3934425 & 3978573 \\
\hline EXP 4.6 & FC & P40 & I90 & 7083485 & 9049109 & 7800695 \\
\hline EXP 4.7 & FC & P360 & I10 & 9213876 & 8377817 & 8349314 \\
\hline EXP 4.8 & FC & P360 & I90 & 22515079 & 20437884 & 23560919 \\
\hline
\end{tabular}

Tabela 5.10: Filtro com Expressões Regulares: Tempos de processamento (ns) obtidos no estudo reduzido.

Uma vez mais, com a experiência dos estudos anteriores, já é conhecido que os dados devem ser transformados através do cálculo do log. Os valores calculados se encontram na tabela 5.11.

\begin{tabular}{|c|c|c|c|c|c|c|}
\hline Experimento & Uso do filtro & Num. Perc. & Perc. Interesse & \multicolumn{3}{|c|}{ Valores Calculados } \\
\hline EXP 4.1 & FS & P40 & I10 & 6.833 & 6.863 & 6.862 \\
\hline EXP 4.2 & FS & P40 & I90 & 6.838 & 6.867 & 6.858 \\
\hline EXP 4.3 & FS & P360 & I10 & 7.535 & 7.434 & 7.451 \\
\hline EXP 4.4 & FS & P360 & I90 & 7.427 & 7.429 & 7.433 \\
\hline EXP 4.5 & FC & P40 & I10 & 6.635 & 6.595 & 6.600 \\
\hline EXP 4.6 & FC & P40 & I90 & 6.850 & 6.957 & 6.892 \\
\hline EXP 4.7 & FC & P360 & I10 & 6.964 & 6.923 & 6.922 \\
\hline EXP 4.8 & FC & P360 & I90 & 7.352 & 7.310 & 7.372 \\
\hline
\end{tabular}

Tabela 5.11: Filtro com Expressões Regulares:Logs dos tempos de processamento do estudo reduzido.

Tendo o modelo sido validado pelos testes visuais presentes na figura 5.7, é possível analisar o impacto do filtro na variação do tempo de processamento.

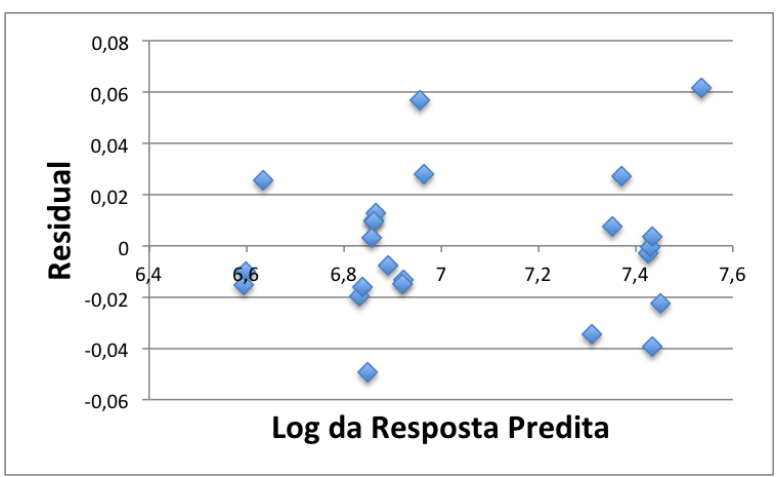

(a) Gráfico de dispersão.

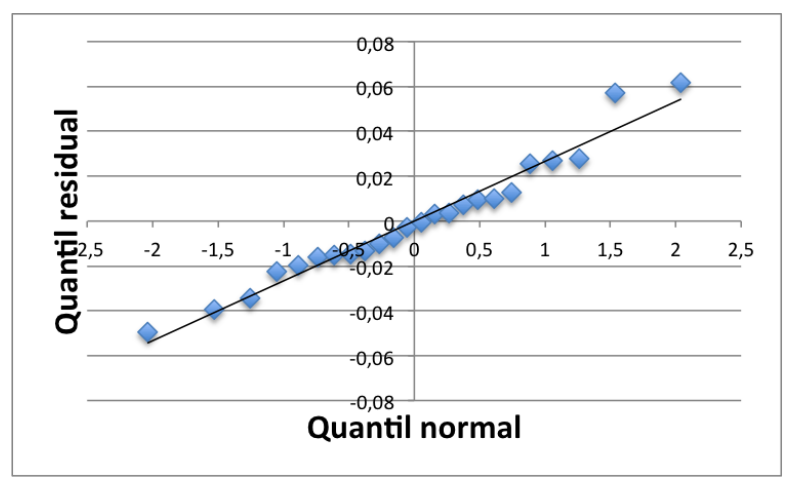

(b) Gráfico do quantil-quantil normal.

Figura 5.7: Filtro com Expressões Regulares: Testes visuais do estudo reduzido sobre tempos de processamento.

A tabela 5.12 apresenta os valores da variação atribuídos a cada fator e às suas interações. É possível notar que o filtro de propriedade não obteve um desempenho muito expressivo na redução do tempo de resposta (em torno de 11\%). É interessante notar, no entanto, que existe uma grande interação entre os fatores Uso do Filtro e Porcentagem de Interesse (em torno de 10\%). 


\begin{tabular}{|l|c|}
\hline Fator & Variação atribuída \\
\hline Número de percepções (P) & $67,02 \%$ \\
\hline Uso do Filtro (F) & $11,61 \%$ \\
\hline Porcentagem de interesse (I) & $7,46 \%$ \\
\hline Interação entre P e F & $3,11 \%$ \\
\hline Interação entre I e F & $9,47 \%$ \\
\hline Interação entre P e I & $0,09 \%$ \\
\hline Interação entre P, I e F & $0,46 \%$ \\
\hline Erro de medição & $0,78 \%$ \\
\hline
\end{tabular}

Tabela 5.12: Filtro com Expressões Regulares: Variação atribuída a cada fator do estudo reduzido transformado no tempo de processamento.

De modo a avaliar essa interação entre os dois fatores, foi construído o gráfico da figura 5.8. Esse gráfico compara os 95-percentis dos tempos de resposta e permite uma clara visualização da interação entre a utilização do filtro e a porcentagem de interesse. É possível notar que quando existe somente $10 \%$ de insetos que interessam o agente, o filtro consegue apresentar uma redução no tempo de processamento; no entanto, o mesmo não acontece quando se utiliza o filtro em um cenário com $90 \%$ de insetos que interessam o agente. Esse comportamento pode ser justificado pela seguinte argumentação: dado que o processamento de expressões regulares é computacionalmente custoso, quando o agente possui poucas crenças para excluir, este custo de processamento da filtragem não compensa o possível ganho de tratar menos percepções no Jason; nos experimentos estudados, o uso do filtro pode inclusive causar uma piora no tempo de resposta, como pode ser visto no experimento 4.2 , com 40 insetos e $90 \%$ de insetos interessantes.

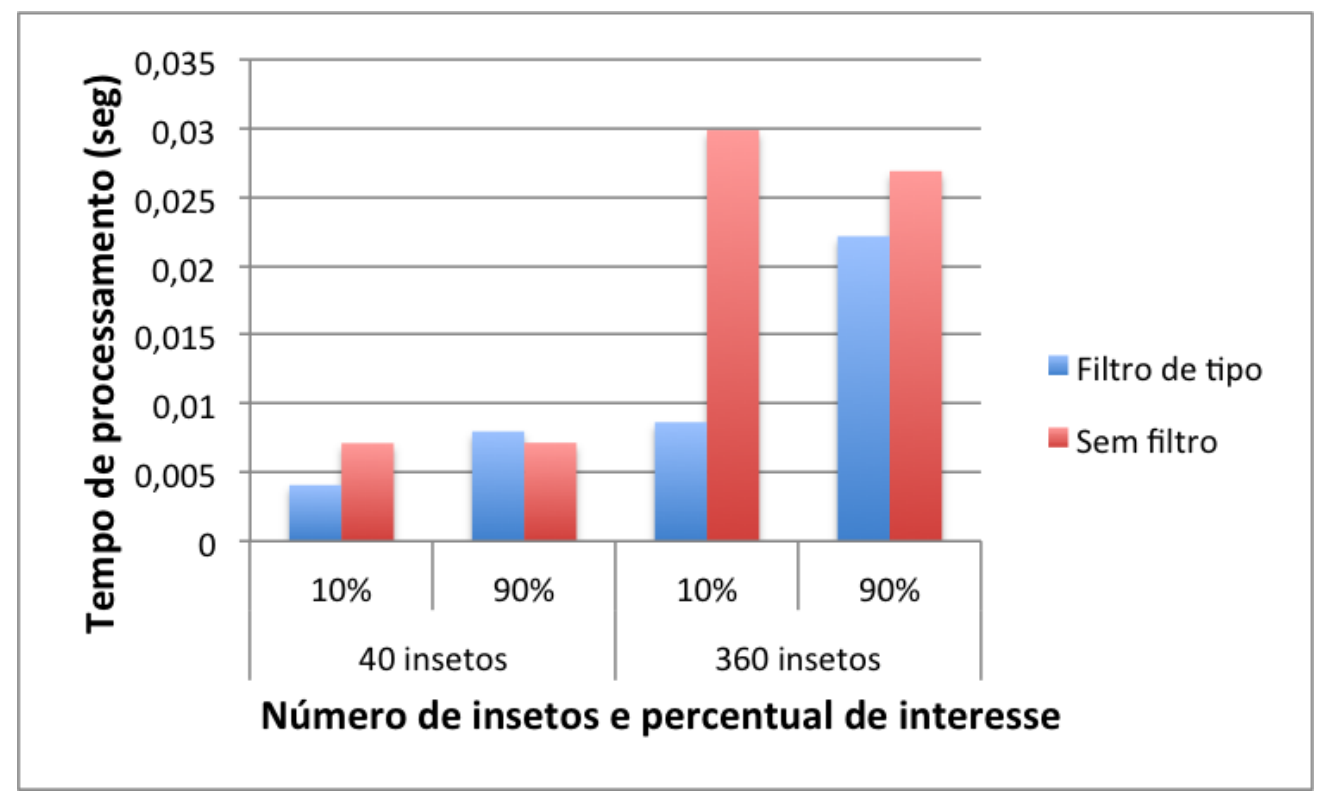

Figura 5.8: Filtro com Expressões Regulares: 95 percentil do tempo de processamento do agente.

Como tais conclusões sobre o efeito do filtro de propriedade utilizando expressões regulares já são suficientemente interessantes, não foram realizados experimentos completos utilizando este tipo de filtro.

\subsubsection{Estudo reduzido sobre o impacto na função de utilidade}

Apesar do filtro de propriedade especificado neste capítulo não conseguir reduzir o tempo de resposta para todos os casos, ainda é interessante avaliar se há perda na qualidade das ações realizadas. Para tal, foi realizado um conjunto de experimentos com os mesmos fatores e níveis do 
primeiro estudo, mas com a variável resposta sendo a quantidade de insetos capturados durante a simulação. A tabela 5.13 mostra o número de insetos capturados pelo agente em cada execução, considerado como um valor de utilidade.

\begin{tabular}{|c|c|c|c|c|c|c|}
\hline Experimento & Uso do filtro & Num. Perc. & Perc. Interesse & \multicolumn{2}{|c|}{ Insetos Capturados } \\
\hline EXP 5.1 & FS & P40 & I10 & 8 & 8 & 11 \\
\hline EXP 5.2 & FS & P40 & I90 & 28 & 21 & 29 \\
\hline EXP 5.3 & FS & P360 & I10 & 30 & 29 & 28 \\
\hline EXP 5.4 & FS & P360 & I90 & 106 & 85 & 91 \\
\hline EXP 5.5 & FC & P40 & I10 & 8 & 12 & 5 \\
\hline EXP 5.6 & FC & P40 & I90 & 33 & 30 & 31 \\
\hline EXP 5.7 & FC & P360 & I10 & 28 & 26 & 29 \\
\hline EXP 5.8 & FC & P360 & I90 & 96 & 110 & 85 \\
\hline
\end{tabular}

Tabela 5.13: Filtro com Expressões Regulares: Valores de utilidade (número de insetos capturados) obtidos no estudo reduzido.

Tendo aplicado esses valores para o modelo, descobrimos que, diferentemente do modelo que avaliava a interferência dos filtros de intervalo, o modelo aqui resultante não era válido, uma vez que os testes visuais utilizados para a validação falharam. Foi efetuada então uma transformação logarítmica, calculando o log dos valores e esses valores calculados foram aplicados ao modelo. Mais uma vez, no entanto, o modelo resultante não pode ser validado, uma vez que os problemas nos testes visuais se mantiveram. Para solucionar o problema e obter um modelo válido se fez necessário aplicar um outro tipo de transformação aos dados. Ao invés de calcular o log dos valores medidos, foi calculada a sua raiz quadrada. Esse método de transformação também se encontra descrito por Jain (1991). Os valores calculados aproximados são apresentados na tabela 5.14.

\begin{tabular}{|c|c|c|c|c|c|c|}
\hline Experimento & Uso do filtro & Num. Perc. & Perc. Interesse & \multicolumn{3}{|c|}{ Valores Calculados } \\
\hline EXP 5.1 & FS & P40 & I10 & 2.828 & 2.828 & 3.317 \\
\hline EXP 5.2 & FS & P40 & I90 & 5.292 & 4.583 & 5.385 \\
\hline EXP 5.3 & FS & P360 & I10 & 5.477 & 5.385 & 5.292 \\
\hline EXP 5.4 & FS & P360 & I90 & 10.296 & 9.220 & 9.539 \\
\hline EXP 5.5 & FC & P40 & I10 & 2.828 & 3.464 & 2.236 \\
\hline EXP 5.6 & FC & P40 & I90 & 5.745 & 5.477 & 5.568 \\
\hline EXP 5.7 & FC & P360 & I10 & 5.292 & 5.099 & 5.385 \\
\hline EXP 5.8 & FC & P360 & I90 & 9.798 & 10.488 & 9.220 \\
\hline
\end{tabular}

Tabela 5.14: Filtro com Expressões Regulares: Raiz quadrada dos valores de utilidade (número de insetos capturados) obtidos no estudo reduzido.

Os testes visuais para o modelo com os dados transformados são apresentados na figura 5.9

Tendo este modelo válido, foi possível então analisar a variação do número de capturas atribuída a cada um dos fatores e às suas interações. Os valores calculados são mostrados na tabela 5.15.

Apesar do filtro não ter causado um impacto positivo no tempo de processamento em todos os casos analisados, é interessante verificar que ele não exerce impacto algum na qualidade de resposta do agente. Esse resultado se deve principalmente à descrição do experimento, que diz que os insetos que o filtro descarta deveriam ser ignorados pelo agente.

Deste modo, o uso do filtro de propriedade baseado em expressões regulares pode ser bastante vantajoso quando existem muitas crenças de certo tipo que seriam ignoradas pelo agente.

\subsubsection{Filtro com comparações simples}

A segunda implementação foi realizada através do uso de simples comparações entre inteiros. O filtro utilizado está apresentado no código 10. 


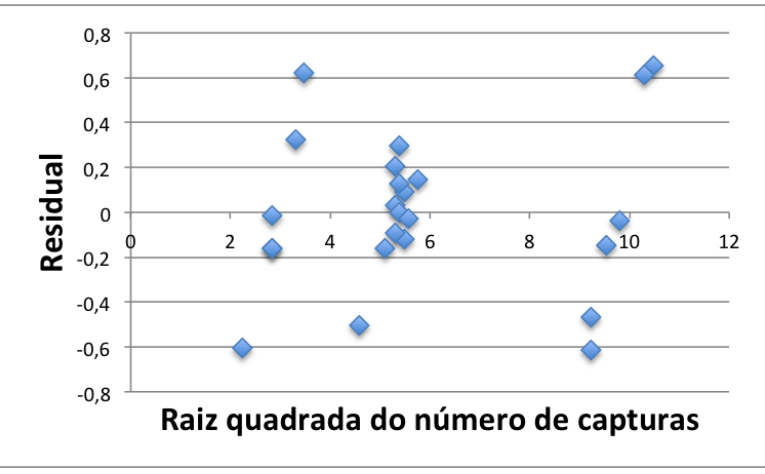

(a) Gráfico de dispersão.

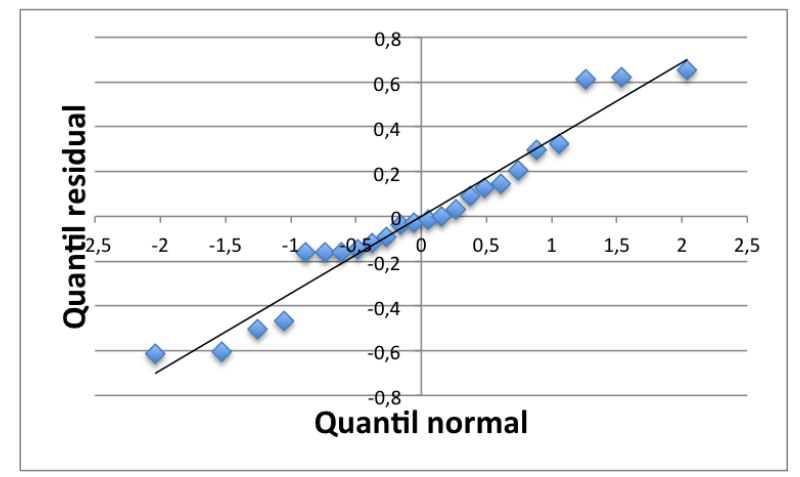

(b) Gráfico do quantil-quantil normal.

Figura 5.9: Filtro com Expressões Regulares: Testes visuais do estudo reduzido transformado sobre valores de utilidade.

\begin{tabular}{|l|c|}
\hline Fator & Variação atribuída \\
\hline Número de percepções (P) & $46,60 \%$ \\
\hline Porcentagem de interesse (I) & $47,14 \%$ \\
\hline Uso do Filtro (F) & $0,04 \%$ \\
\hline Interação entre P e F & $0,03 \%$ \\
\hline Interação entre I e F & $0,22 \%$ \\
\hline Interação entre P e I & $4,06 \%$ \\
\hline Interação entre P, I e F & $0,03 \%$ \\
\hline Erro de medição & $1,88 \%$ \\
\hline
\end{tabular}

Tabela 5.15: Filtro com Expressões Regulares: Variação de cada fator sobre a interferência na utilidade.

Para este conjunto de experimentos, o simulador foi levemente alterado para que enviasse juntamente da posição do inseto, uma anotação que informava se ele seria do tipo 0 (interessante) ou do tipo 1 (desinteressante). Assim, através de uma verificação numérica mais simples, o filtro eliminaria os insetos da mesma forma que no teste anterior, mas sem utilizar um método computacionalmente mais custoso como o de avaliação de expressões regulares.

\subsubsection{Estudo reduzido sobre o tempo de processamento}

Como explicado anteriormente, este estudo também foi do tipo fatorial reduzido $2^{k} r$, onde foram comparadas combinações de execuções considerando os níveis extremos dos fatores uso do filtro (com e sem filtro), número de percepções (40 insetos e 360 insetos) e percentual de interesse (10\% e 90\%).

A tabela 5.16 apresenta então os tempos de resposta encontrados para cada execução dos experimentos, medidos em nanosegundos.

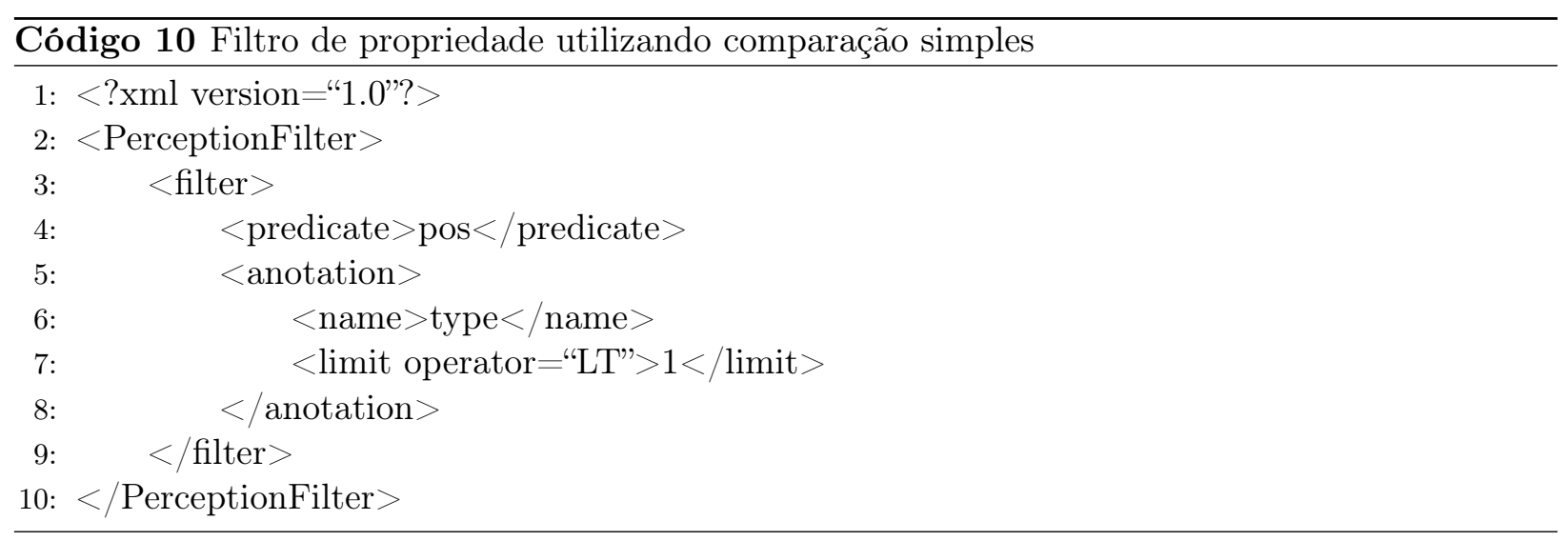




\begin{tabular}{|c|c|c|c|c|c|c|}
\hline Experimento & Uso do filtro & Num. Perc. & Perc. Interesse & \multicolumn{3}{|c|}{ 95 percentil } \\
\hline EXP 6.1 & FS & P40 & I10 & 8834568 & 7892852 & 7524572 \\
\hline EXP 6.2 & FS & P40 & I90 & 6204835 & 6567080 & 7266475 \\
\hline EXP 6.3 & FS & P360 & I10 & 36940841 & 36035538 & 34018143 \\
\hline EXP 6.4 & FS & P360 & I90 & 32256630 & 32586427 & 33241105 \\
\hline EXP 6.5 & FC & P40 & I10 & 3443045 & 3285697 & 3323060 \\
\hline EXP 6.6 & FC & P40 & I90 & 7752365 & 6528232 & 7679615 \\
\hline EXP 6.7 & FC & P360 & I10 & 7295025 & 7833263 & 7040962 \\
\hline EXP 6.8 & FC & P360 & I90 & 20629128 & 22765487 & 26323640 \\
\hline
\end{tabular}

Tabela 5.16: Filtro com Comparações: Tempos de processamento (ns) obtidos no estudo reduzido.

Uma vez mais, com a experiência dos estudos anteriores, já é conhecido que os dados devem ser transformados através do cálculo do log. Os valores calculados se encontram na tabela 5.17.

\begin{tabular}{|c|c|c|c|c|c|c|}
\hline Experimento & Uso do filtro & Num. Perc. & Perc. Interesse & \multicolumn{3}{|c|}{ Valores Calculados } \\
\hline EXP 6.1 & FS & P40 & I10 & 6,946 & 6,897 & 6,876 \\
\hline EXP 6.2 & FS & P40 & I90 & 6,793 & 6,817 & 6,861 \\
\hline EXP 6.3 & FS & P360 & I10 & 7,568 & 7,557 & 7,532 \\
\hline EXP 6.4 & FS & P360 & I90 & 7,509 & 7,513 & 7,522 \\
\hline EXP 6.5 & FC & P40 & I10 & 6,537 & 6,517 & 6,522 \\
\hline EXP 6.6 & FC & P40 & I90 & 6,889 & 6,815 & 6,885 \\
\hline EXP 6.7 & FC & P360 & I10 & 6,863 & 6,894 & 6,848 \\
\hline EXP 6.8 & FC & P360 & I90 & 7,314 & 7,357 & 7,420 \\
\hline
\end{tabular}

Tabela 5.17: Filtro com Comparações: Logs dos tempos de processamento do estudo reduzido.

Tendo o modelo sido validado pelos testes visuais presentes na figura 5.10, é possível analisar o impacto do filtro na variação do tempo de processamento.

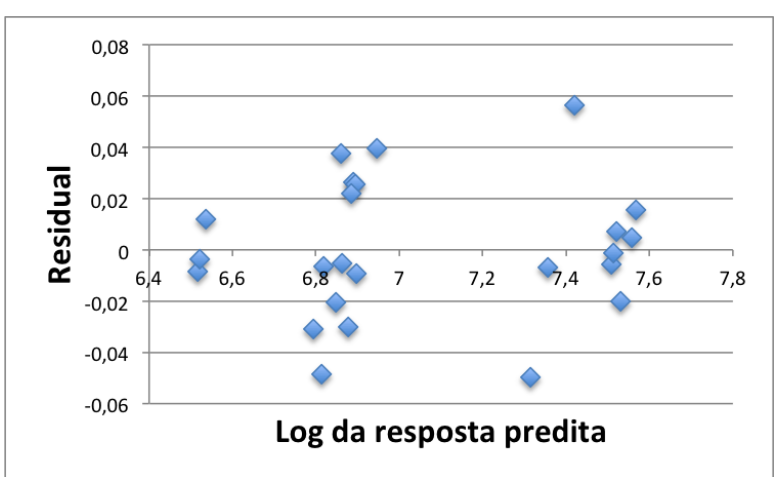

(a) Gráfico de dispersão.

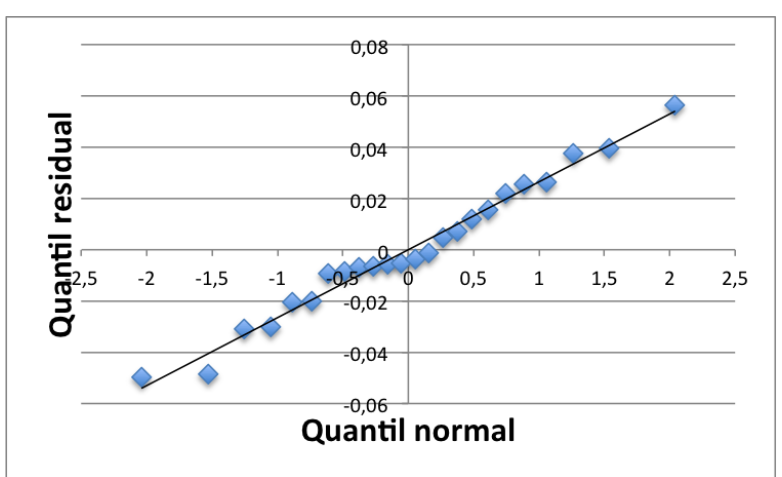

(b) Gráfico do quantil-quantil normal.

Figura 5.10: Filtro com Comparações: Testes visuais do estudo reduzido sobre tempo de processamento.

A tabela 5.18 apresenta os valores da variação atribuídos a cada fator e às suas interações. $\mathrm{O}$ filtro desta vez apresentou um impacto bem maior na variação do tempo de processamento, quando comparado àquele obtido nos experimentos anteriores com uso de expressões regulares. Acumulandose a variação do fator e das suas interações com outros fatores, o filtro por comparação possui um impacto de cerca de $30 \%$ na variação no tempo de processamento. Além disso, como no caso do filtro por expressões regulares, se manteve uma importante interação (cerca de 12\%) entre o Uso do Filtro e a Porcentagem de Interesse.

Da mesma forma como foi apresentado na subseção 5.3.2.1, o gráfico da figura 5.11 permite uma melhor visualização dos tempos de resposta. É possível perceber que o filtro implementado 


\begin{tabular}{|l|c|}
\hline Fator & Variação atribuída \\
\hline Número de percepções (P) & $60,19 \%$ \\
\hline Uso do Filtro (F) & $17,53 \%$ \\
\hline Porcentagem de interesse (I) & $6,45 \%$ \\
\hline Interação entre P e F & $3,07 \%$ \\
\hline Interação entre I e F & $11,53 \%$ \\
\hline Interação entre P e I & $0,52 \%$ \\
\hline Interação entre P, I e F & $0,16 \%$ \\
\hline Erro de medição & $0,55 \%$ \\
\hline
\end{tabular}

Tabela 5.18: Filtro com Comparações: Variação atribuída a cada fator do estudo reduzido.

por comparação simples apresentou o mesmo comportamento do que aquele implementado com expressões regulares: em particular, causou uma piora no tempo de processamento no mesmo experimento 4.2, com 40 insetos e $90 \%$ de insetos interessantes. Tal resultado sugere que o uso das expressões regulares neste experimento não seja o responsável pela piora no tempo de resposta, mas sim a própria utilização de um filtro de propriedade que deva eliminar um número pequeno de percepções.

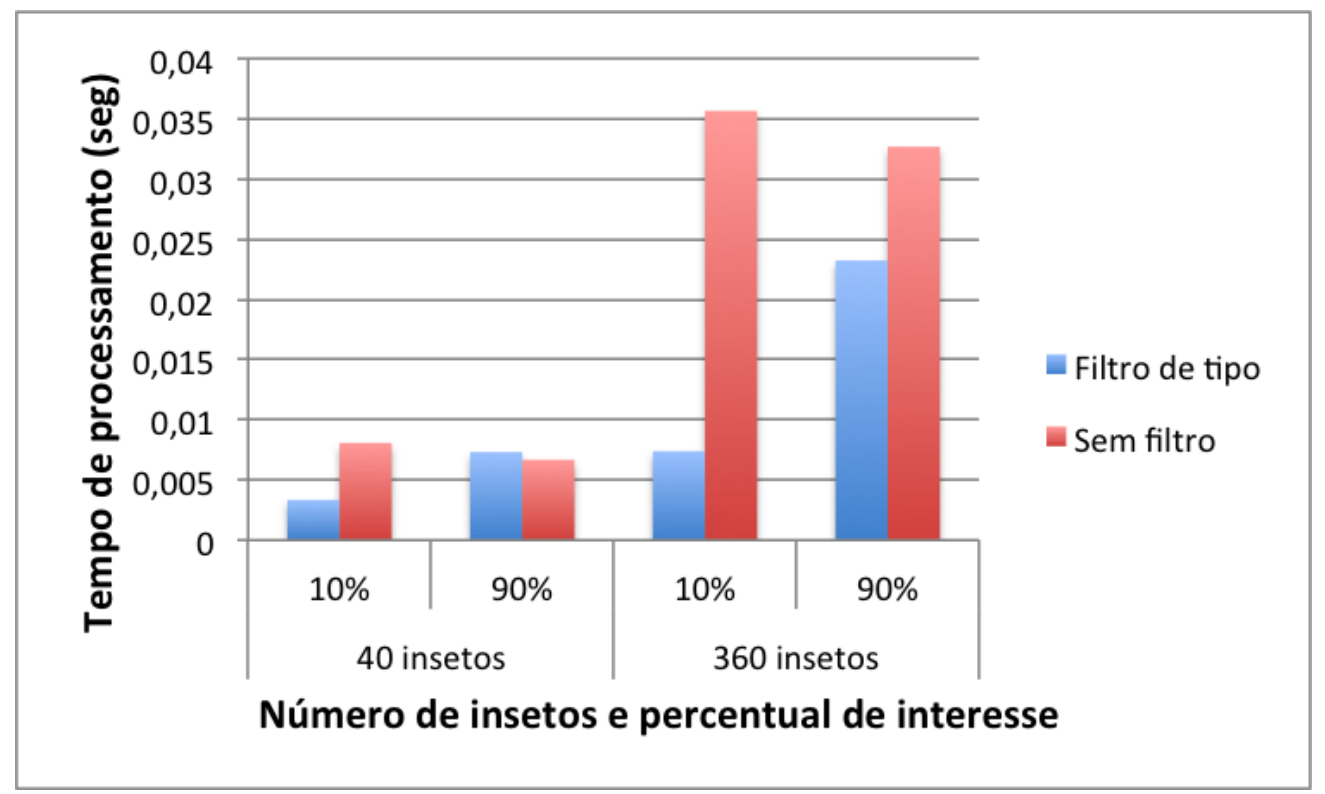

Figura 5.11: Filtro com Comparações: 95 percentil dos tempos de processamento do agente.

Uma vez mais, o estudo reduzido dos efeitos do filtro de propriedade utilizando comparações simples já foi capaz de identificar as propriedades interessantes deste filtro, tornando desnecessária a execução do conjunto de experimentos completo.

\subsubsection{Estudo reduzido sobre o impacto na função de utilidade}

Dado que o filtro de propriedade implementado através de comparações simples teve um maior impacto na melhora de desempenho do agente, é importante verificar se, assim como o filtro implementado com expressões regulares, esse filtro não exerce impacto na qualidade de resposta do agente. Para isso, foi realizado um conjunto de experimentos com os mesmos fatores e níveis do primeiro estudo, mas com a variável resposta sendo a quantidade de insetos capturados durante a simulação, considerada como uma medida de utilidade. A tabela 5.19 mostra o número de insetos capturados pelo agente em cada execução.

Tendo aplicado os valores ao modelo, semelhantemente ao caso do filtro com expressões regulares, o modelo precisou ser transformado, uma vez que os testes visuais utilizados para a validação inicial 


\begin{tabular}{|c|c|c|c|c|c|c|}
\hline Experimento & Uso do filtro & Num. Perc. & Perc. Interesse & \multicolumn{3}{|c|}{ Capturas } \\
\hline EXP 7.1 & FS & P40 & I10 & 7 & 5 & 6 \\
\hline EXP 7.2 & FS & P40 & I90 & 36 & 30 & 25 \\
\hline EXP 7.3 & FS & P360 & I10 & 28 & 28 & 27 \\
\hline EXP 7.4 & FS & P360 & I90 & 99 & 96 & 108 \\
\hline EXP 7.5 & FC & P40 & I10 & 7 & 5 & 6 \\
\hline EXP 7.6 & FC & P40 & I90 & 32 & 27 & 27 \\
\hline EXP 7.7 & FC & P360 & I10 & 31 & 32 & 28 \\
\hline EXP 7.8 & FC & P360 & I90 & 94 & 113 & 93 \\
\hline
\end{tabular}

Tabela 5.19: Filtro com Comparações: Valores de utilidade (número de insetos capturados) obtidos no estudo reduzido.

falharam. No entanto, neste caso a transformação logarítmica já foi suficiente para gerar um modelo válido. Os valores calculados aproximados são então apresentados na tabela 5.20

\begin{tabular}{|c|c|c|c|c|c|c|}
\hline Experimento & Uso do filtro & Num. Perc. & Perc. Interesse & \multicolumn{3}{|c|}{ Valores calculados } \\
\hline EXP 7.1 & FS & P40 & I10 & 2,646 & 2,236 & 2,449 \\
\hline EXP 7.2 & FS & P40 & I90 & 6,000 & 5,477 & 5,000 \\
\hline EXP 7.3 & FS & P360 & I10 & 5,292 & 5,292 & 5,196 \\
\hline EXP 7.4 & FC & P360 & I90 & 9,950 & 9,798 & 10,392 \\
\hline EXP 7.5 & FC & P40 & I10 & 2,646 & 2,236 & 2,449 \\
\hline EXP 7.6 & FC & P360 & I90 & 5,657 & 5,196 & 5,196 \\
\hline EXP 7.7 & FC & P360 & I10 & 5,568 & 5,657 & 5,292 \\
\hline EXP 7.8 & FC & P360 & I90 & 9,695 & 10,630 & 9,644 \\
\hline
\end{tabular}

Tabela 5.20: Filtro com Comparações: Logs dos valores calculados para o estudo sobre a interferência na utilidade.

Os testes visuais para o modelo com os dados transformados são apresentados na figura 5.12

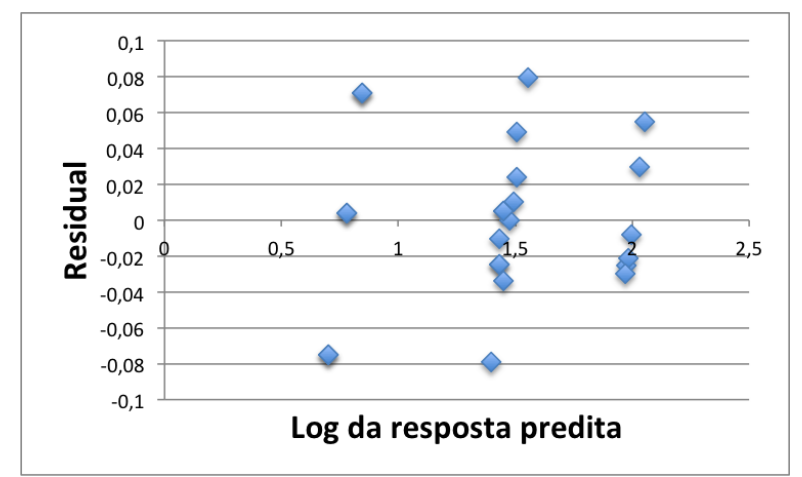

(a) Gráfico de dispersão.

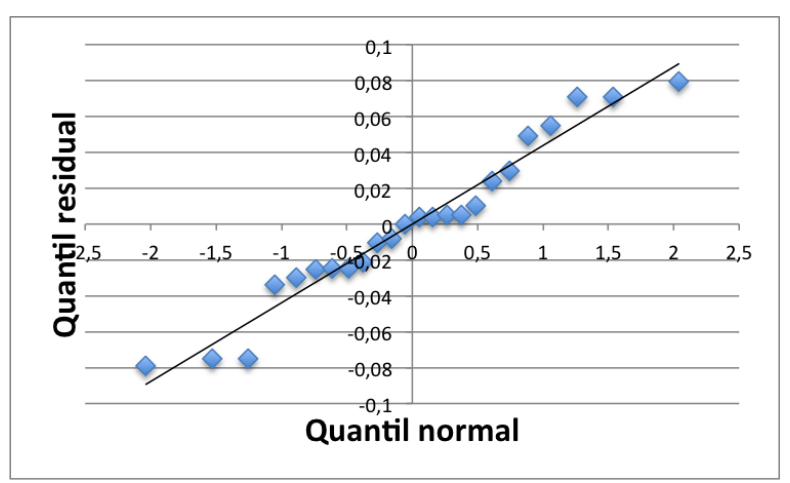

(b) Gráfico do quantil-quantil normal.

Figura 5.12: Filtro com Comparações: Testes visuais do estudo reduzido transformado sobre valores de utilidade.

Tendo este modelo válido, foi possível então analisar a variação do número de capturas atribuída a cada um dos fatores e interações. Os valores calculados são mostrados na tabela 5.21

Uma vez que os resultados com o conjunto de experimentos usando filtro de propriedade com expressões regulares já haviam apontado que ao se remover crenças que não seriam utilizadas não há redução na qualidade da resposta do processo de tomada de decisão do agente, esperava-se o mesmo comportamento para o filtro de propriedade com comparações simples. Efetivamente, o uso deste filtro tampouco exerceu impacto na qualidade de resposta do agente, corroborando as conclusões do conjunto de experimentos anterior. 


\begin{tabular}{|l|c|}
\hline Fator & Variação atribuída \\
\hline Número de percepções (P) & $48,69 \%$ \\
\hline Porcentagem de interesse (I) & $49,49 \%$ \\
\hline Uso do Filtro (F) & $0,01 \%$ \\
\hline Interação entre P e F & $0,02 \%$ \\
\hline Interação entre I e F & $0,04 \%$ \\
\hline Interação entre P e I & $0,76 \%$ \\
\hline Interação entre P, I e F & $0,00 \%$ \\
\hline Erro de medição & $0,99 \%$ \\
\hline
\end{tabular}

Tabela 5.21: Filtro com Comparações: Variação de cada fator no estudo sobre a interferência na utilidade.

\subsubsection{Comparação entre os filtros de propriedade}

Para realizar uma análise mais precisa sobre a diferença de se implementar um filtro de propriedade utilizando expressões regulares ou comparação mais simples, foi gerado e apresentado na tabela 5.22 um novo modelo utilizando os valores já obtidos nos estudos anteriores apresentados respectivamente nas tabelas 5.10 e 5.16 . Os fatores e níveis são:

P Número de percepções. Representa novamente o número de insetos que estão presentes no grid. Os níveis escolhidos são proporcionais ao grid:

P10 10\% do grid (40 insetos);

P90 90\% do grid (360 insetos);

F Tipo do filtro. Neste conjunto de experimentos, somente um tipo de filtro de propriedade foi avaliado, responsável por excluir todos os insetos que não interessavam ao agente. Assim, o fator uso do filtro pode assumir somente dois valores, se o filtro está sendo utilizado ou se a execução está sendo realizada sem filtro.

FE 'Expressão regular', que corresponde ao uso do filtro de propriedade implementado através de uma expressão regular;

FC 'Comparações', que corresponde ao uso do filtro de propriedade implementado através de comparações;

I Percentual de interesse. Representa a proporção entre os insetos que são de interesse do agente e o número total de insetos. Os níveis escolhidos são:

I10 10\% dos insetos;

I90 90\% dos insetos;

\begin{tabular}{|c|c|c|c|c|c|c|}
\hline Experimento & Tipo do filtro & Num. Perc. & Perc. Interesse & \multicolumn{3}{|c|}{ 95 percentil } \\
\hline EXP 4.5 & FE & P40 & I10 & 4318976 & 3934425 & 3978573 \\
\hline EXP 4.6 & FE & P40 & I90 & 7083485 & 9049109 & 7800695 \\
\hline EXP 4.7 & FE & P360 & I10 & 9213876 & 8377817 & 8349314 \\
\hline EXP 4.8 & FE & P360 & I90 & 22515079 & 20437884 & 23560919 \\
\hline EXP 6.5 & FC & P40 & I10 & 3443045 & 3285697 & 3323060 \\
\hline EXP 6.6 & FC & P40 & I90 & 7752365 & 6528232 & 7679615 \\
\hline EXP 6.7 & FC & P360 & I90 & 7295025 & 7833263 & 7040962 \\
\hline EXP 6.8 & FC & P360 & I90 & 20629128 & 22765487 & 26323640 \\
\hline
\end{tabular}

Tabela 5.22: Comparação entre filtros de propriedade: Tempos de processamento (ns) obtidos nos estudos reduzidos. 
Para gerar um modelo válido, os valores tiveram que sofrer uma transformação logarítmica como nos próprios experimentos originais. Os testes visuais para o modelo com os dados transformados são apresentados na figura 5.13

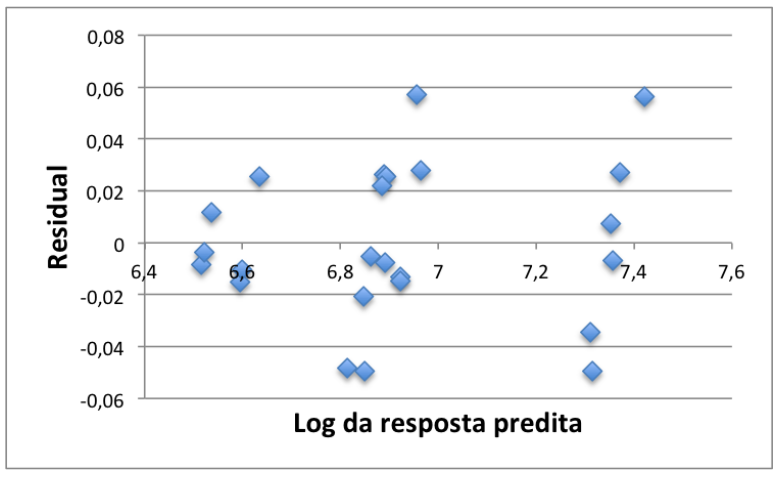

(a) Gráfico de dispersão.

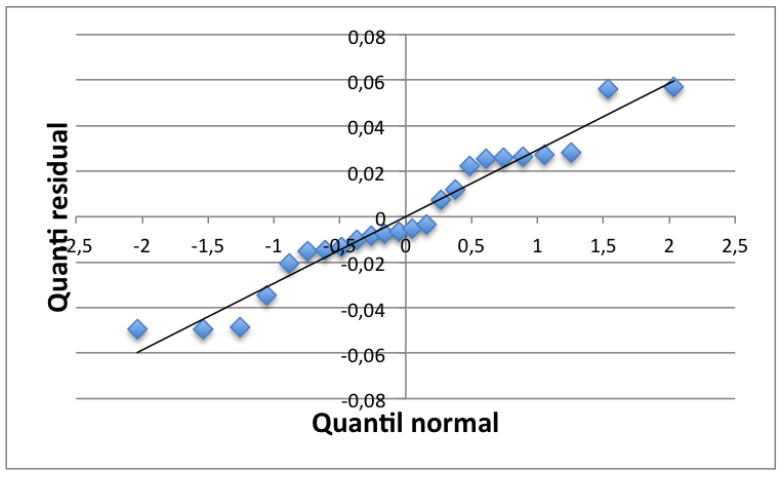

(b) Gráfico do quantil-quantil normal.

Figura 5.13: Comparação entre filtros de propriedade: Testes visuais do estudo reduzido sobre diferença de tempos de processamento.

Construído o modelo válido, tornou-se possível analisar a variação no tempo de resposta atribuída à diferença entre as implementações do filtro de propriedade. Os valores calculados são mostrados na tabela 5.23 .

\begin{tabular}{|l|c|}
\hline Fator & Variação atribuída \\
\hline Número de percepções (P) & $50,76 \%$ \\
\hline Porcentagem de interesse (I) & $45,64 \%$ \\
\hline Implementação do Filtro (F) & $0,57 \%$ \\
\hline Interação entre P e F & $0,10 \%$ \\
\hline Interação entre I e F & $0,36 \%$ \\
\hline Interação entre P e I & $1,49 \%$ \\
\hline Interação entre P, I e F & $0,03 \%$ \\
\hline Erro de medição & $1,06 \%$ \\
\hline
\end{tabular}

Tabela 5.23: Comparação entre filtros de propriedade: Variação atribuída a cada fator do estudo reduzido transformado na diferença entre tempo de processamento.

Tanto na tabela 5.23 quanto no gráfico 5.14, é possível visualizar que no caso analisado não há uma diferença significativa entre implementar o filtro através de expressões regulares ou através de comparações simples. Isso sugere que o uso das expressões regulares neste experimento, mesmo tendo uma estrutura mais complexa, pode não causar um impacto significativo no tempo de processamento do filtro. Isso possibilita que o desenvolvedor possa optar por uma implementação mais simples ou pelo uso das expressões regulares quando for necessário.

\subsection{Múltiplos agentes}

Neste terceiro conjunto de experimentos, o objetivo era avaliar o possível ganho de desempenho aos utilizar filtros de distância em um ambiente multi-agentes. O cenário original do simulador foi então alterado para permitir a participação de múltiplos agentes simultaneamente.

Além da movimentação dos insetos, os agentes consideram agora a posição dos outros agentes: tentam se mover em direção aos insetos e para longe dos outros agentes, para conseguirem cobrir uma área maior.

Para este cenário, foram utilizados os mesmos filtros de distância do primeiro conjunto de experimentos. Em um experimento, todos os agentes se utilizam do mesmo filtro de percepção. O 


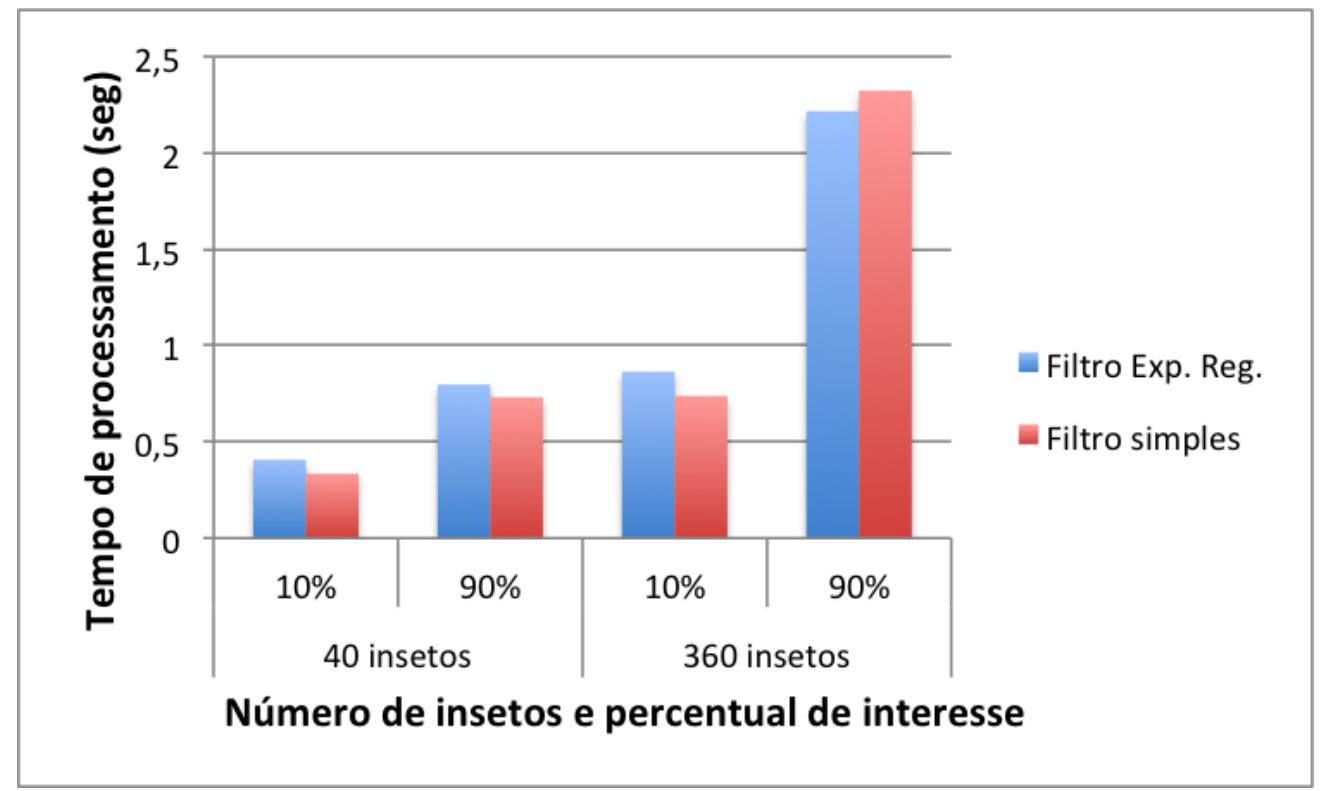

Figura 5.14: Comparação entre filtros de propriedade: 95 percentil da diferença entre os tempos de processamento do agente.

cálculo da distância, no entanto, é realizado de forma independente para cada agente, excluindo os insetos mais distantes e fazendo com que cada agente só perceba os insetos mais próximos a ele.

As regras utilizadas foram as seguintes:

R1 Quando o agente estiver perseguindo os insetos, o filtro irá excluir os insetos que estão mais longe do que um determinado valor expresso no parâmetro;

R2 Quando o agente estiver voltando para a base carregando um inseto, o filtro elimina todas as percepções que contém as posições de insetos e de agentes.

Para este conjunto de experimentos, os fatores e níveis escolhidos para a avaliação foram:

$\mathbf{P}$ Número de percepções. Representa novamente o número de insetos que estão presentes no grid. Os níveis escolhidos são proporcionais ao tamanho do grid:

P10 10\% do grid (40 insetos);

P20 20\% do grid (80 insetos);

P30 30\% do grid (120 insetos);

P40 40\% do grid (160 insetos);

P50 50\% do grid (200 insetos);

P60 $60 \%$ do grid (240 insetos);

P70 $70 \%$ do grid (280 insetos);

P80 $80 \%$ do grid (320 insetos);

P90 90\% do grid (360 insetos);

F Tamanho do filtro. Representa a distância euclidiana em espaços que o agente pode perceber os insetos. Os filtros são os mesmos utilizados no conjunto de experimentos da seção 5.2.

F2 'Filtro 2', que corresponde a uma percepção máxima de 20\% do raio;

F5 'Filtro 5', que corresponde a uma percepção máxima de $50 \%$ do raio;

F7 'Filtro 7', que corresponde a uma percepção máxima de $70 \%$ do raio; 
F0 'Sem filtro', que corresponde à percepção de todo o grid.

A Número de agentes. Representa a quantidade de agentes que tentam simultaneamente capturar os insetos no grid.

A2 2 agentes;

A3 3 agentes;

A4 4 agentes;

A5 5 agentes;

Nesse conjunto de experimentos, devido a existência de mais de um agente, ao invés da variável de resposta ser o tempo de resposta do agente, foi tomado o tempo de resposta máximo, ou seja, o tempo necessário para que todos os agentes executassem suas ações. Os mesmos três estudos descritos na seção 5.2 foram novamente realizados.

\subsubsection{Estudo reduzido sobre o tempo de processamento}

O primeiro conjunto de experimentos teve como objetivo identificar a variação atribuída ao número de percepções, ao percentual de interesse e ao número de agentes sobre o tempo de processamento. Esse primeiro estudo foi também um estudo do tipo fatorial reduzido $2^{k} r$ onde foram comparadas combinações de execuções considerando os níveis extremos dos fatores tamanho do filtro (filtro de tamanho 2 e sem filtro), número de percepções (40 insetos e 360 insetos) e número de agentes ( 2 e 5 agentes). A tabela 5.24 apresenta o 95 percentil dos tempos de resposta encontrados para cada execução dos experimentos, medidos em nanosegundos.

\begin{tabular}{|c|c|c|c|c|c|c|}
\hline Experimento & Filtro & Num. Perc. & Num. Agentes & \multicolumn{3}{|c|}{ 95 percentil } \\
\hline EXP 8.1 & F0 & P40 & A5 & 13329574 & 10185855 & 8818994 \\
\hline EXP 8.2 & F0 & P40 & A2 & 8735715 & 8198393 & 8622323 \\
\hline EXP 8.3 & F0 & P360 & A5 & 67877745 & 69167287 & 81490780 \\
\hline EXP 8.4 & F0 & P360 & A2 & 43518085 & 32293954 & 34696250 \\
\hline EXP 8.5 & F2 & P40 & A5 & 4000203 & 5305418 & 5204463 \\
\hline EXP 8.6 & F2 & P40 & A2 & 3686420 & 4103553 & 3850447 \\
\hline EXP 8.7 & F2 & P360 & A5 & 9602709 & 9293357 & 8344702 \\
\hline EXP 8.8 & F2 & P360 & A2 & 5968769 & 4911250 & 5324024 \\
\hline
\end{tabular}

Tabela 5.24: Filtro de intervalo com multi-agentes: Tempos de processamento (ns) obtidos no estudo reduzido.

Os valores calculados pela transformação logarítmica são apresentados na tabela 5.25.

\begin{tabular}{|c|c|c|c|c|c|c|}
\hline Experimento & Filtro & Num. Perc. & Num. Agentes & \multicolumn{3}{|c|}{ Valores calculados } \\
\hline EXP 8.1 & F0 & P40 & A5 & 7,125 & 7,008 & 6,945 \\
\hline EXP 8.2 & F0 & P40 & A2 & 6,941 & 6,914 & 6,936 \\
\hline EXP 8.3 & F0 & P360 & A5 & 7,832 & 7,840 & 7,911 \\
\hline EXP 8.4 & F0 & P360 & A2 & 7,639 & 7,509 & 7,540 \\
\hline EXP 8.5 & F2 & P40 & A5 & 6,602 & 6,725 & 6,716 \\
\hline EXP 8.6 & F2 & P40 & A2 & 6,567 & 6,613 & 6,586 \\
\hline EXP 8.7 & F2 & P360 & A5 & 6,982 & 6,968 & 6,921 \\
\hline EXP 8.8 & F2 & P360 & A2 & 6,776 & 6,691 & 6,726 \\
\hline
\end{tabular}

Tabela 5.25: Filtro de intervalo com multi-agentes: Logs dos tempos de processamento do estudo reduzido.

Construído o modelo e tendo sido validado pelos testes visuais presentes na figura 5.15, é possível analisar o impacto do filtro de intervalo na variação do tempo de processamento no cenário multiagentes. 


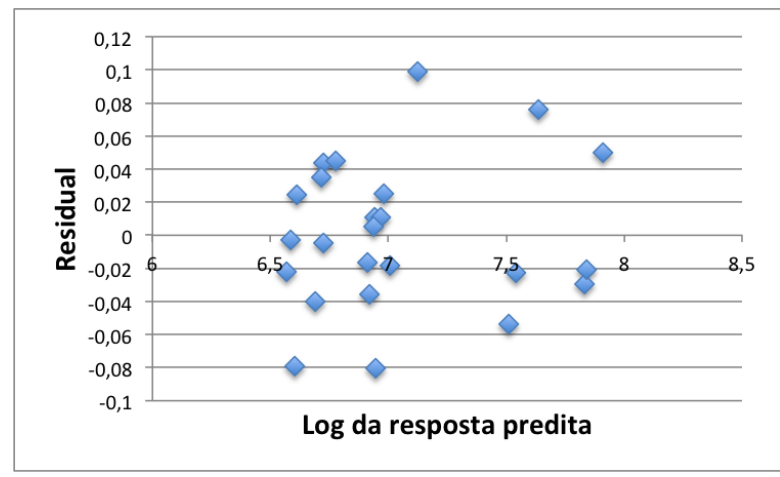

(a) Gráfico de dispersão.

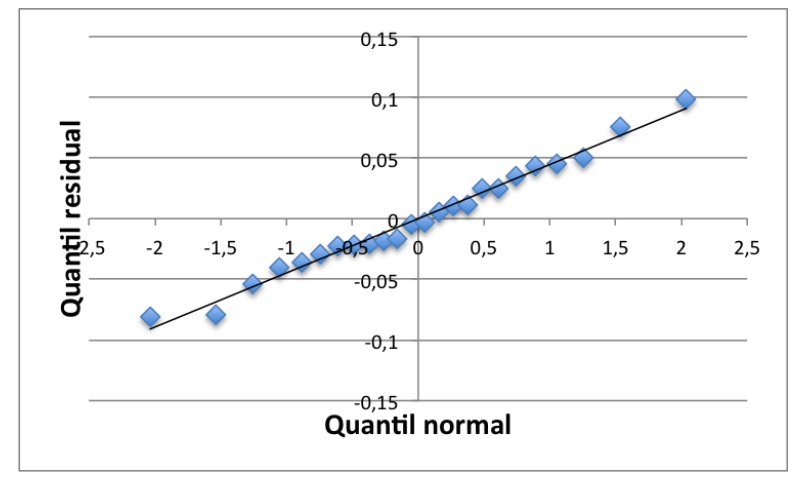

(b) Gráfico do quantil-quantil normal.

Figura 5.15: Filtro de intervalo com multi-agentes: Testes visuais do estudo reduzido transformado sobre tempos de processamento.

A tabela 5.27 apresenta os valores da variação atribuídos a cada fator e às suas interações. Quando comparamos estes resultados com os resultados obtidos no teste com um único agente (Tabela 5.4), pode-se perceber que a variação atribuída ao filtro de intervalo se mantém bastante alta, em torno de $52 \%$. Um outro ponto interessante que pode ser percebido é o fato da interação entre o filtro de percepção e o número de agentes ser praticamente zero. Isso sugere que o filtro está reduzindo o tempo de processamento de cada agente individualmente, sem afetar o conjunto dos agentes. Além disso, a interação entre o filtro e o número de percepções corrobora com o conjunto de experimentos sobre filtros de propriedade, ao indicar que o filtro se sai melhor quando existem mais crenças para serem descartadas.

\begin{tabular}{|l|c|}
\hline Fator & Variação atribuída \\
\hline Número de percepções (P) & $31,55 \%$ \\
\hline Filtro (F) & $52,02 \%$ \\
\hline Número de Agentes (A) & $4,51 \%$ \\
\hline Interação entre P e F & $9,74 \%$ \\
\hline Interação entre A e F & $0,05 \%$ \\
\hline Interação entre P e A & $1,00 \%$ \\
\hline Interação entre P, A e F & $0,04 \%$ \\
\hline Erro de medição & $1,09 \%$ \\
\hline
\end{tabular}

Tabela 5.26: Filtro de intervalo com multi-agentes: Variação atribuída a cada fator do estudo reduzido.

O gráfico da figura 5.16 ilustra as propriedades apresentadas comparando a média dos 95 percentis dos tempos de resposta medidos.

Sabendo que o filtro de intervalo causa uma redução significativa também em um cenário multiagentes, podemos avaliar os outros filtros de intervalo menos restritivos e também cenários com números mais variados de insetos. Para isso, foi conduzido o conjunto de experimentos completo a seguir.

\subsubsection{Estudo completo sobre o tempo de processamento}

O segundo estudo ampliou a análise dos resultados do primeiro estudo por meio da execução de um estudo fatorial completo de três fatores com variação nos filtros, na quantidade de insetos e no número de agentes.

Todos os filtros descritos foram novamente utilizados em combinação com quantidades de percepções que variavam de $10 \%$ do grid (40 insetos) a $90 \%$ (360 insetos), com intervalos de $10 \%$ e agora também com 2, 3, 4 e 5 agentes, totalizando assim 144 experimentos distintos.

Os valores de tempo medidos podem ser encontrados no apêndice C. Já sendo conhecido que os 


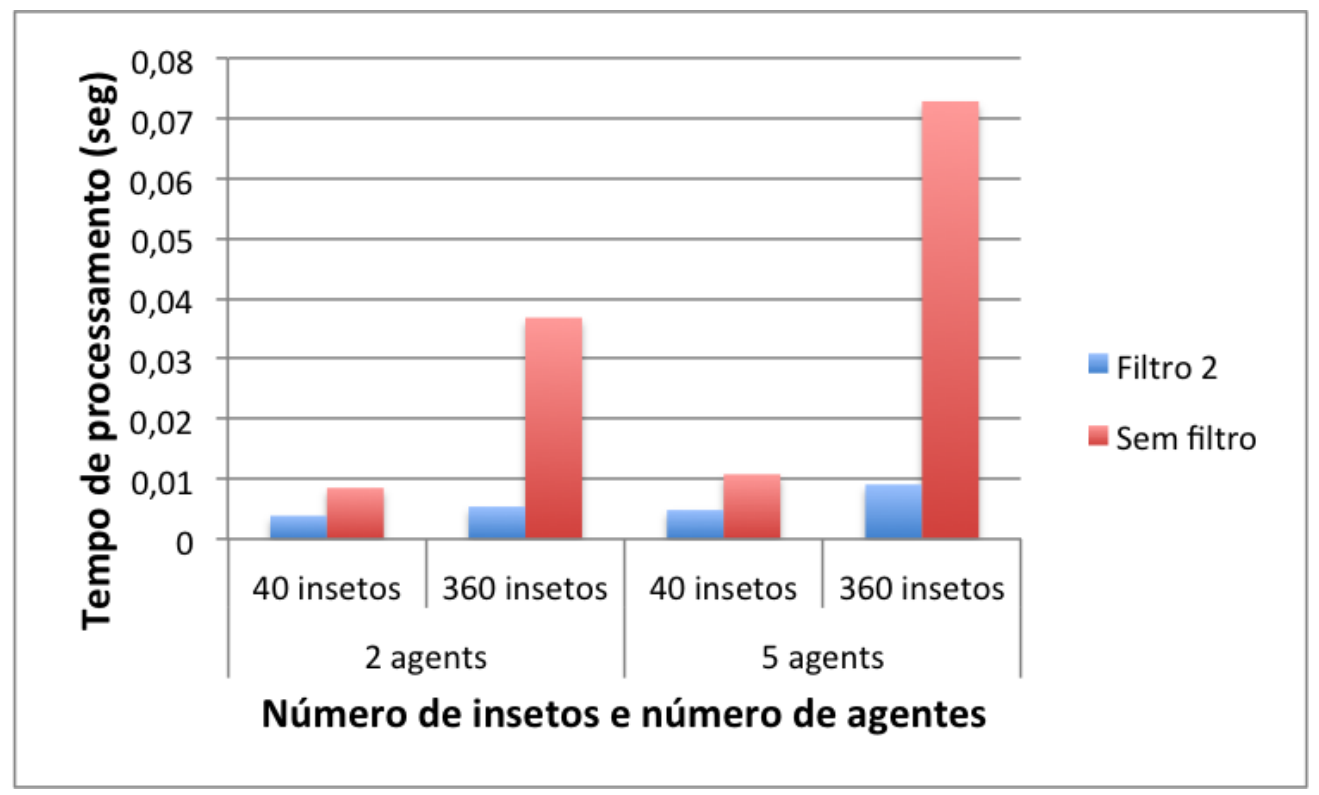

Figura 5.16: Filtro de intervalo com multi-agentes:95 percentil do tempo total de processamento dos múltiplos agentes.

dados devem ser transformados através do cálculo do log, o resultado do cálculo pode ser visto no apêndice D. O emprego da transformação logarítmica novamente apresentou o resultado desejado, como pode ser visto na figura 5.17.

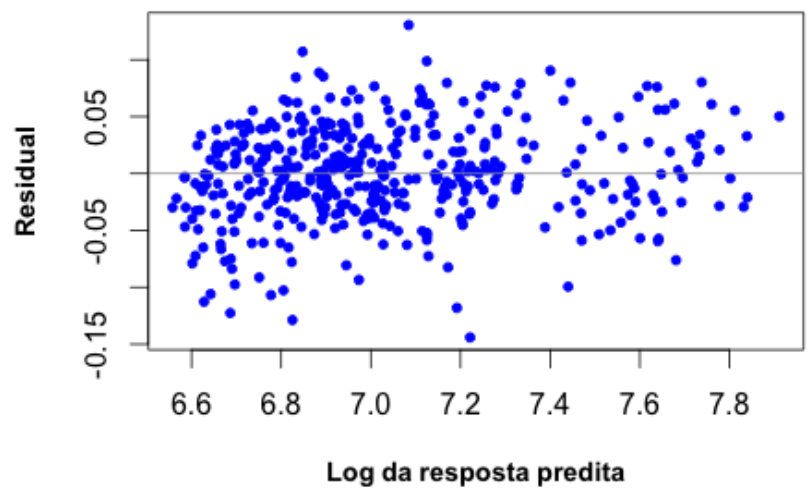

(a) Gráfico de dispersão.

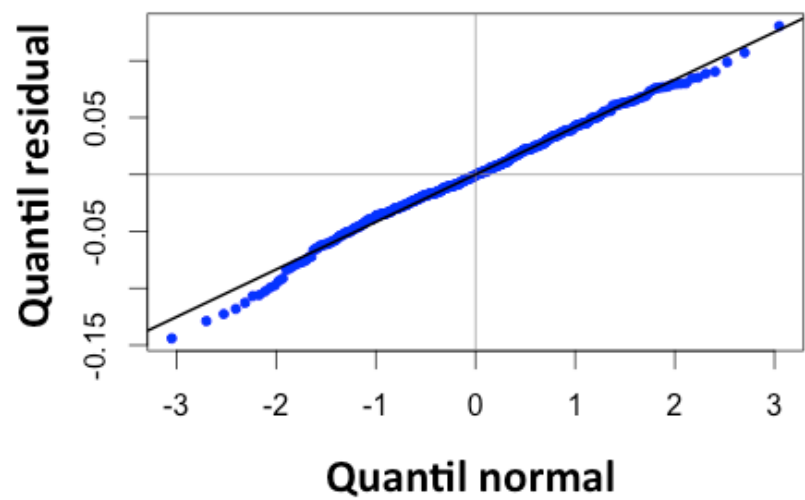

(b) Gráfico do quantil-quantil normal.

Figura 5.17: Multi-agentes: Testes visuais do estudo completo transformado sobre tempos de processamento.

A tabela 5.27 apresenta os valores da variação atribuídos a cada fator e às suas interações. Quando comparamos estes resultados com os resultados obtidos no teste com um único agente (Tabela 5.5), percebe-se que a variação atribuída ao filtro de intervalo ainda se mantém bastante alta, ao redor de $66 \%$. Um outro ponto interessante é o fato da interação entre o filtro de percepção e o número de agentes mais uma vez ser praticamente zero, como no caso do estudo reduzido ilustrado na Tabela 5.27. Isso sugere mais uma vez que o filtro está reduzindo o tempo de processamento de cada agente individualmente, sem afetar o conjunto dos agentes. Além disso, a interação entre o filtro e o número de percepções corrobora novamente com o conjunto de experimentos sobre filtros de propriedade, ao indicar que o filtro se sai melhor conforme existem mais crenças para serem descartadas. 


\begin{tabular}{|l|c|}
\hline Fator & Variação atribuída \\
\hline Número de percepções (P) & $19.05 \%$ \\
\hline Filtro (F) & $66.79 \%$ \\
\hline Número de Agentes (A) & $6.06 \%$ \\
\hline Interação entre P e F & $5.24 \%$ \\
\hline Interação entre A e F & $0.13 \%$ \\
\hline Interação entre P e A & $0.52 \%$ \\
\hline Interação entre P, A e F & $1.26 \%$ \\
\hline Erro de medição & $0.95 \%$ \\
\hline
\end{tabular}

Tabela 5.27: Multi-agentes: Variação atribuída a cada fator do estudo reduzido.

Com estes resultados obtidos através destas duas experiências, foi possível verificar que a aplicação do filtro de percepção em cenários multi-agentes também causa uma redução bastante significativa no tempo de processamento, pois reduz individualmente o tempo de cada agente, gerando assim uma grande redução no tempo total de processamento.

\subsubsection{Estudo reduzido sobre o impacto na função de utilidade}

De forma a avaliar novamente se haveria uma perda na capacidade dos agentes tomarem boas decisões, o terceiro estudo com design fatorial $2^{k} r$ utilizou os mesmos fatores e níveis do primeiro estudo com a finalidade de medir a interferência dos filtros de percepção na função de utilidade dos agentes, agora em um cenário multi-agentes. A tabela 5.28 mostra o número de insetos capturados pelo conjunto de agentes em cada execução dos experimentos.

\begin{tabular}{|c|c|c|c|c|c|c|}
\hline Experimento & Filtro & Num. Perc. & Num. Agentes & \multicolumn{3}{|c|}{ Insetos capturados } \\
\hline EXP 10.1 & F0 & P40 & A5 & 69 & 63 & 68 \\
\hline EXP 10.2 & F0 & P40 & A2 & 38 & 42 & 43 \\
\hline EXP 10.3 & F0 & P360 & A5 & 144 & 161 & 143 \\
\hline EXP 10.4 & F0 & P360 & A2 & 80 & 89 & 95 \\
\hline EXP 10.5 & F2 & P40 & A5 & 71 & 71 & 66 \\
\hline EXP 10.6 & F2 & P40 & A2 & 40 & 33 & 37 \\
\hline EXP 10.7 & F2 & P360 & A5 & 163 & 179 & 167 \\
\hline EXP 10.8 & F2 & P360 & A2 & 85 & 76 & 76 \\
\hline
\end{tabular}

Tabela 5.28: Filtro de intervalo com multi-agentes: Valores obtidos no estudo reduzido sobre a interferência no valor de utilidade.

Para poder construir um modelo válido, foi necessário aplicar uma transformação logarítmica sobre os valores. Os resultados do cálculo são apresentados na tabela 5.29

\begin{tabular}{|c|c|c|c|c|c|c|}
\hline Experimento & Filtro & Num. Perc. & Num. Agentes & \multicolumn{3}{|c|}{ Valores calculados } \\
\hline EXP 10.1 & F0 & P40 & A5 & 1,839 & 1,799 & 1,833 \\
\hline EXP 10.2 & F0 & P40 & A2 & 1,580 & 1,623 & 1,633 \\
\hline EXP 10.3 & F0 & P360 & A5 & 2,158 & 2,207 & 2,155 \\
\hline EXP 10.4 & F0 & P360 & A2 & 1,903 & 1,949 & 1,978 \\
\hline EXP 10.5 & F2 & P40 & A5 & 1,851 & 1,851 & 1,820 \\
\hline EXP 10.6 & F2 & P40 & A2 & 1,602 & 1,519 & 1,568 \\
\hline EXP 10.7 & F2 & P360 & A5 & 2,212 & 2,253 & 2,223 \\
\hline EXP 10.8 & F2 & P360 & A2 & 1,929 & 1,881 & 1,881 \\
\hline
\end{tabular}

Tabela 5.29: Filtro de intervalo com multi-agentes: Valores de utilidade (número de insetos capturados) obtidos no estudo reduzido transformado. 
Os testes visuais que validam o modelo são apresentados na figura 5.18.

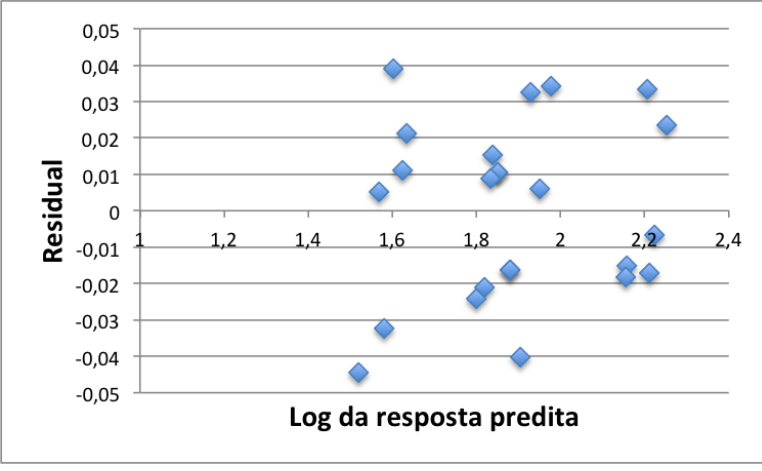

(a) Gráfico de dispersão.

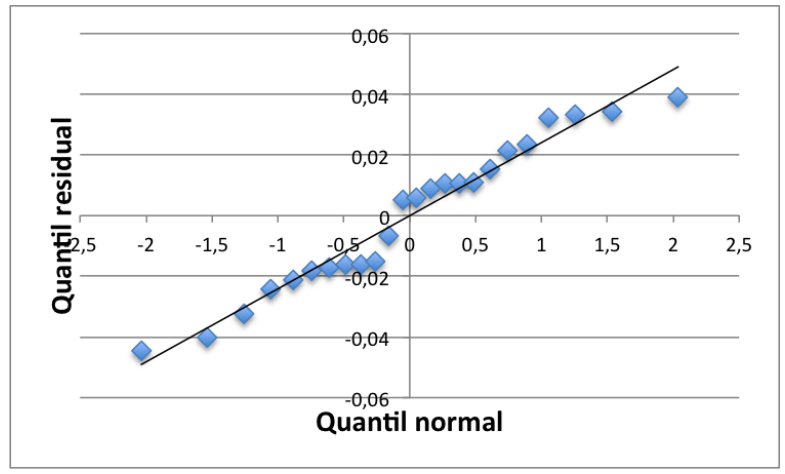

(b) Gráfico do quantil-quantil normal.

Figura 5.18: Multi-agentes: Testes visuais do estudo reduzido transformado sobre valores de utilidade.

A variação atribuída a cada fator e interação está apresentada na tabela 5.30. Nela é possível ver que, diferentemente de quando se utilizou o filtro de intervalo em um cenário com um único agente (Tabela 5.8), a interferência do filtro de intervalo nesse cenário multi-agente foi praticamente zero. Isto sugere que a existência de múltiplos agentes fez com que não perceber uma grande parte dos insetos não causasse perda no número total de capturas. Tal resultado pode ser atribuído ao fato de que os agentes percebiam e levavam em conta a posição dos outros agentes, ocupando uma maior porção do grid, e consequentemente capturavam uma quantidade de insetos praticamente igual à que seria capturada se houvesse um único agente que percebesse todos os insetos.

\begin{tabular}{|l|c|}
\hline Fator & Variação atribuída \\
\hline Número de percepções (P) & $62,56 \%$ \\
\hline Filtro (F) & $0,02 \%$ \\
\hline Número de Agentes (A) & $35,10 \%$ \\
\hline Interação entre P e F & $0,05 \%$ \\
\hline Interação entre A e F & $0,90 \%$ \\
\hline Interação entre P e A & $0,17 \%$ \\
\hline Interação entre P, A e F & $0,04 \%$ \\
\hline Erro de medição & $1,16 \%$ \\
\hline
\end{tabular}

Tabela 5.30: Multi-agentes: Variação de cada fator do estudo sobre a interferência na função de utilidade.

Estes três conjuntos de experimentos mostraram então que foi possível construir um filtro de percepção para um cenário multo-agentes que reduziu significativamente o tempo de processamento necessário para o conjunto de agentes responder ao simulador, sem que a utilidade global do conjunto de agentes fosse afetada. 


\section{Capítulo 6}

\section{Conclusões}

\subsection{Considerações finais}

Esse trabalho abordou o problema da ausência de controle sobre as percepções na execução do ciclo de raciocínio de agentes BDI, mais particularmente em agentes programados em Jason. Não havendo alguma forma de percepção direcionada ao objetivo, o agente pode ser inundado por informações irrelevantes causando um aumento injustificado do tempo de processamento. Este aumento tem grande impacto quando se deseja integrar tais agentes a sistemas de simulação discretos externos, que demandam dos agentes respostas num limite de tempo pré-determinado. Em alguns casos, pode-se até mesmo inviabilizar o uso de agentes BDI em cenários muito competitivos, tais como RoboCup abordada por Pereira et al. (2012) e MAPC abordado por Ahlbrecht et al. (2013)

Como forma de reduzir a ocorrência deste problema e dar maior segurança aos desenvolvedores no uso do Jason em sistemas de simulação, foi proposto neste trabalho a inclusão de um mecanismo de filtragem das percepções para o interpretador do Jason que visa remover percepções desnecessárias, de forma a reduzir o tempo de processamento dos agentes.

Esse mecanismo foi implementado no interpretador Jason e pode ser utilizado pelo usuário através da criação de filtros pré-definidos que especificam quais as crenças que devem e quais as que não devem ser processadas pelo agente em uma determinada situação, conforme descrito por Stabile Jr. e Sichman (2015a). Além disso, através de uma nova ação interna, é possível alterar o filtro utilizado pelo agente em função do seu objetivo atual durante a execução dos seus planos.

O mecanismo proposto foi então aplicado a três cenários que utilizaram um simulador base, onde foram testados e analisados o uso de filtros de intervalo, tanto em um ambiente com um único agente como feito por Stabile Jr. e Sichman (2015b) como em um ambiente multi-agentes, e o uso de filtros de propriedade em um cenário com um único agente, com duas implementações distintas.

Testes estatísticos foram realizados, utilizando técnicas provenientes do domínio de análise de desempenho, em particular tendo como base os dois modelos de design de experimentos apresentados por Jain (1991). O primeiro modelo, denominado $2^{k} r$, permitiu a realização de um estudo de tamanho reduzido que possibilitou uma visão inicial da influência dos fatores nos valores medidos, de modo a justificar a necessidade de realização de experimentos mais completos. No segundo modelo, denominado fatorial completo, permitiu uma visão mais precisa da influência dos fatores com o objetivo de validar os resultados obtidos pelo primeiro modelo e analisar filtros diferentes, no caso do estudo dos filtros de intervalo.

Nos casos de estudo analisados, os filtros atingiram o objetivo de reduzir o tempo de processamento do agente na grande maioria dos casos, chegando em alguns experimentos a obter uma melhoria de até $80 \%$ no desempenho dos agentes.

No que diz respeito ao valor de utilidade obtido pelos agentes com o uso destes filtros, houve uma pequena redução, em torno de 7\%, no valor de utilidade obtido com o uso de filtros de intervalo em ambiente monoagente; nos outros casos, quando utilizamos este mesmo filtro de intervalo com múltiplos agentes ou quando testamos o uso de filtros de propriedade, praticamente não houve alteração no valor de utilidade obtido pelos agentes. 
Além disto, é importante salientar que o simples uso de filtros de percepção causa um aumento de processamento dos agentes. Assim, o uso dos filtros somente é interessante se o tempo que seria gasto pelo interpretador Jason para atualizar e processar as crenças provenientes destas percepções removidas for maior do que o tempo demandado pela função de filtragem. Nos experimentos realizados, obtivemos um resultados intuitivo: vale a pena usar filtros se houver muits percepções a filtrar. Caso o filtro tenha de avaliar muitos literais, mas remova apenas uma porção muito pequena dos mesmos, possivelmente ocorrerá um aumento indesejado no tempo de processamento do agente.

Por fim, os resultados obtidos nos permitiram responder às perguntas realizadas na seção 1.2:

1. Dado um certo limite de tempo de resposta do simulador, é possível para o agente processar todas as informações provenientes das percepções?

A partir dos resultados obtidos em nossos experimentos, pode-se constatar que dependendo do limite de tempo de resposta do simulador, é possível se prever aproximadamente se o agente terá ou não tempo para processar todas as percepções e executar suas ações. Para tal, é necessário construir um gráfico semelhante o da Figura 5.5, e verificar se no tempo limite a porcentagem de ações enviadas corresponde a $100 \%$.

2. Ao utilizar um filtro de percepção, é possível melhorar o tempo de resposta?

Os experimentos mostraram que ao utilizar os filtros de percepção, os agentes obtêm um controle maior sobre o tempo de resposta, reduzindo-o significativamente através da escolha de filtros mais restritivos. Em particular, os resultados mostraram casos em que um agente não conseguiria responder a tempo ao simulador sem o uso de filtros de percepção.

3. Caso melhore, como se identificaria o filtro adequado?

Dado que os experimentos tornaram possível identificar, para um dado tempo limite de resposta, quais dos filtros testados permitem que a porcentagem de ações enviadas corresponda a $100 \%$, poderia-se escolher dentre esses o menos restritivo, ou seja, o que oferece maior informação ao agente.

4. Qual seria a influência dos filtros de percepção no valor de utilidade do agente?

Os estudos estatísticos obtidos nos casos de estudo mostraram que foi possível utilizar filtros que não causam perda significativa no valor de utilidade dos agentes. Observou-se também que em alguns casos, filtros que causem perda na utilidade individual de um agente podem amortizar tal perda quando utilizados em um sistema multi-agentes. Finalmente, em alguns casos a perde de utilidade permite transformar uma situação onde um agente não teria tempo hábil para executar uma ação no limite de tempo fixado pelo simulador (utilidade zero ou negativa) para outra, onde o agente executaria uma ação subótima.

\subsection{Trabalhos futuros}

Como próximos passos, alguns pontos deste trabalho merecem pesquisas mais aprofundadas:

1. Observamos nos experimentos que existe um limiar a partir do qual o uso dos filtros de percepção causa um impacto positivo sobre o tempo de processamento do agente. Seria interessante então analisar esse aspecto com maior profundidade, para avaliar se é possível definir formalmente esse limiar, de modo a auxiliar os desenvolvedores de agentes Jason a projetar seus agentes e seus filtros;

2. Os experimentos realizados foram restritos a um único domínio. Um próximo passo seria verificar a aplicação dos filtros de percepção em outros domínios, inclusive em alguma das competições citadas, como o MAPC, que possui uma variedade de papéis de agentes que utilizam informações diferentes para tomar ações também distintas;

3. Somente foram analisados filtros de intervalo e de propriedade. Dado que alguns filtros se saem melhor do que outros em determinados casos, efetuar testes com outros métodos de filtragem 
pode fornecer novas perspectivas de utilização em cenários diferentes.Uma possibilidade seria eliminar percepções de elementos que não geram eventos para os quais haja planos ou ainda propriedades do ambiente que não sejam utilizadas em nenhum plano do agente.

Apesar dos filtros propostos auxiliarem os desenvolvedores de agentes Jason fornecendo maior controle sobre o tempo de processamento, ainda não é possível garantir que o agente fornecerá uma resposta dentro de um tempo limite especificado. Esta propriedade seria de grande valia em competições de agentes. Para isso, seria necessário um novo mecanismo que pudesse manipular o ciclo de raciocínio do Jason e coordenar o tempo de processamento de cada função, podendo inclusive alterar dinamicamente os filtros de percepção de forma a reduzir o tempo de processamento quando necessário. 
CONCLUSÕES 


\section{Apêndice A}

\section{Valores medidos com uso de filtros de intervalo no cenário monoagente}

A tabela A.1 apresenta os valores de tempo medidos em nanosegundos para o estudo completo sobre o tempo de processamento de filtros de intervalo.

\begin{tabular}{|c|c|c|c|c|c|}
\hline Experimento & Percepções & Filtro & \multicolumn{3}{|c|}{95 percentil } \\
\hline EXP 2.1 & $\mathrm{P} 40$ & $\mathrm{~F} 2$ & 3505788 & 3234758 & 3553195 \\
\hline EXP 2.2 & $\mathrm{P} 40$ & F5 & 4546453 & 4073197 & 4622397 \\
\hline EXP 2.3 & $\mathrm{P} 40$ & F7 & 5089825 & 4971696 & 5581141 \\
\hline EXP 2.4 & $\mathrm{P} 40$ & F0 & 6744400 & 7336382 & 7631987 \\
\hline EXP 2.5 & P80 & F2 & 3739792 & 3743885 & 3510352 \\
\hline EXP 2.6 & P80 & F5 & 4499247 & 5123518 & 5278289 \\
\hline EXP 2.7 & P80 & F7 & 5740462 & 5864020 & 6055759 \\
\hline EXP 2.8 & P80 & F0 & 9361550 & 9832705 & 9260685 \\
\hline EXP 2.9 & P120 & F2 & 4064398 & 4315664 & 4133840 \\
\hline EXP 2.10 & P120 & F5 & 5530913 & 5213625 & 5816396 \\
\hline EXP 2.11 & P120 & F7 & 6575537 & 6833461 & 6597482 \\
\hline EXP 2.12 & P120 & F0 & 10776034 & 10263953 & 12497518 \\
\hline EXP 2.13 & P160 & F2 & 4162295 & 4287424 & 4613842 \\
\hline EXP 2.14 & P160 & F5 & 6163699 & 6308279 & 6500983 \\
\hline EXP 2.15 & P160 & F7 & 6531710 & 7065343 & 7945270 \\
\hline EXP 2.16 & P160 & F0 & 15688783 & 13188860 & 13068616 \\
\hline EXP 2.17 & P200 & F2 & 4132775 & 4446836 & 4498696 \\
\hline EXP 2.18 & P200 & F5 & 5632576 & 6107778 & 5915401 \\
\hline EXP 2.19 & P200 & F7 & 7263510 & 5218 & 8161350 \\
\hline EXP 2.20 & P200 & F0 & 18197572 & 13310866 & 13231903 \\
\hline EXP 2.21 & P240 & F2 & 4795679 & 4831346 & 4363098 \\
\hline EXP 2.22 & P240 & F5 & 7528428 & 6104440 & 7784464 \\
\hline EXP 2.23 & P240 & F7 & 8812875 & 8423980 & 10298067 \\
\hline EXP 2.24 & P240 & F0 & 19395737 & 22443356 & 18827792 \\
\hline EXP 2.25 & P280 & F2 & 467 & 803 & 4686350 \\
\hline EXP 2.26 & P280 & F5 & 5686431 & 6017220 & 6603150 \\
\hline EXP 2.27 & P280 & F7 & 8500038 & 8551874 & 7677240 \\
\hline EXP 2.28 & P280 & F0 & 21954307 & 25922429 & 20967431 \\
\hline EXP 2.29 & P320 & F2 & 4681683 & 4621802 & 5240278 \\
\hline EXP 2.30 & P320 & F5 & 6187360 & 5253 & 8019007 \\
\hline EXP 2.31 & P320 & F7 & 8040235 & 8273194 & 9918010 \\
\hline EXP 2.32 & P320 & F0 & 21387297 & 24885557 & 19289844 \\
\hline EXP 2.33 & P360 & F2 & 5129042 & 4904584 & 4907715 \\
\hline EXP 2.34 & P360 & F5 & 7376483 & 6567088 & 7601439 \\
\hline EXP 2.35 & P360 & F7 & 9715453 & 8688310 & 10653772 \\
\hline EXP 2.36 & P360 & F0 & 29534793 & 21788849 & 22990713 \\
\hline
\end{tabular}

Tabela A.1: Filtros de intervalo: Resultados do estudo completo sobre o tempo de processamento. 
APÊNDICE A 


\section{Apêndice B}

\section{Valores calculados com uso de filtros de intervalo no cenário monoagente}

A tabela B.1 apresenta os valores de tempo após a transformação logaritmica para o estudo completo sobre o tempo de processamento de filtros de intervalo.

\begin{tabular}{|c|c|c|c|c|c|}
\hline Experimento & Percepções & Filtro & \multicolumn{3}{|c|}{ Valores calculados } \\
\hline EXP 2.1 & P40 & F2 & 6,545 & 6,510 & 6,551 \\
\hline EXP 2.2 & P40 & F5 & 6,658 & 6,610 & 6,665 \\
\hline EXP 2.3 & P40 & F7 & 6,707 & 6,697 & 6,747 \\
\hline EXP 2.4 & P40 & F0 & 6,829 & 6,865 & 6,883 \\
\hline EXP 2.5 & P80 & F2 & 6,573 & 6,573 & 6,545 \\
\hline EXP 2.6 & P80 & F5 & 6,653 & 6,710 & 6,722 \\
\hline EXP 2.7 & P80 & F7 & 6,759 & 6,768 & 6,782 \\
\hline EXP 2.8 & P80 & F0 & 6,971 & 6,993 & 6,967 \\
\hline EXP 2.9 & P120 & F2 & 6,609 & 6,635 & 6,616 \\
\hline EXP 2.10 & P120 & F5 & 6,743 & 6,717 & 6,765 \\
\hline EXP 2.11 & P120 & F7 & 6,818 & 6,835 & 6,819 \\
\hline EXP 2.12 & P120 & F0 & 7,032 & 7,011 & 7,097 \\
\hline EXP 2.13 & P160 & F2 & 6,619 & 6,632 & 6,664 \\
\hline EXP 2.14 & P160 & F5 & 6,790 & 6,800 & 6,813 \\
\hline EXP 2.15 & P160 & F7 & 6,815 & 6,849 & 6,900 \\
\hline EXP 2.16 & P160 & F0 & 7,196 & 7,120 & 7,116 \\
\hline EXP 2.17 & P200 & F2 & 6,616 & 6,648 & 6,653 \\
\hline EXP 2.18 & P200 & F5 & 6,751 & 6,786 & 6,772 \\
\hline EXP 2.19 & P200 & F7 & 6,861 & 6,886 & 6,912 \\
\hline EXP 2.20 & P200 & F0 & 7,260 & 7,124 & 7,122 \\
\hline EXP 2.21 & P240 & F2 & 6,681 & 6,684 & 6,640 \\
\hline EXP 2.22 & P240 & F5 & 6,877 & 6,786 & 6,891 \\
\hline EXP 2.23 & P240 & F7 & 6,945 & 6,926 & 7,013 \\
\hline EXP 2.24 & P240 & F0 & 7,288 & 7,351 & 7,275 \\
\hline EXP 2.25 & P280 & F2 & 6,670 & 6,660 & 6,671 \\
\hline EXP 2.26 & P280 & F5 & 6,755 & 6,779 & 6,820 \\
\hline EXP 2.27 & P280 & F7 & 6,929 & 6,932 & 6,885 \\
\hline EXP 2.28 & P280 & F0 & 7,341 & 7,414 & 7,321 \\
\hline EXP 2.29 & P320 & 6,670 & 6,665 & 6,719 \\
\hline EXP 2.30 & P320 & F5 & 6,792 & 6,847 & 6,904 \\
\hline EXP 2.31 & P320 & 6,905 & 6,918 & 6,996 \\
\hline EXP 2.32 & P320 & 7,330 & 7,396 & 7,285 \\
\hline EXP 2.33 & P360 & F2 & 6,710 & 6,691 & 6,691 \\
\hline EXP 2.34 & P360 & F5 & 6,868 & 6,817 & 6,881 \\
\hline EXP 2.35 & P360 & F7 & 6,987 & 6,939 & 7,028 \\
\hline EXP 2.36 & P360 & F0 & 7,470 & 7,338 & 7,362 \\
\hline
\end{tabular}

Tabela B.1: Filtros de intervalo: Resultados do estudo completo sobre o tempo de processamento. 
APÊNDICE B 


\section{Apêndice C}

\section{Valores medidos com uso de filtros de intervalo no cenário multi-agentes}

A tabela C.1 apresenta os valores de tempo medidos para o estudo completo sobre o tempo de processamento de filtros de intervalo no cenário multi-agentes.

Tabela C.1: Multi-agentes: Resultados do estudo completo sobre o tempo de processamento.

\begin{tabular}{|c|c|c|c|c|c|c|}
\hline Experimento & Percepções & Agentes & Filtro & \multicolumn{3}{|c|}{ Valores calculados } \\
\hline EXP 9.1 & P40 & A2 & F2 & 11134680 & 8166400 & 3933676 \\
\hline EXP 9.2 & $\mathrm{P} 40$ & A2 & F5 & 6494111 & 4872038 & 6134418 \\
\hline EXP 9.3 & $\mathrm{P} 40$ & A2 & F7 & 6274693 & 6189297 & 6673148 \\
\hline EXP 9.4 & $\mathrm{P} 40$ & $\mathrm{~A} 2$ & F0 & 8735715 & 8198393 & 8622323 \\
\hline EXP 9.5 & $\mathrm{P} 40$ & A3 & F2 & 4542832 & 3849412 & 4506333 \\
\hline EXP 9.6 & $\mathrm{P} 40$ & A3 & F5 & 5836538 & 5613189 & 4620522 \\
\hline EXP 9.7 & $\mathrm{P} 40$ & A3 & F7 & 6944761 & 6987039 & 4973497 \\
\hline EXP 9.8 & $\mathrm{P} 40$ & A3 & F0 & 8385030 & 8486956 & 7697438 \\
\hline EXP 9.9 & $\mathrm{P} 40$ & A4 & F2 & 4063636 & 4992932 & 5450872 \\
\hline EXP 9.10 & $\mathrm{P} 40$ & A4 & F5 & 7464122 & 6522229 & 6587260 \\
\hline EXP 9.11 & $\mathrm{P} 40$ & A4 & F7 & 6552578 & 7638805 & 8806269 \\
\hline EXP 9.12 & $\mathrm{P} 40$ & $\mathrm{~A} 4$ & F0 & 10044551 & 10336273 & 9153379 \\
\hline EXP 9.13 & $\mathrm{P} 40$ & A5 & $\mathrm{F} 2$ & 4000203 & 5305418 & 5204463 \\
\hline EXP 9.14 & $\mathrm{P} 40$ & A5 & F5 & 7839327 & 7022089 & 4858253 \\
\hline EXP 9.15 & $\mathrm{P} 40$ & A5 & F7 & 6644939 & 7181452 & 6640825 \\
\hline EXP 9.16 & $\mathrm{P} 40$ & A5 & F0 & 13329574 & 10185855 & 8818994 \\
\hline EXP 9.17 & $\mathrm{P} 80$ & $\overline{\mathrm{A} 2}$ & $\overline{\mathrm{F} 2}$ & 4178624 & 3612080 & 3838560 \\
\hline EXP 9.18 & P80 & $\mathrm{A} 2$ & F5 & 5887795 & 4389968 & 6806098 \\
\hline EXP 9.19 & $\mathrm{P} 80$ & A2 & F7 & 7366129 & 5637469 & 8110088 \\
\hline EXP 9.20 & $\mathrm{P} 80$ & $\mathrm{~A} 2$ & F0 & 10175215 & 10617541 & 10493750 \\
\hline EXP 9.21 & P80 & A3 & $\mathrm{F} 2$ & 4058832 & 3865694 & 4524392 \\
\hline EXP 9.22 & $\mathrm{P} 80$ & A3 & F5 & 6245068 & 4900092 & 6857902 \\
\hline EXP 9.23 & $\mathrm{P} 80$ & A3 & F7 & 7731262 & 8001270 & 7790108 \\
\hline EXP 9.24 & P80 & A3 & F0 & 12615985 & 13779112 & 11926854 \\
\hline EXP 9.25 & P80 & A4 & $\mathrm{F} 2$ & 5373048 & 5211617 & 4227420 \\
\hline EXP 9.26 & $\mathrm{P} 80$ & A4 & F5 & 6352085 & 6487584 & 6107339 \\
\hline EXP 9.27 & P80 & $\mathrm{A} 4$ & F7 & 9080044 & 7477385 & 8901112 \\
\hline EXP 9.28 & $\mathrm{P} 80$ & A4 & F0 & 15808369 & 15170535 & 15589556 \\
\hline EXP 9.29 & P80 & A5 & F2 & 7043758 & 4246438 & 5577331 \\
\hline EXP 9.30 & P80 & A5 & F5 & 7848524 & 6998857 & 8626363 \\
\hline EXP 9.31 & $\mathrm{P} 80$ & A5 & F7 & 12145295 & 8960125 & 6685936 \\
\hline EXP 9.32 & P80 & A5 & F0 & 17421576 & 20184227 & 16035903 \\
\hline EXP 9.33 & P120 & A2 & $\mathrm{F} 2$ & 4845641 & 4289584 & 4072585 \\
\hline EXP 9.34 & P120 & $\mathrm{A} 2$ & F5 & 6391625 & 5079563 & 5137688 \\
\hline EXP 9.35 & P120 & A2 & F7 & 7837782 & 7150570 & 7319682 \\
\hline
\end{tabular}


Tabela C.1 - Continuação da página anterior

\begin{tabular}{|c|c|c|c|c|c|c|}
\hline Experimento & Percepções & Agentes & Filtro & \multicolumn{3}{|c|}{ Valores calculados } \\
\hline EXP 9.36 & P120 & A2 & F0 & 14097893 & 13996370 & 14427415 \\
\hline EXP 9.37 & $\mathrm{P} 120$ & A3 & F2 & 4562700 & 4610400 & 3997253 \\
\hline EXP 9.38 & P120 & A3 & F5 & 5658860 & 6183470 & 5762560 \\
\hline EXP 9.39 & P120 & A3 & F7 & 7066116 & 7078649 & 7935558 \\
\hline EXP 9.40 & P120 & A3 & F0 & 16472941 & 16659776 & 16075960 \\
\hline EXP 9.41 & P120 & A4 & F2 & 4501867 & 5018900 & 5157922 \\
\hline EXP 9.42 & $\mathrm{P} 120$ & $\mathrm{~A} 4$ & F5 & 8020354 & 9357908 & 7769919 \\
\hline EXP 9.43 & P120 & A4 & F7 & 8538473 & 9918890 & 9323520 \\
\hline EXP 9.44 & P120 & A4 & F0 & 19088632 & 15978877 & 17965897 \\
\hline EXP 9.45 & P120 & A5 & F2 & 5761568 & 7534541 & 6707266 \\
\hline EXP 9.46 & P120 & A5 & F5 & 9404635 & 6384492 & 8812959 \\
\hline EXP 9.47 & P120 & A5 & F7 & 11464197 & 10719427 & 10141793 \\
\hline EXP 9.48 & P120 & A5 & F0 & 21290622 & 23081088 & 21116390 \\
\hline EXP 9.49 & P160 & $\mathrm{A} 2$ & F2 & 4386558 & 4260141 & 4154076 \\
\hline EXP 9.50 & P160 & $\mathrm{A} 2$ & F5 & 6179946 & 5629540 & 6664735 \\
\hline EXP 9.51 & P160 & A2 & F7 & 8960254 & 8327415 & 10785637 \\
\hline EXP 9.52 & P160 & A2 & F0 & 18591367 & 17829649 & 18890647 \\
\hline EXP 9.53 & P160 & A3 & F2 & 4563490 & 4456496 & 4971642 \\
\hline EXP 9.54 & $\mathrm{P} 160$ & A3 & F5 & 8027433 & 6291160 & 7518894 \\
\hline EXP 9.55 & P160 & A3 & F7 & 9261076 & 11085286 & 9740825 \\
\hline EXP 9.56 & P160 & A3 & F0 & 25151006 & 21766258 & 15560544 \\
\hline EXP 9.57 & P160 & A4 & F2 & 5694493 & 4877210 & 5077177 \\
\hline EXP 9.58 & P160 & A4 & F5 & 8580379 & 9742798 & 9184445 \\
\hline EXP 9.59 & P160 & $\mathrm{A} 4$ & F7 & 11120230 & 10380277 & 11383872 \\
\hline EXP 9.60 & P160 & A4 & F0 & 27336786 & 30363180 & 24464994 \\
\hline EXP 9.61 & P160 & A5 & F2 & 5871568 & 7668548 & 5430580 \\
\hline EXP 9.62 & P160 & A5 & F5 & 10035473 & 10657859 & 11173954 \\
\hline EXP 9.63 & P160 & A5 & F7 & 14780787 & 11824696 & 10660055 \\
\hline EXP 9.64 & P160 & A5 & F0 & 35723735 & 30811294 & 29416289 \\
\hline EXP 9.65 & P200 & A2 & F2 & 4209552 & 4543530 & 4341820 \\
\hline EXP 9.66 & P200 & A2 & F5 & 6552677 & 6385441 & 6433434 \\
\hline EXP 9.67 & $\overline{\mathrm{P} 200}$ & $\mathrm{~A} 2$ & F7 & 8378244 & 8956076 & 8931057 \\
\hline EXP 9.68 & P200 & A2 & F0 & 22250773 & 21140020 & 21429190 \\
\hline EXP 9.69 & P200 & A3 & F2 & 4969613 & 4963372 & 4674510 \\
\hline EXP 9.70 & P200 & A3 & F5 & 8774142 & 6660845 & 8657996 \\
\hline EXP 9.71 & P200 & A3 & F7 & 10188210 & 10136896 & 11493335 \\
\hline EXP 9.72 & $\overline{\mathrm{P} 200}$ & A3 & F0 & 29495854 & 26228067 & 28595042 \\
\hline EXP 9.73 & P200 & A4 & F2 & 5989430 & 5677043 & 4634947 \\
\hline EXP 9.74 & P200 & A4 & F5 & 8802850 & 9939561 & 9385053 \\
\hline EXP 9.75 & P200 & $\mathrm{A} 4$ & F7 & 13902432 & 12043362 & 16093867 \\
\hline EXP 9.76 & P200 & A4 & F0 & 39501888 & 29533477 & 33150599 \\
\hline EXP 9.77 & $\overline{\mathrm{P} 200}$ & A5 & F2 & 8276647 & 5988253 & 9061912 \\
\hline EXP 9.78 & P200 & A5 & F5 & 10538143 & 10180426 & 12859539 \\
\hline EXP 9.79 & P200 & A5 & F7 & 15682543 & 14768274 & 14617054 \\
\hline EXP 9.80 & P200 & A5 & F0 & 37861570 & 34234368 & 43685720 \\
\hline EXP 9.81 & P240 & A2 & F2 & 4118671 & 4677043 & 5091483 \\
\hline EXP 9.82 & P240 & A2 & F5 & 6221650 & 7163993 & 7397607 \\
\hline EXP 9.83 & $\overline{\mathrm{P}} 240$ & $\mathrm{~A} 2$ & F7 & 9381134 & 8679630 & 10948368 \\
\hline EXP 9.84 & P240 & A2 & F0 & 26891353 & 16649898 & 27880759 \\
\hline EXP 9.85 & P240 & A3 & F2 & 4727766 & 5835573 & 6527634 \\
\hline EXP 9.86 & P240 & A3 & F5 & 7975915 & 8639912 & 8493490 \\
\hline EXP 9.87 & $\mathrm{P} 240$ & A3 & F7 & 11280548 & 12565165 & 10731498 \\
\hline EXP 9.88 & $\mathrm{P} 240$ & A3 & F0 & 41342772 & 36484982 & 27546846 \\
\hline EXP 9.89 & P240 & A4 & F2 & 5817156 & 5600024 & 5337594 \\
\hline EXP 9.90 & P240 & A4 & F5 & 9843584 & 11656974 & 10639620 \\
\hline EXP 9.91 & P240 & A4 & F7 & 15774915 & 13443495 & 18923931 \\
\hline EXP 9.92 & P240 & A4 & F0 & 36117255 & 45374917 & 38703950 \\
\hline
\end{tabular}


Tabela C.1 - Continuação da página anterior

\begin{tabular}{|c|c|c|c|c|c|c|}
\hline Experimento & Percepções & Agentes & Filtro & \multicolumn{3}{|c|}{ Valores calculados } \\
\hline EXP 9.93 & P240 & A5 & F2 & 6738798 & 7331723 & 8151788 \\
\hline EXP 9.94 & P240 & A5 & F5 & 12867140 & 9910338 & 10016958 \\
\hline EXP 9.95 & P240 & A5 & F7 & 14261953 & 17440956 & 14792165 \\
\hline EXP 9.96 & P240 & A5 & F0 & 46461560 & 42602930 & 44409926 \\
\hline EXP 9.97 & P280 & A2 & F2 & 4567009 & 4164763 & 4747322 \\
\hline EXP 9.98 & P280 & $\mathrm{A} 2$ & F5 & 7960768 & 7839474 & 8299370 \\
\hline EXP 9.99 & $\mathrm{P} 280$ & A2 & F7 & 10369332 & 11981342 & 9766928 \\
\hline EXP 9.100 & P280 & A2 & F0 & 29589530 & 28623413 & 32646300 \\
\hline EXP 9.101 & $\mathrm{P} 280$ & A3 & F2 & 4963290 & 6133178 & 5717413 \\
\hline EXP 9.102 & P280 & A3 & F5 & 9551916 & 8629988 & 9404982 \\
\hline EXP 9.103 & $\mathrm{P} 280$ & A3 & F7 & 13968047 & 11497002 & 13424988 \\
\hline EXP 9.104 & $\mathrm{P} 280$ & A3 & F0 & 47515587 & 37937690 & 38958874 \\
\hline EXP 9.105 & P280 & $\mathrm{A} 4$ & F2 & 6876844 & 7218703 & 6283829 \\
\hline EXP 9.106 & P280 & A4 & F5 & 11775912 & 13553251 & 11527503 \\
\hline EXP 9.107 & $\mathrm{P} 280$ & A4 & F7 & 16078899 & 17930608 & 17093840 \\
\hline EXP 9.108 & P280 & A4 & F0 & 48526117 & 44599496 & 51707927 \\
\hline EXP 9.109 & P280 & A5 & $\mathrm{F} 2$ & 7551504 & 7747817 & 8510868 \\
\hline EXP 9.110 & P280 & A5 & F5 & 15278357 & 15714310 & 13012598 \\
\hline EXP 9.111 & P280 & A5 & F7 & 17413098 & 19045148 & 15886389 \\
\hline EXP 9.112 & $\mathrm{P} 280$ & A5 & F0 & 57543163 & 49623220 & 43841960 \\
\hline EXP 9.113 & P320 & $\mathrm{A} 2$ & F2 & 5370433 & 5718522 & 4649675 \\
\hline EXP 9.114 & P320 & A2 & F5 & 7922053 & 9388354 & 8207008 \\
\hline EXP 9.115 & P320 & A2 & F7 & 13289612 & 10828718 & 10726888 \\
\hline EXP 9.116 & P320 & $\mathrm{A} 2$ & F0 & 38302268 & 41651870 & 37465375 \\
\hline EXP 9.117 & P320 & A3 & $\mathrm{F} 2$ & 5418264 & 5644252 & 5826307 \\
\hline EXP 9.118 & P320 & A3 & F5 & 10354302 & 9629500 & 11950779 \\
\hline EXP 9.119 & P320 & A3 & F7 & 18093166 & 14389064 & 13342870 \\
\hline EXP 9.120 & P320 & A3 & F0 & 54217858 & 43709669 & 53145867 \\
\hline EXP 9.121 & P320 & A4 & $\mathrm{F} 2$ & 7836897 & 6864322 & 6847705 \\
\hline EXP 9.122 & P320 & A4 & F5 & 11315250 & 10629477 & 13519653 \\
\hline EXP 9.123 & P320 & A4 & F7 & 16661919 & 16594890 & 21146242 \\
\hline EXP 9.124 & P320 & A4 & F0 & 54092752 & 53469205 & 49280125 \\
\hline EXP 9.125 & P320 & A5 & F2 & 7860195 & 7770414 & 10182245 \\
\hline EXP 9.126 & P320 & A5 & F5 & 15961152 & 16683395 & 13335659 \\
\hline EXP 9.127 & P320 & A5 & F7 & 19500609 & 19232518 & 18965940 \\
\hline EXP 9.128 & P320 & A5 & F0 & 59899299 & 63355252 & 68996413 \\
\hline EXP 9.129 & P360 & A2 & F2 & 5968769 & 4911250 & 5324024 \\
\hline EXP 9.130 & P360 & A2 & F5 & 8248722 & 8293423 & 8014140 \\
\hline EXP 9.131 & P360 & A2 & F7 & 9403520 & 12554200 & 13437498 \\
\hline EXP 9.132 & P360 & A2 & F0 & 43518085 & 32293954 & 34696250 \\
\hline EXP 9.133 & P360 & A3 & F2 & 6060209 & 6089987 & 7092330 \\
\hline EXP 9.134 & P360 & A3 & F5 & 9828419 & 10749908 & 13029656 \\
\hline EXP 9.135 & P360 & A3 & F7 & 14513260 & 13346910 & 17604112 \\
\hline EXP 9.136 & P360 & A3 & F0 & 43095035 & 54684120 & 39878021 \\
\hline EXP 9.137 & P360 & A4 & $\mathrm{F} 2$ & 7766505 & 6818405 & 6457483 \\
\hline EXP 9.138 & P360 & A4 & F5 & 11039320 & 12127200 & 13815561 \\
\hline EXP 9.139 & P360 & A4 & F7 & 14868030 & 21563585 & 18117637 \\
\hline EXP 9.140 & P360 & A4 & F0 & 59942104 & 64907193 & 47951716 \\
\hline EXP 9.141 & P360 & A5 & F2 & 9602709 & 9293357 & 8344702 \\
\hline EXP 9.142 & P360 & A5 & F5 & 17985215 & 16465852 & 16302464 \\
\hline EXP 9.143 & P360 & A5 & F7 & 18812147 & 22186793 & 18641339 \\
\hline EXP 9.144 & P360 & A5 & F0 & 67877745 & 69167287 & 81490780 \\
\hline
\end{tabular}


APÊNDICE C 


\section{Apêndice D}

\section{Valores calculados com uso de filtros de intervalo no cenário multi-agentes}

A tabela D.1 apresenta os valores de tempo transformados logaritmicamente para o estudo completo sobre o tempo de processamento de filtros de intervalo no cenário multi-agentes.

Tabela D.1: Multi-agentes: Resultados transformados do estudo completo sobre o tempo de processamento.

\begin{tabular}{|c|c|c|c|c|c|c|}
\hline Experimento & Percepções & Agentes & Filtro & \multicolumn{3}{|c|}{ Valores calculados } \\
\hline EXP 9.1 & P40 & $\mathrm{A} 2$ & F2 & 7,047 & 6,912 & 6,595 \\
\hline EXP 9.2 & $\mathrm{P} 40$ & A2 & F5 & 6,813 & 6,688 & 6,788 \\
\hline EXP 9.3 & $\mathrm{P} 40$ & A2 & F7 & 6,798 & 6,792 & 6,824 \\
\hline EXP 9.4 & $\mathrm{P} 40$ & $\overline{\mathrm{A} 2}$ & F0 & 6,941 & 6,914 & 6,936 \\
\hline EXP 9.5 & $\mathrm{P} 40$ & A3 & $\mathrm{F} 2$ & 6,657 & 6,585 & 6,654 \\
\hline EXP 9.6 & $\mathrm{P} 40$ & A3 & F5 & 6,766 & 6,749 & 6,665 \\
\hline EXP 9.7 & $\mathrm{P} 40$ & $\bar{A} 3$ & F7 & 6,842 & 6,844 & 6,697 \\
\hline EXP 9.8 & $\mathrm{P} 40$ & A3 & F0 & 6,924 & 6,929 & 6,886 \\
\hline EXP 9.9 & $\mathrm{P} 40$ & $\mathrm{~A} 4$ & $\mathrm{~F} 2$ & 6,609 & 6,698 & 6,736 \\
\hline EXP 9.10 & $\mathrm{P} 40$ & A4 & F5 & 6,873 & 6,814 & 6,819 \\
\hline EXP 9.11 & $\mathrm{P} 40$ & A4 & F7 & 6,816 & 6,883 & 6,945 \\
\hline EXP 9.12 & $\mathrm{P} 40$ & $\mathrm{~A} 4$ & F0 & 7,002 & 7,014 & 6,962 \\
\hline EXP 9.13 & $\mathrm{P} 40$ & A5 & F2 & 6,602 & 6,725 & 6,716 \\
\hline EXP 9.14 & $\mathrm{P} 40$ & A5 & F5 & 6,894 & 6,846 & 6,686 \\
\hline EXP 9.15 & $\mathrm{P} 40$ & A5 & F7 & 6,822 & 6,856 & 6,822 \\
\hline EXP 9.16 & $\mathrm{P} 40$ & A5 & F0 & 7,125 & 7,008 & 6,945 \\
\hline EXP 9.17 & $\mathrm{P} 80$ & $\mathrm{~A} 2$ & $\mathrm{~F} 2$ & 6,621 & 6,558 & 6,584 \\
\hline EXP 9.18 & $\mathrm{P} 80$ & $\mathrm{~A} 2$ & F5 & 6,770 & 6,642 & 6,833 \\
\hline EXP 9.19 & $\mathrm{P} 80$ & A2 & F7 & 6,867 & 6,751 & 6,909 \\
\hline EXP 9.20 & $\mathrm{P} 80$ & $\mathrm{~A} 2$ & F0 & 7,008 & 7,026 & 7,021 \\
\hline EXP 9.21 & P80 & A3 & F2 & 6,608 & 6,587 & 6,656 \\
\hline EXP 9.22 & $\mathrm{P} 80$ & A3 & F5 & 6,796 & 6,690 & 6,836 \\
\hline EXP 9.23 & $\mathrm{P} 80$ & A3 & F7 & 6,888 & 6,903 & 6,892 \\
\hline EXP 9.24 & $\mathrm{P} 80$ & A3 & F0 & 7,101 & 7,139 & 7,077 \\
\hline EXP 9.25 & $\mathrm{P} 80$ & $\mathrm{~A} 4$ & F2 & 6,730 & 6,717 & 6,626 \\
\hline EXP 9.26 & P80 & A4 & F5 & 6,803 & 6,812 & 6,786 \\
\hline EXP 9.27 & P80 & $\mathrm{A} 4$ & F7 & 6,958 & 6,874 & 6,949 \\
\hline EXP 9.28 & $\mathrm{P} 80$ & $\mathrm{~A} 4$ & F0 & 7,199 & 7,181 & 7,193 \\
\hline EXP 9.29 & $\mathrm{P} 80$ & A5 & F2 & 6,848 & 6,628 & 6,746 \\
\hline EXP 9.30 & P80 & A5 & F5 & 6,895 & 6,845 & 6,936 \\
\hline EXP 9.31 & $\mathrm{P} 80$ & A5 & F7 & 7,084 & 6,952 & 6,825 \\
\hline EXP 9.32 & P80 & A5 & F0 & 7,241 & 7,305 & 7,205 \\
\hline EXP 9.33 & P120 & A2 & F2 & 6,685 & 6,632 & 6,610 \\
\hline EXP 9.34 & P120 & $\mathrm{A} 2$ & F5 & 6,806 & 6,706 & 6,711 \\
\hline EXP 9.35 & P120 & A2 & F7 & 6,894 & 6,854 & 6,864 \\
\hline
\end{tabular}


Tabela D.1 - Continuação da página anterior

\begin{tabular}{|c|c|c|c|c|c|c|}
\hline Experimento & Percepções & Agentes & Filtro & \multicolumn{3}{|c|}{ Valores calculados } \\
\hline EXP 9.36 & P120 & A2 & F0 & 7,149 & 7,146 & 7,159 \\
\hline EXP 9.37 & P120 & A3 & F2 & 6,659 & 6,664 & 6,602 \\
\hline EXP 9.38 & P120 & A3 & F5 & 6,753 & 6,791 & 6,761 \\
\hline EXP 9.39 & P120 & A3 & F7 & 6,849 & 6,850 & 6,900 \\
\hline EXP 9.40 & P120 & A3 & F0 & 7,217 & 7,222 & 7,206 \\
\hline EXP 9.41 & P120 & A4 & F2 & 6,653 & 6,701 & 6,712 \\
\hline EXP 9.42 & $\mathrm{P} 120$ & $\mathrm{~A} 4$ & F5 & 6,904 & 6,971 & 6,890 \\
\hline EXP 9.43 & P120 & A4 & F7 & 6,931 & 6,996 & 6,970 \\
\hline EXP 9.44 & P120 & A4 & F0 & 7,281 & 7,204 & 7,254 \\
\hline EXP 9.45 & P120 & A5 & F2 & 6,761 & 6,877 & 6,827 \\
\hline EXP 9.46 & P120 & A5 & F5 & 6,973 & 6,805 & 6,945 \\
\hline EXP 9.47 & P120 & A5 & F7 & 7,059 & 7,030 & 7,006 \\
\hline EXP 9.48 & P120 & A5 & F0 & 7,328 & 7,363 & 7,325 \\
\hline EXP 9.49 & P160 & $\mathrm{A} 2$ & F2 & 6,642 & 6,629 & 6,618 \\
\hline EXP 9.50 & P160 & A2 & F5 & 6,791 & 6,750 & 6,824 \\
\hline EXP 9.51 & P160 & A2 & F7 & 6,952 & 6,921 & 7,033 \\
\hline EXP 9.52 & P160 & A2 & F0 & 7,269 & 7,251 & 7,276 \\
\hline EXP 9.53 & P160 & A3 & F2 & 6,659 & 6,649 & 6,696 \\
\hline EXP 9.54 & P160 & A3 & F5 & 6,905 & 6,799 & 6,876 \\
\hline EXP 9.55 & P160 & A3 & F7 & 6,967 & 7,045 & 6,989 \\
\hline EXP 9.56 & P160 & A3 & F0 & 7,401 & 7,338 & 7,192 \\
\hline EXP 9.57 & P160 & A4 & F2 & 6,755 & 6,688 & 6,706 \\
\hline EXP 9.58 & P160 & A4 & F5 & 6,934 & 6,989 & 6,963 \\
\hline EXP 9.59 & P160 & $\mathrm{A} 4$ & F7 & 7,046 & 7,016 & 7,056 \\
\hline EXP 9.60 & P160 & A4 & F0 & 7,437 & 7,482 & 7,389 \\
\hline EXP 9.61 & P160 & A5 & F2 & 6,769 & 6,885 & 6,735 \\
\hline EXP 9.62 & P160 & A5 & F5 & 7,002 & 7,028 & 7,048 \\
\hline EXP 9.63 & P160 & A5 & F7 & 7,170 & 7,073 & 7,028 \\
\hline EXP 9.64 & P160 & A5 & F0 & 7,553 & 7,489 & 7,469 \\
\hline EXP 9.65 & P200 & A2 & F2 & 6,624 & 6,657 & 6,638 \\
\hline EXP 9.66 & $\mathrm{P} 200$ & A2 & F5 & 6,816 & 6,805 & 6,808 \\
\hline EXP 9.67 & $\overline{\mathrm{P} 200}$ & A2 & F7 & 6,923 & 6,952 & 6,951 \\
\hline EXP 9.68 & P200 & A2 & F0 & 7,347 & 7,325 & 7,331 \\
\hline EXP 9.69 & P200 & A3 & F2 & 6,696 & 6,696 & 6,670 \\
\hline EXP 9.70 & P200 & A3 & F5 & 6,943 & 6,824 & 6,937 \\
\hline EXP 9.71 & P200 & A3 & F7 & 7,008 & 7,006 & 7,060 \\
\hline EXP 9.72 & $\overline{\mathrm{P} 200}$ & A3 & F0 & 7,470 & 7,419 & 7,456 \\
\hline EXP 9.73 & $\mathrm{P} 200$ & A4 & F2 & 6,777 & 6,754 & 6,666 \\
\hline EXP 9.74 & P200 & A4 & F5 & 6,945 & 6,997 & 6,972 \\
\hline EXP 9.75 & P200 & A4 & F7 & 7,143 & 7,081 & 7,207 \\
\hline EXP 9.76 & $\mathrm{P} 200$ & A4 & F0 & 7,597 & 7,470 & 7,520 \\
\hline EXP 9.77 & $\mathrm{P} 200$ & A5 & F2 & 6,918 & 6,777 & 6,957 \\
\hline EXP 9.78 & P200 & A5 & F5 & 7,023 & 7,008 & 7,109 \\
\hline EXP 9.79 & P200 & A5 & F7 & 7,195 & 7,169 & 7,165 \\
\hline EXP 9.80 & P200 & A5 & F0 & 7,578 & 7,534 & 7,640 \\
\hline EXP 9.81 & P240 & A2 & F2 & 6,615 & 6,670 & 6,707 \\
\hline EXP 9.82 & P240 & A2 & F5 & 6,794 & 6,855 & 6,869 \\
\hline EXP 9.83 & $\overline{\mathrm{P}} 240$ & A2 & F7 & 6,972 & 6,939 & 7,039 \\
\hline EXP 9.84 & $\mathrm{P} 240$ & A2 & F0 & 7,430 & 7,221 & 7,445 \\
\hline EXP 9.85 & $\mathrm{P} 240$ & A3 & F2 & 6,675 & 6,766 & 6,815 \\
\hline EXP 9.86 & P240 & A3 & F5 & 6,902 & 6,937 & 6,929 \\
\hline EXP 9.87 & P240 & A3 & F7 & 7,052 & 7,099 & 7,031 \\
\hline EXP 9.88 & P240 & $\mathrm{A} 3$ & F0 & 7,616 & 7,562 & 7,440 \\
\hline EXP 9.89 & $\mathrm{P} 240$ & A4 & F2 & 6,765 & 6,748 & 6,727 \\
\hline EXP 9.90 & $\mathrm{P} 240$ & A4 & F5 & 6,993 & 7,067 & 7,027 \\
\hline EXP 9.91 & P240 & A4 & F7 & 7,198 & 7,129 & 7,277 \\
\hline EXP 9.92 & P240 & A4 & F0 & 7,558 & 7,657 & 7,588 \\
\hline
\end{tabular}

Continua na próxima página 
Tabela D.1 - Continuação da página anterior

\begin{tabular}{|c|c|c|c|c|c|c|}
\hline Experimento & Percepções & Agentes & Filtro & \multicolumn{3}{|c|}{ Valores calculados } \\
\hline EXP 9.93 & P240 & A5 & F2 & 6,829 & 6,865 & 6,911 \\
\hline EXP 9.94 & $\mathrm{P} 240$ & A5 & F5 & 7,109 & 6,996 & 7,001 \\
\hline EXP 9.95 & $\mathrm{P} 240$ & A5 & F7 & 7,154 & 7,242 & 7,170 \\
\hline EXP 9.96 & $\mathrm{P} 240$ & A5 & F0 & 7,667 & 7,629 & 7,647 \\
\hline EXP 9.97 & $\mathrm{P} 280$ & A2 & F2 & 6,660 & 6,620 & 6,676 \\
\hline EXP 9.98 & $\mathrm{P} 280$ & A2 & F5 & 6,901 & 6,894 & 6,919 \\
\hline EXP 9.99 & $\mathrm{P} 280$ & A2 & F7 & 7,016 & 7,079 & 6,990 \\
\hline EXP 9.100 & $\mathrm{P} 280$ & A2 & F0 & 7,471 & 7,457 & 7,514 \\
\hline EXP 9.101 & $\mathrm{P} 280$ & A3 & $\mathrm{F} 2$ & 6,696 & 6,788 & 6,757 \\
\hline EXP 9.102 & $\mathrm{P} 280$ & A3 & F5 & 6,980 & 6,936 & 6,973 \\
\hline EXP 9.103 & $\mathrm{P} 280$ & A3 & F7 & 7,145 & 7,061 & 7,128 \\
\hline EXP 9.104 & $\mathrm{P} 280$ & A3 & F0 & 7,677 & 7,579 & 7,591 \\
\hline EXP 9.105 & $\overline{\mathrm{P}} 280$ & $\mathrm{~A} 4$ & F2 & 6,837 & 6,858 & 6,798 \\
\hline EXP 9.106 & P280 & A4 & F5 & 7,071 & 7,132 & 7,062 \\
\hline EXP 9.107 & $\mathrm{P} 280$ & A4 & F7 & 7,206 & 7,254 & 7,233 \\
\hline EXP 9.108 & $\mathrm{P} 280$ & A4 & F0 & 7,686 & 7,649 & 7,714 \\
\hline EXP 9.109 & P280 & A5 & $\mathrm{F} 2$ & 6,878 & 6,889 & 6,930 \\
\hline EXP 9.110 & $\mathrm{P} 280$ & A5 & F5 & 7,184 & 7,196 & 7,114 \\
\hline EXP 9.111 & P280 & A5 & F7 & 7,241 & 7,280 & 7,201 \\
\hline EXP 9.112 & $\mathrm{P} 280$ & A5 & F0 & 7,760 & 7,696 & 7,642 \\
\hline EXP 9.113 & P320 & A2 & F2 & 6,730 & 6,757 & 6,667 \\
\hline EXP 9.114 & P320 & A2 & F5 & 6,899 & 6,973 & 6,914 \\
\hline EXP 9.115 & P320 & A2 & F7 & 7,124 & 7,035 & 7,030 \\
\hline EXP 9.116 & P320 & A2 & F0 & 7,583 & 7,620 & 7,574 \\
\hline EXP 9.117 & P320 & A3 & $\mathrm{F} 2$ & 6,734 & 6,752 & 6,765 \\
\hline EXP 9.118 & P320 & A3 & F5 & 7,015 & 6,984 & 7,077 \\
\hline EXP 9.119 & P320 & A3 & F7 & 7,258 & 7,158 & 7,125 \\
\hline EXP 9.120 & P320 & A3 & F0 & 7,734 & 7,641 & 7,725 \\
\hline EXP 9.121 & P320 & A4 & $\mathrm{F} 2$ & 6,894 & 6,837 & 6,836 \\
\hline EXP 9.122 & P320 & A4 & F5 & 7,054 & 7,027 & 7,131 \\
\hline EXP 9.123 & P320 & A4 & F7 & 7,222 & 7,220 & 7,325 \\
\hline EXP 9.124 & P320 & A4 & F0 & 7,733 & 7,728 & 7,693 \\
\hline EXP 9.125 & P320 & A5 & $\mathrm{F} 2$ & 6,895 & 6,890 & 7,008 \\
\hline EXP 9.126 & P320 & A5 & F5 & 7,203 & 7,222 & 7,125 \\
\hline EXP 9.127 & P320 & A5 & F7 & 7,290 & 7,284 & 7,278 \\
\hline EXP 9.128 & P320 & A5 & F0 & 7,777 & 7,802 & 7,839 \\
\hline EXP 9.129 & P360 & A2 & F2 & 6,776 & 6,691 & 6,726 \\
\hline EXP 9.130 & P360 & A2 & F5 & 6,916 & 6,919 & 6,904 \\
\hline EXP 9.131 & P360 & A2 & F7 & 6,973 & 7,099 & 7,128 \\
\hline EXP 9.132 & P360 & $\mathrm{A} 2$ & F0 & 7,639 & 7,509 & 7,540 \\
\hline EXP 9.133 & P360 & A3 & F2 & 6,782 & 6,785 & 6,851 \\
\hline EXP 9.134 & P360 & A3 & F5 & 6,992 & 7,031 & 7,115 \\
\hline EXP 9.135 & P360 & A3 & F7 & 7,162 & 7,125 & 7,246 \\
\hline EXP 9.136 & P360 & A3 & F0 & 7,634 & 7,738 & 7,601 \\
\hline EXP 9.137 & P360 & A4 & $\mathrm{F} 2$ & 6,890 & 6,834 & 6,810 \\
\hline EXP 9.138 & P360 & A4 & F5 & 7,043 & 7,084 & 7,140 \\
\hline EXP 9.139 & P360 & A4 & F7 & 7,172 & 7,334 & 7,258 \\
\hline EXP 9.140 & P360 & A4 & F0 & 7,778 & 7,812 & 7,681 \\
\hline EXP 9.141 & P360 & A5 & $\mathrm{F} 2$ & 6,982 & 6,968 & 6,921 \\
\hline EXP 9.142 & P360 & A5 & F5 & 7,255 & 7,217 & 7,212 \\
\hline EXP 9.143 & P360 & A5 & F7 & 7,274 & 7,346 & 7,270 \\
\hline EXP 9.144 & P360 & A5 & F0 & 7,832 & 7,840 & 7,911 \\
\hline
\end{tabular}


APÊNDICE D 


\title{
Referências Bibliográficas
}

\begin{abstract}
Ahlbrecht et al. (2013) Tobias Ahlbrecht, Christian Bender-Saebelkampf, Maiquel de Brito, Nicolai Christian Christensen, Jürgen Dix, Mariana Ramos Franco, Hendrik Heller, Andreas Viktor Hess, Axel Heßler, Jomi Fred Hübner, Andreas Schmidt Jensen, Jannick Boese Johnsen, Michael Köster, Chengqian Li, Lu Liu, Marcelo Menezes Morato, Philip Bratt Ørum, Federico Schlesinger, Tiago Luiz Schmitz, Jaime Simão Sichman, Kaio Siqueira de Souza, Daniela Maria Uez, Jørgen Villadsen, Sebastian Werner, Øyvind Grønland Woller e Maicon Rafael Zatelli. Multiagent programming contest 2013: The teams and the design of their systems. Em Engineering Multi-Agent Systems - First International Workshop, EMAS 2013, St. Paul, MN, USA, May 67, 2013, Revised Selected Papers, páginas 366-390. doi: 10.1007/978-3-642-45343-4_22. URL http://dx.doi.org/10.1007/978-3-642-45343-4_22. Citado na pág. 1, 51
\end{abstract}

Bellifemine et al. (1999) Fabio Bellifemine, Agostino Poggi e Giovanni Rimassa. JADE-A FIPAcompliant agent framework. Proceedings of PAAM, páginas 97-108. doi: 10.1145/375735.376120. URL http://www.dia.fi.upm.es/〜 phernan/AgentesInteligentes/referencias/bellifemine99.pdf. Citado na pág. 6

Bordeux et al. (1999) Christophe Bordeux, Ronan Boulic e Daniel Thalmann. An Efficient and Flexible Perception Pipeline for Autonomous Agents. Computer Graphics Forum, 18(3):23-30. ISSN 0167-7055. doi: 10.1111/1467-8659.00324. Citado na pág. 15, 16

Bordini et al. (2006) Rafael H. Bordini, Lars Braubach, Mehdi Dastani, Amal El, Fallah Seghrouchni, Jorge J. Gomez-Sanz, João Leite, Alexander Pokahr e Alessandro Ricci. A survey of programming languages and platforms for multi-agent systems, 2006. Citado na pág. 6, 7

Bordini et al. (2007) Rafael H. Bordini, Jomi Fred Hübner e Michael Wooldridge. Programming Multi-Agent Systems in AgentSpeak using Jason. John Wiley \& Sons Ltd. ISBN 9780470057476. Citado na pág. xi, $7,8,9,15$

Boulic et al. (1997) Ronan Boulic, Pascal Bécheiraz, Luc Emering e Daniel Thalmann. Integration of motion control techniques for virtual human and avatar real-time animation. Em Proceedings of the ACM Symposium on Virtual Reality Software and Technology, VRST '97, páginas 111118, New York, NY, USA. ACM. ISBN 0-89791-953-X. doi: 10.1145/261135.261156. URL http://doi.acm.org/10.1145/261135.261156. Citado na pág. 16

Braubach et al. (2003) L Braubach, W Lamersdorf e a Pokahr. Jadex : Implementing a BDIInfrastructure for JADE. EXP in search of innovation, 3(September):76-85. Citado na pág. 6, 15

Dastani (2008) Mehdi Dastani. 2APL: A practical agent programming language. Autonomous Agents and Multi-Agent Systems, 16(3):214-248. ISSN 1387-2532. doi: 10.1007/ s10458-008-9036-y. URL http://dx.doi.org/10.1007/s10458-008-9036-y. Citado na pág. 15

Dastani et al. (2003) Mehdi Dastani, Frank de Boer, Frank Dignum e John-Jules Meyer. Programming agent deliberation: An approach illustrated using the 3APL language. Em Proceedings of the Second International Joint Conference on Autonomous Agents and Multiagent Sys- 
tems, AAMAS '03, páginas 97-104, New York, NY, USA. ACM. ISBN 1-58113-683-8. doi: 10.1145/860575.860592. URL http://doi.acm.org/10.1145/860575.860592. Citado na pág. 6

Hindriks et al. (1999) Koen V Hindriks, Frank S De Boer, Wiebe Van Der Hoek e John-Jules Ch. Meyer. Agent Programming in 3APL. Autonomous Agents and Multi-Agent Systems, 2(4): 357-401. ISSN 1387-2532. doi: 10.1023/A:1010084620690. URL http://dx.doi.org/10.1023/A: 1010084620690. Citado na pág. 6

Jain (1991) Raj Jain. The art of computer system performance analysis: techniques for experimental design, measurement, simulation and modeling. New York: John Willey. Citado na pág. xi, $2,20,22,24,28,38,51$

Pereira et al. (2012) André Hahn Pereira, Luis G. Nardin e Jaime Simão Sichman. LTI agent rescue: A partial global approach for task allocation in the robocup rescue. RITA, 19(1):71-92. URL http://www.seer.ufrgs.br/index.php/rita/article/view/rita_v19_n1_p71. Citado na pág. 1, 51

Rao (1996) Anand S Rao. AgentSpeak(L): BDI agents speak out in a logical computable language. Em Walter Van de Velde e John W Perram, editors, Proceedings of the 7th European workshop on Modelling autonomous agents in a multi-agent world (MAAMAW'96), volume 1038 of Lecture Notes in Artificial Intelligence, páginas 42-55, Secaucus, USA. Springer-Verlag. Citado na pág. 1, 7

Rao e Georgeff (1995) Anand S Rao e Michael P Georgeff. BDI Agents : From Theory to Practice. Em First International Conference on Multiagent Systems. Citado na pág. 5

Shoham (1993) Y Shoham. Agent-oriented programming. Artificial Intelligence, 60(1):5192. ISSN 00043702. doi: 10.1016/0004-3702(93)90034-9. URL http://www.sciencedirect.com/ science/article/pii/0004370293900349. Citado na pág. xiii, 5

Stabile Jr. e Sichman (2015a) Márcio F. Stabile Jr. e Jaime S. Sichman. Incorporando Filtros de Percepção para Aumentar o Desempenho de Agentes Jason. Em $9^{\circ}$ Workshop-Escola de Sistemas de Agentes, seus Ambientes e apliCações (Niterói, RJ), páginas 54-65. Citado na pág. 18, 51

Stabile Jr. e Sichman (2015b) Márcio F. Stabile Jr. e Jaime S. Sichman. Evaluating perception filters in BDI Jason agents. Em 4th Brazilian Conference on Intelligent Systems (BRACIS), páginas 116-121. Citado na pág. 28, 51

van Oijen e Dignum (2011) Joost van Oijen e Frank Dignum. Scalable Perception for BDI-Agents Embodied in Virtual Environments. 2011 IEEE/WIC/ACM International Conferences on Web Intelligence and Intelligent Agent Technology, páginas 46-53. doi: 10.1109/WI-IAT.2011.176. URL http://ieeexplore.ieee.org/lpdocs/epic03/wrapper.htm?arnumber=6040752. Citado na pág. xi, $2,15,16,17$

Wooldridge (1997) Michael Wooldridge. Agent-Based Software Engineering. Em IEE Proceedings of Software Engineering 144. Citado na pág. 5

Wooldridge (2009) Michael Wooldridge. An Introduction to Multiagent Systems. John Wiley \& Sons Ltd, second ed. ISBN 0470519460. Citado na pág. 5 